$10 / 1.96085(1)$
6 SANDIA REPORT

SAND96-8241 • UC-401

, Unlimited Release

Printed May 1996

\title{
Results from Modeling and Simulation of Chemical Downstream Etch Systems
}

E. Meeks, S. R. Vosen, J. W. Shon, R. S. Larson, C. A. Fox, D. Buchenauer

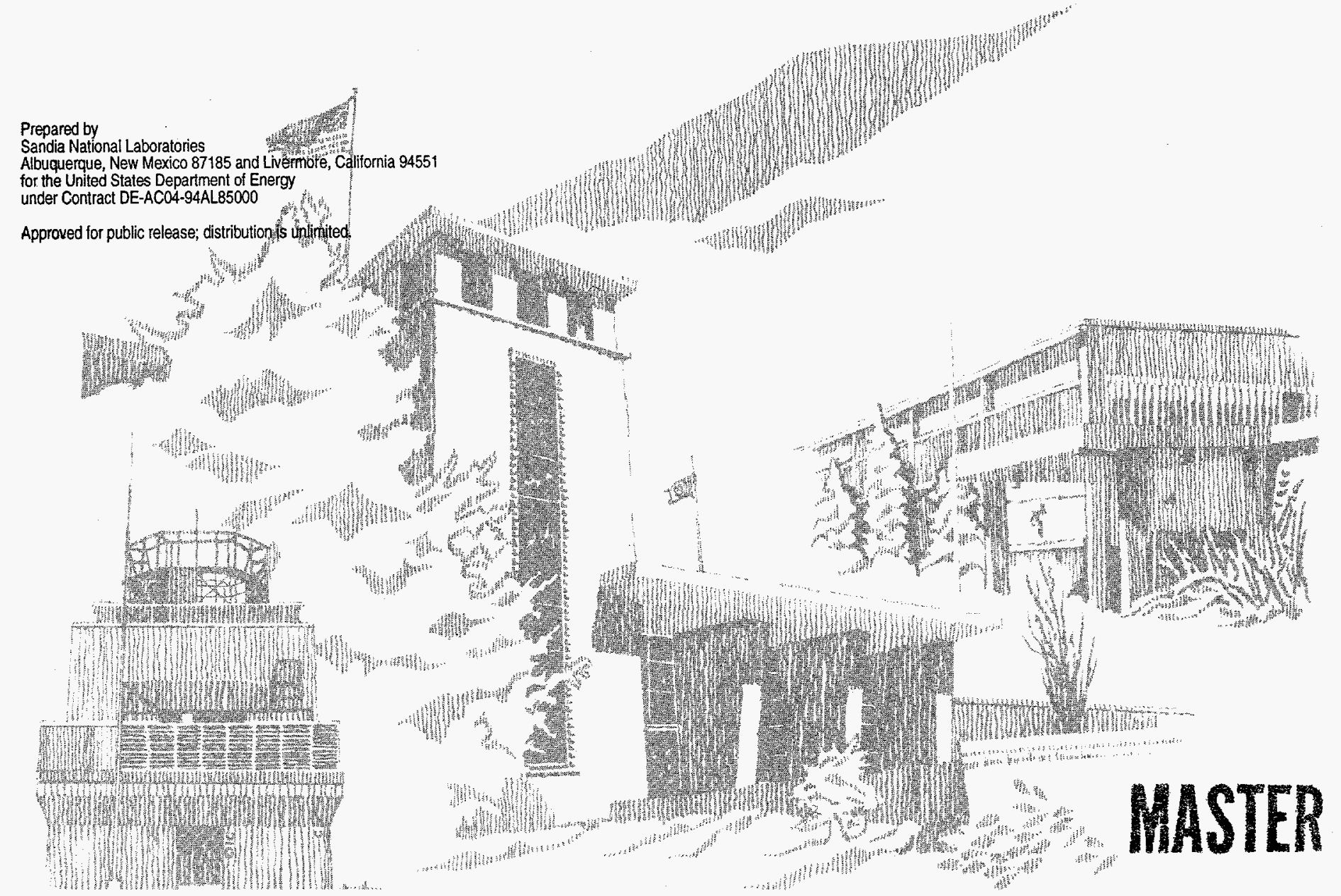


Issued by Sandia National Laboratories, operated for the United States Department of Energy by Sandia Corporation.

NOTICE: This report was prepared as an account of work sponsored by an agency of the United States Government. Neither the United States Government nor any agency thereof, nor any of their employees, nor any of the contractors, subcontractors, or their employees, makes any warranty, express or implied, or assumes any legal liability or responsibility for the accuracy, completeness, or usefulness of any information, apparatus, product, or process disclosed, or represents that its use would not infringe privately owned rights. Reference herein to any specific commercial product, process, or service by trade name, trademark, manufacturer, or otherwise, does not necessarily constitute or imply its endorsement, recommendation, or favoring by the United States Government, any agency thereof or any of their contractors or subconractors. The views and opinions expressed herein do not necessarily state or reflect those of the United States Government, any agency thereof or any of their contractors or subcontractors. 


\section{DISCLAIMER}

This report was prepared as an account of work sponsored by an agency of the United States Government. Neither the United States Government nor any agency thereof, nor any of their employees, make any warranty, express or implied, or assumes any legal liability or responsibility for the accuracy, completeness, or usefulness of any information, apparatus, product, or process disclosed, or represents that its use would not infringe privately owned rights. Reference herein to any specific commercial product, process, or service by trade name, trademark, manufacturer, or otherwise does not necessarily constitute or imply its endorsement, recommendation, or favoring by the United States Government or any agency thereof. The views and opinions of authors expressed herein do not necessarily state or reflect those of the United States Government or any agency thereof. 


\section{DISCLAMERR}

Portions of this document may be illegible in electronic image products. Images are produced from the best available original document. 
UC-401

SAND96-8241

Unlimited Release

Printed May 1996

\title{
RESULTS FROM MODELING AND SIMULATION OF CHEMICAL DOWNSTREAM ETCH SYSTEMS
}

\author{
E. Meeks, S. R. Vosen, J. W. Shon, R. S. Larson, C. A. Fox, D. Buchenauer \\ Sandia National Laboratories \\ Livermore, CA 94551-0969
}

\begin{abstract}
This report summarizes modeling work performed at Sandia in support of Chemical Downstream Etch (CDE) benchmark and tool development programs under a Cooperative Research and Development Agreement (CRADA) with SEMATECH. The Chemical Downstream Etch (CDE) Modeling Project supports SEMATECH Joint Development Projects (JDPs) with Matrix Integrated Systems, Applied Materials, and Astex Corporation in the development of new CDE reactors for wafer cleaning and stripping processes. These dry-etch reactors replace wet-etch steps in microelectronics fabrication, enabling compatibility with other process steps and reducing the use of hazardous chemicals. Models were developed at Sandia to simulate the gas flow, chemistry and transport in CDE reactors. These models address the essential components of the CDE system: a microwave source, a transport tube, a showerhead/gas inlet, and a downstream etch chamber. The models have been used in tandem to determine the evolution of reactive species throughout the system, and to make recommendations for process and tool optimization. A significant part of this task has been in the assembly of a reasonable set of chemical rate constants and species data necessary for successful use of the models. Often the kinetic parameters were uncertain or unknown. For this reason, a significant effort was placed on model validation to obtain industry confidence in the model predictions. Data for model validation were obtained from the Sandia Molecular Beam Mass Spectrometry (MBMS) experiments, from the literature, from the CDE Benchmark Project (also part of the Sandia/SEMATECH CRADA), and from the JDP partners. The validated models were used to evaluate process behavior as a function of microwave-source operating parameters, transporttube geometry, system pressure, and downstream chamber geometry. In addition, quantitative correlations were developed between CDE tool performance and operation set points.
\end{abstract}




\section{ACKNOWLEDGMENTS}

Work was supported by Sandia National Laboratories through the Department of Energy and a Cooperative Research and Development Agreement with SEMATECH. The authors thank M. Blain, T. Meisenheimer, and J. Stevens for their assistance in supplying and interpreting experimental measurements on the CDE-80 tool; Ellis Hyman and Barton Lane for initial collaboration on $\mathrm{CF}_{4} / \mathrm{O}_{2}$ chemistry; and Gary Powell of Matrix Integrated Systems for his interest in the modeling work and for supplying wafer etch measurements. 


\section{TABLE OF CONTENTS}

\section{MODELING THE $\mathrm{NF}_{3} / \mathrm{O}_{2}$ CHEMISTRY SYSTEM AND SIMULATION}

COMPARISONS WITH EXPERIMENTAL DATA .............................................. 9

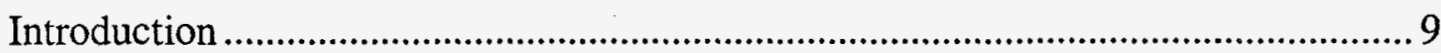

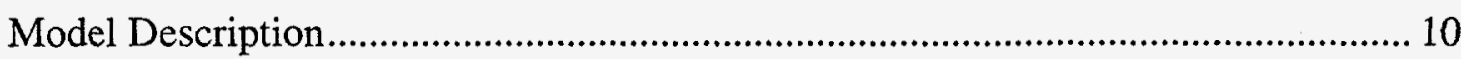

CDE System Model Approach ................................................................... 10

Kinetic Parameters for $\mathrm{NF}_{3} / \mathrm{O}_{2}$ Plasmas ..................................................... 11

Microwave Applicator Plasma Model .............................................................. 13

Transport Tube Model ............................................................................ 14

Downstream Chamber Model ................................................................... 15

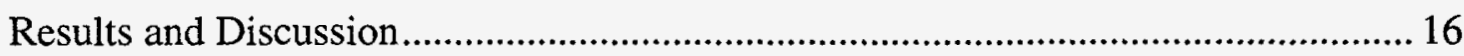

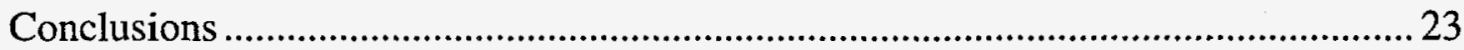

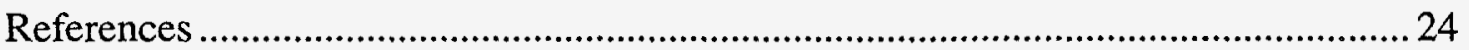

II. MODELING OF CHEMICAL DOWNSTREAM ETCHING USING $\mathrm{CF}_{4} / \mathrm{O}_{2}$, AND

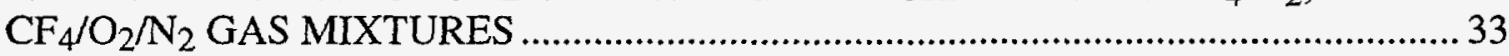

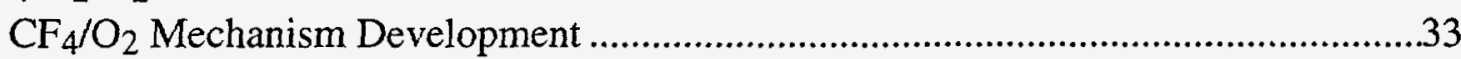

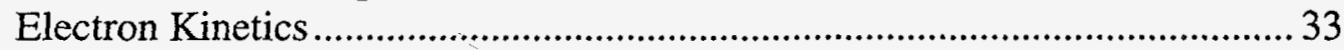

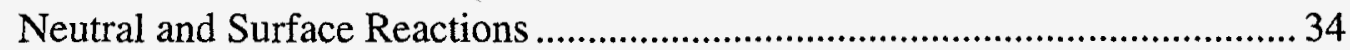

Dominant Reactions in the $\mathrm{CF}_{4} / \mathrm{O}_{2}$ Mechanism .............................................. 36

Model Validation with Experiments ............................................................................. 38

Experimental Setup ........................................................................................... 38

Model Results for $\mathrm{CF}_{4} / \mathrm{O}_{2}$ Plasmas............................................................... 39

Effects of Nitrogen Addition............................................................................ 41

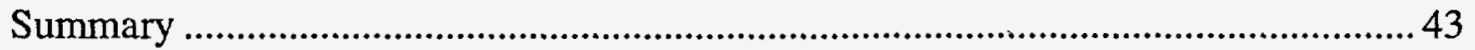

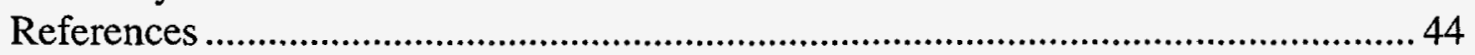

III. MODELING THE EFFECTS OF ETCHANT CONCENTRATION AND

TRANSPORT ON CHEMICAL DOWNSTREAM ETCH SYSTEM

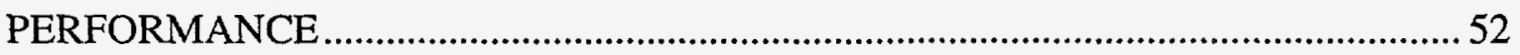

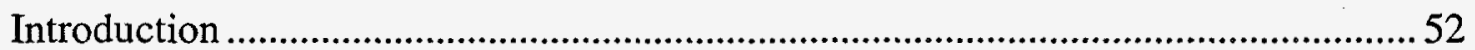

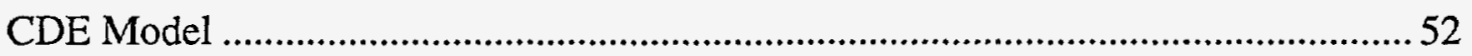

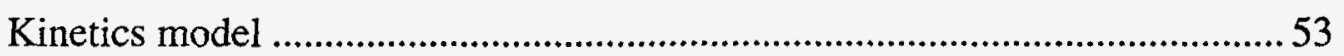

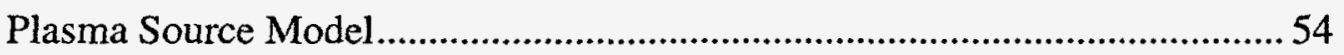

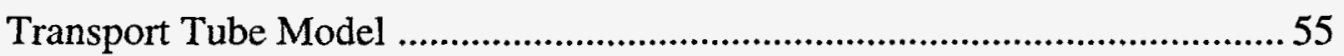

Showerhead Model ………………………………...................................... 56

Etch Chamber Model ..................................................................................5 57

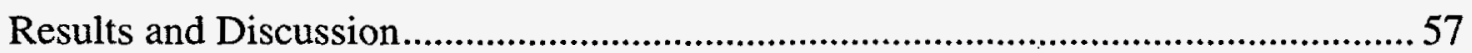

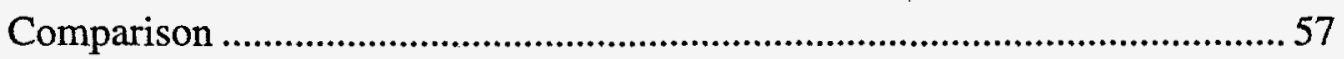

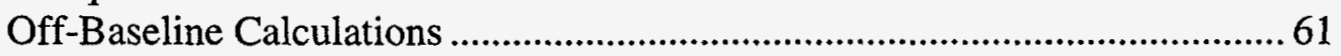

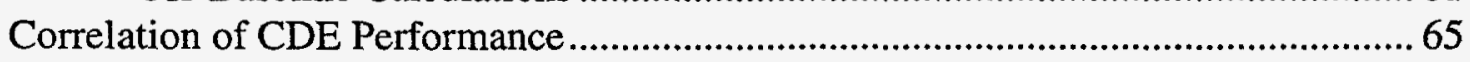

Summary and Conclusions........................................................................................ 70

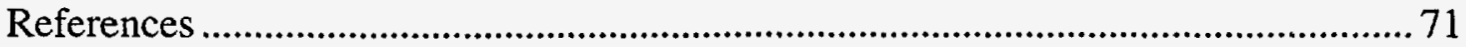




\section{LIST OF FIGURES}

Page

Figure I-1. Schematic of the Chemical Downstream Etch System............................... 10

Figure I-2. Comparison of plasma source model results with experimental data for the rf plasma system of Perrin. 29

Figure I-3. Plasma source model predictions of neutral densities in the CDE-80 source region as functions of a) power $b$ ) gas flow rate, c) percent oxygen with constant total flow rate, and d) pressure. Nominal conditions are $75 \mathrm{sccm}$ total flow rate, $0 \% \mathrm{O}_{2}, 0.525 \mathrm{Torr}$, and $500 \mathrm{~W}$ deposited power.

Figure I-4. Transport tube axial density profiles predicted for nominal conditions for a) neutral species and b) ions.

Figure I-5. Comparison of model predictions of silicon dioxide etch rates in the downstream chamber with experimental measurements in the CDE-80 tool. 30

Figure I-6. Mole fraction contours for $\mathrm{F}_{\text {and }} \mathrm{SiF}_{4}$ for nominal conditions in the downstream chamber.

Figure I-7. Mass-flow streamlines compared to streamlines for the fluorine atoms calculated from the addition of convective and diffusive fluxes, for the nominal conditions.

Figure II-1. Power loss percentages over a range of average electron energy for $\mathrm{CF}_{4} / \mathrm{O}_{2}=50 / 50 \%$ at 0.5 torr of pressure

Figure II-2. Diagram of dominant $\mathrm{CF}_{4}$ plasma-chemistry mechanisms for 0.5 torr......

Figure II-3. Diagram of the dominant $\mathrm{CF}_{4} / \mathrm{O}_{2}$ reactions at 0.5 torr................................. 37

Figure II-4. Schematic of the molecular beam mass spectrometer (MBMS) system......... 38

Figure II-5. Comparisons between model and experimental data of the mole fractions of $\mathrm{CF}_{4}$ and $\mathrm{O}_{2}$

Figure II-6. Comparisons of the predicted mole fractions of $\mathrm{F}, \mathrm{O}$, and $\mathrm{SiF}_{4}$ with MBMS Signal Intensity versus inlet $\mathrm{O}_{2}$ mole fraction. The MBMS Signal intensity was scaled to match peak values of the predicted mole fractions and is shown with symbols and dashed lines, while the model predictions are solid lines.

Figure II-7. Mole fractions of $\mathrm{CF}_{3}, \mathrm{CF}_{2}, \mathrm{CF}, \mathrm{CO}_{2}, \mathrm{CO}$, and $\mathrm{COF}_{2}$ versus inlet $\mathrm{O}_{2}$ mole fraction.

Figure II-8. Comparisons between model and experimental results of the mole fractions of a) $\mathrm{F}$ and $b$ ) $\mathrm{F}_{2}$, versus inlet $\mathrm{N}_{2}$ mole fraction.

Figure II-9. Comparison between the ratio of $\mathrm{SiF}_{4} / \mathrm{F}$ mole fractions from the model and the corresponding ratio of MBMS signal ratio. 


\section{LIST OF FIGURES (CONT'D)}

Page

Figure II-10. Normalized rates of $\mathrm{SiF}_{4}$ production due to thermal etching by $\mathrm{F}$ atoms and ion enhanced etching contributions. Etching of $\mathrm{SiF}_{4}$ is enhanced by the increase in $\mathrm{NO}^{+}$density for larger $\mathrm{N}_{2}$ inlet mole fractions

Figure III-1. Baseline Distribution of a) Neutral Species and b) Charged Species Down the Transport Tube.

Figure III-2. Results of 2-D Calculation. 3a) (top) Fluorine atom concentration and flux lines, and $3 \mathrm{~b}$ ) (bottom) polysilicon etch rate profile - Baseline Case.

Figure III-3. Plasma Source Parametric Study. Effect of varying plasma source input $\mathrm{O}_{2}$ flow rate, pressure, power and total flow rate on plasma source output mole fractions.

Figure III-4. Three-variable correlations of (a) poly etch rate and (b) poly etch-rate uniformity corresponding to Table III-3(b), Table III-4(b) and Table III-5....69 


\section{LIST OF TABLES}

Table I-1. Gas-Phase Reactions and Reaction Rate Coefficients for $\mathrm{NF}_{3} / \mathrm{O}_{2} \ldots \ldots \ldots \ldots . . .28$

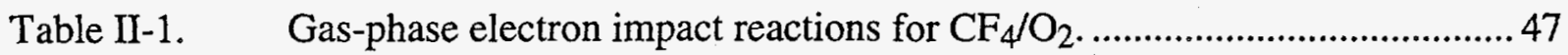

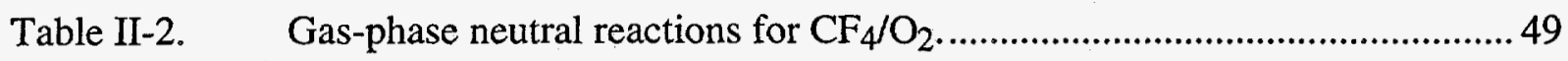

Table III-1. Comparison between CDE model predictions and experimental results. ..... 58

Table III-2. Off-Baseline Calculation Results............................................................ 64

Table III-3(a). Correlation Based on Plasma Source Parameters. .....................................66 66

Table III-3(b). Correlation Based on Plasma Source Parameters with the largest influence.......................................................................................... 66

Table III-4(a). Correlations Based on Plasma Source Flow Rate and Power and Etch Chamber Pressure.

Table III-4(b). Correlations Based on Plasma Source Flow Rate and Etch Chamber Pressure.

Table III-5. Correlations Based on Etch Chamber Parameters. 68 


\title{
I. MODELING THE $\mathrm{NF}_{3} / \mathrm{O}_{2}$ CHEMISTRY SYSTEM AND SIMULATION COMPARISONS WITH EXPERIMENTAL DATA
}

\author{
E. Meeks, R. S. Larson, S. R. Vosen, and J. W. Shon
}

\section{INTRODUCTION}

Chemical Downstream Etch (CDE) systems provide alternatives to wet-etch processes for wafer cleaning and stripping in the manufacture of integrated circuits. CDE systems are compatible with other dry-etch process steps for process integration and reduce the need for hazardous wetetch chemicals. $\mathrm{CDE}$ reactors typically consist of an upstream microwave-excited plasma region and a downstream chamber where etching of the wafer occurs. Often these two regions are connected with a transport tube that serves to minimize the ion content downstream. The CDE system represents a complex coupling of regions where transport processes and chemical kinetics compete. Empirical optimization of these systems is difficult, due to the complex dependencies between processes in different regions and tradeoffs between the production and transport of etchant species to the downstream chamber. Issues for process development include minimizing wafer damage due to impingement of energetic ions, and maximizing etch rate and uniformity at the wafer surface. Modeling of the essential components of the CDE system provides important insight into process tradeoffs and allows optimization of the overall system.

Many models ${ }^{1}$ of remote plasma systems follow only the neutral etchant species generation and transport. Kushner ${ }^{2}$ modeled the two-dimensional plasma transport and chemistry in a remoteplasma chemical vapor deposition system for silane-ammonia deposition of silicon. Our method of dividing the remote-plasma processing system into distinct regions for modeling is similar to the approach taken by Deshmukh and Economou ${ }^{3}$ for a chlorine downstream etch system. In this work, however, we follow both the ions and radicals through the transport tube region and perform detailed simulations in the downstream chamber, including multicomponent diffusion and etch-product transport from the wafer surface. By separating the system into distinct regions, we are able to capture the essential kinetics in each tool segment. At the same time, each model segment is computationally fast enough to allow detailed parametric studies of the effects of process and reactor-design variables. 


\section{MODEL DESCRIPTION}

\section{CDE System Model Approach}

Our approach to modeling the CDE system is to model each of the system components in tandem, using the level of detail necessary to achieve meaningful predictions of downstream etch performance. An example CDE system is shown schematically in Figure I-1. The geometry is that of a Shibaura CDE-80 system applied to the etching of polysilicon and silicon-nitride layers for a strip process of a poly-buffered LOCOS (PBL) mask (where LOCOS stands for LOCal Oxidation of Silicon). Chemistries typically used for this process step include $\mathrm{CF}_{4} / \mathrm{O}_{2} / \mathrm{N}_{2}$ and $\mathrm{NF}_{3} / \mathrm{O}_{2}$ mixtures. Since fluorine etches silicon dioxide as well as polysilicon, an important consideration in process development is etch selectivity between polysilicon, silicon nitride, and oxide. The analysis here focuses on the $\mathrm{NF}_{3} / \mathrm{O}_{2}$ chemistry. Our analysis follows the reactive species from creation in the plasma source and throughout the CDE system, using sequentially linked models of the microwave source, transport tube region, and downstream chamber.

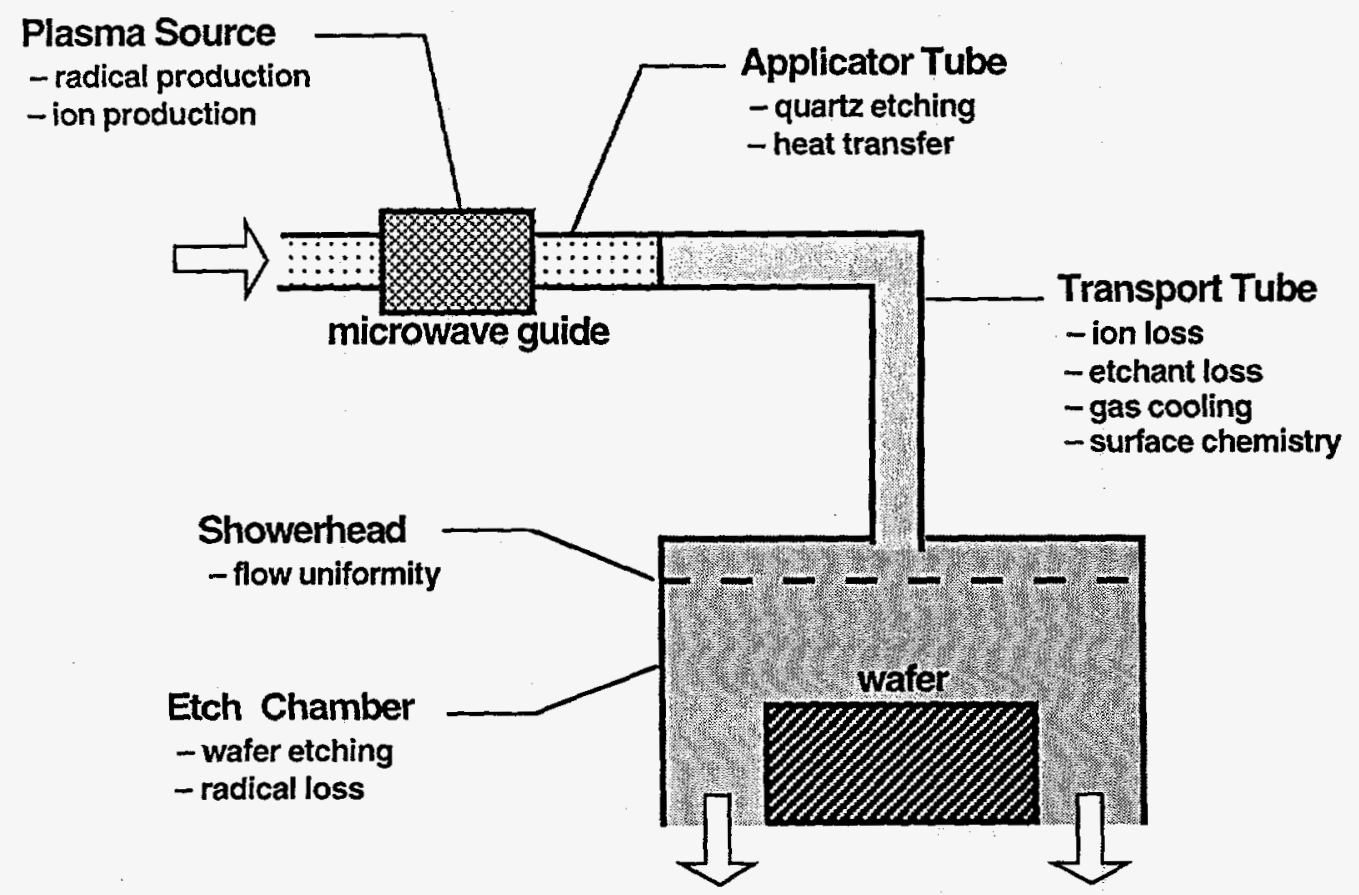

Figure I-1. Schematic of the Chemical Downstream Etch System.

In the plasma source, we are primarily interested in the generation of ions and radicals, rather than spatially resolved plasma behavior within the microwave applicator. For this region, then, we apply a well mixed reactor model. This computationally efficient numerical model is also the primary tool used in developing and refining the reaction kinetics mechanism for the $\mathrm{NF}_{3} / \mathrm{O}_{2}$ chemistry. In addition, the plasma-source model includes etching of the quartz microwave applicator tube by fluorine atoms and by ion bombardment. The erosion of the quartz tube by 
the plasma is an important limitation in the lifetime of the applicator and contributes significantly to CDE operating costs. Also, the etching of the quartz tube accounts for a significant loss of fluorine atoms in the discharge, and fluorine atoms are the primary etchant in the downstream chamber.

We use a one-dimensional plug-flow model to address the transport-tube region between the plasma source and the downstream etch chamber. The plug-flow approach is sufficient as we are not interested in resolving the radial variations within the transport tube, but are instead concerned with overall loss rates versus transport time for the etchant species. This transporttube model takes the exit conditions of the plasma-source model as the inlet conditions for the transport tube. The pressure drop between the downstream chamber (where pressure is measured) and the upstream plasma region is determined through iteration between the plasmasource model and the transport-tube model. The transport-tube model includes gas-phase neutral, ion, and electron-impact chemistry, as well as gas-surface interactions.

To compare radially averaged etch rates at the wafer surface with experimental data, we employ the Sandia 1-D stagnation-flow model, SPIN. ${ }^{4,5}$ The stagnation-flow model is generally a good approximation of the flow impinging on the wafer surface, and is convenient for parameter studies when spatial variations across the wafer surface are not desired. This model also proved useful in mechanism reduction, i.e. in determining the set of reactions required for accurate predictions using the downstream chamber model

For more detailed modeling of the downstream chamber, a 2-D axisymmetric reacting-flow model determines spatial gradients across the wafer surface. The inlet to the downstream chamber is assumed to be a uniform flux, as provided by a showerhead manifold, with the same gas composition as the flow exiting the transport tube. In the downstream model, a reduced set of reaction kinetics is used to follow the evolution of the neutral species in the etch chamber. This reduction saves considerable computational expense and allows investigation of a larger parameter set. With fluorine-etch reactions on the wafer, the downstream chamber model then provides etch-rate uniformity across the wafer surface and etch-product evolution profiles.

\section{Kinetic Parameters for $\mathrm{NF}_{3} \underline{\mathrm{O}}_{2}$ Plasmas}

Incorporation of chemical kinetics data into all three model segments employs the CHEMKIN III and SURFACE CHEMKIN III software packages, ${ }^{6-9}$ allowing inclusion of electron-impact, neutralneutral, ion-neutral, and ion-ion kinetics. At the pressures considered here ( $\sim .5$ Torr $)$, we find that both electron-impact reactions and neutral third-body recombination can be significant in the source region. As the ionized gas relaxes beyond the discharge region, ion-electron recombination on tube walls causes the electron density to decay quickly. Ion-surface interactions and gas-phase ion-ion recombination control the loss of ions along the transport tube 
length. The plasma source and transport tube models consider the reactions listed in Table I- 1 .

By the time the gas flows into the downstream chamber, it is primarily composed of neutral species, and the dominant chemical processes are gas-phase radical recombination and the waferetch surface chemistry. For the downstream model, then, we consider only the transport and reaction of neutral species in the gas phase. The reduced reaction mechanism for the neutral flow simulation was determined through testing and sensitivity analysis using the Sandia 1-D stagnation-flow code SPIN $^{4,5}$ over a range of transport-tube outlet conditions. Through this methodology, we determined a minimum downstream species set of $\mathrm{F}, \mathrm{F}_{2}, \mathrm{NF}_{3}, \mathrm{O}_{2}, \mathrm{~N}_{2}, \mathrm{SiF}_{4}$, and NFO. In addition, we found that the gas-phase reactions in the downstream chamber had less than a $3 \%$ effect on the etch rate predicted at the wafer surface. For the 2-D simulations, then, no gas-phase reactions are included.

We determine reaction rate coefficients for the electron-impact reactions through solution of the Boltzmann equation using the software, ELENDIF. ${ }^{10}$ This requires collision cross-section information for each of the electron processes considered. The references given in Table I-1 for the electron-impact reactions refer to the origin of the electron-impact cross sections. Although much detailed information was available for $\mathrm{NF}_{3}, \mathrm{O}_{2}, \mathrm{O}, \mathrm{N}_{2}, \mathrm{~N}, \mathrm{~F}$, and $\mathrm{F}_{2}$ interactions, many of the remaining cross sections were estimated from analogies to those and other molecules. Given electron collision cross sections, repeated runs of ELENDIF provide a correlation between reaction rate coefficients and the mean electron energy over a range of $\mathrm{E} / \mathrm{n}$ (electric field divided by gas number density) values. This data is then fit with a modified Arrhenius form providing reaction rate coefficient values as a function of electron temperature. In order to use the Boltzmann solutions in this pre-processor mode, we have to make some a priori assumptions about gas composition. The reaction rate coefficients given in Table I-1 used an initial gas composition of $\sim 50 \% \mathrm{NF}_{3}, 40 \% \mathrm{O}_{2}$, and a small percentage for each of $\mathrm{NF}_{2}, \mathrm{NF}, \mathrm{N}_{2}, \mathrm{~N}, \mathrm{~F} 2, \mathrm{~F}$, and $\mathrm{O}$. While previous analysis of plasma chemistry has shown a sensitivity of electron energy distribution functions to the gas neutral composition, ${ }^{11}$ the effect on the well mixed plasma simulation should be at most secondary $(<10 \%)$ and is neglected here. Numerous rotational, vibrational, and electronic excitation processes for $\mathrm{N}, \mathrm{N}_{2}, \mathrm{O}, \mathrm{O}_{2}$, and $\mathrm{F}_{2}$ are included in the Boltzmann solutions to obtain the energy distribution functions. However, the rates tabulated in Table I-1 include only excitations that provide significant energy loss to the global electronenergy balance in the plasma source model. In this way, the plasma source model does not attempt to compute population densities of low-energy quantum states, but does include excitation rates that contribute to the inelastic electron-energy loss term.

Neutral and ion reaction rates are included in Table I-1. These reaction rate coefficients also derive from many sources, as indicated by the references in the right-hand column. In addition to those listed in Table I-1, several ion charge-exchange rates were estimated by scaling a measured charge-exchange rate by the ratio of ionization potentials of the product and reactant ions. 
Unless otherwise listed, all ion-ion mutual neutralization reactions were assumed to have a rate constant of $10^{-8} \mathrm{~cm}^{3} / \mathrm{s}^{12}$ The simulations include these reactions as necessary for the dominant ions present in the system, but they are not listed explicitly in Table I-1. For the reactions that are listed in Table I-1, the entries that show a zero activation energy (i.e., $C=0.0$ ) generally indicate that we were only able to obtain rate-constant values at a single temperature.

As several of the neutral reactions are reversible processes, it is necessary either to include explicitly the reverse rate coefficients or to determine the reverse parameters from species thermodynamic data. Species enthalpy also plays an important role in the energy balances of each of the model segments. We have therefore compiled known or reasonable estimates for the thermodynamic data of all of the species considered in Table I-1. Most of this information for neutral species is available from the CHEMKIN Thermodynamic Database. ${ }^{6}$ For positive ion species, we estimated the species enthalpy by adding the ionization energy to the enthalpy of the corresponding neutral species, and used the entropy of the neutral to represent the ion entropy. The temperature-dependent specific heat was assumed to be the same for the ion and corresponding neutral. A similar approach to negative ions employed values of the electron affinity to estimate thermodynamic properties from the neutral species data.

For surface chemistry, each model segment includes a different set of reaction kinetics. In the plasma source region, heterogeneous reactions account for etching of the quartz applicator, as well as $\mathrm{O}$-atom recombination. The quartz-etch mechanism includes both chemical-etch ${ }^{13}$ and positive-ion enhanced etch pathways, derived from the work of Butterbaugh, et al. ${ }^{14}$ The Oatom recombination employs the measured rate of Greaves and Linnett. ${ }^{15}$ The plasma source region also includes positive ion and electron recombination through surface interaction. In the transport tube, recombination of $\mathrm{F}$ and $\mathrm{O}$ radicals, as well as ion recombination, are the dominant heterogeneous processes. The reaction probabilities for radical recombination come from measured values by Greaves and Linnett ${ }^{15}$ and Ganguli and Kaufman ${ }^{16}$ for Teflon surfaces. For ion recombination, the transport tube is allowed to charge negative, as electrons and negative ions hit the surface. Positive ions then react with these "negative sites" to gain an electron and leave the surface neutral. This results in a net depletion of electrons and ions as the gas traverses the length of the transport tube. In the downstream chamber, the heterogeneous chemistry considers silicon dioxide etch by atomic fluorine on the wafer surface, and radical recombination on the reaction-chamber walls. The etch reaction probability and activation energy at the wafer are taken from the work of Flamm, et al. ${ }^{13}$ for silicon dioxide.

\section{Microwave Applicator Plasma Model}

The plasma source region model uses perfectly stirred reactor approximations that allow predictions of spatially and temporally averaged plasma properties. This model has been described previously in detail. ${ }^{17,18}$ The solution of species, mass, gas-energy and electron- 
energy balance equations determines the steady-state gas and electron temperature, and species concentrations for ions, electrons, and neutral species. The electron energy equation balances power deposition to the electrons with energy loss including elastic and inelastic collision processes. This balance determines the ionization and dissociation level of the plasma. The gas temperature is determined primarily from the balance between losses to the external environment, through a heat-transfer coefficient, and net gains through neutral third-body chemical recombination.

The microwave applicator in the CDE-80 tool is quartz and suffers a significant erosion rate in the presence of $\mathrm{NF}_{3}$ plasmas. The erosion results in a large consumption of $\mathrm{F}$-atom etchant through creation of the etch product $\mathrm{SiF}_{4}$. For this reason, prediction of net $\mathrm{F}$-atom production in the plasma source requires inclusion of the quartz-etch F-loss mechanism, discussed in the previous section. The thermal etch mechanism is strongly dependent on the surface temperature where the etching occurs. For this reason, we included an additional heat balance in the model to estimate the quartz applicator internal surface temperature. A heat transfer coefficient between the hot plasma gas and the internal wall was calculated from an empirical correlation for fully developed, laminar, internal pipe flow, where the Nusselt number is given by: ${ }^{19}$

$$
N u_{d} \equiv \frac{h d}{k}=3.66+\frac{0.0668(d / L) \operatorname{Re}_{d} \operatorname{Pr}}{1+0.04\left[(d / L) \operatorname{Re}_{d} \operatorname{Pr}\right]^{2 / 3}}
$$

Here $h$ is the heat transfer coefficient, $k$ is the thermal conductivity of the fluid in contact with the tube internal walls, $d$ and $L$ are the tube diameter and length, while $\operatorname{Re}_{d}$ and $\operatorname{Pr}$ are the Reynolds and Prandtl numbers of the internal flow. For the gas-mixture properties in the fluid boundary layer, we used estimated values for a mostly dissociated $\mathrm{NF}_{3}$ gas mixture at about $1000 \mathrm{~K}$. The resulting viscosity and thermal conductivity were then $0.00052 \mathrm{~g} / \mathrm{cm}-\mathrm{s}$ and 6500 $\mathrm{erg} / \mathrm{s}-\mathrm{K}-\mathrm{cm}$, respectively. These properties were kept constant for the plasma source through all of the CDE- 80 tool simulations reported here.

By including this surface chemistry we were able to reproduce the observed quartz etch rates for the CDE-80 tool ${ }^{20}$ within a factor of two for the nominal conditions. Under these conditions, the ion-enhanced etch and thermal etch pathways contributed about equally to the loss of bulk $\mathrm{SiO}_{2}$ from the quartz tube. This result was further corroborated by the observation that severe cooling of a similar applicator tube only reduced the erosion rate by about one half. ${ }^{21}$

\section{Transport Tube Model}

The transport tube model solves the steady state plug flow equations in order to relate the gas properties at the inlet of the process chamber to those at the exit of the plasma source. The plugflow approximation assumes that (1) transport in the axial direction is dominated by convection,

14. 
i.e., axial diffusion is negligible; and (2) radial transport is sufficiently rapid to overcome the effects of surface processes and maintain uniformity in the radial direction. The resulting onedimensional model consists of a first-order differential/algebraic system that is mathematically decoupled from the process chamber model and thus much easier to solve.

The transport tube equations consist of the usual mass, momentum, and energy balances for plug flow (see, for example, Bird, et al. ${ }^{22}$ ), but with certain modifications to account for plasma effects. The conservation equations for total mass and for each gas-phase species balance the convective transport with the net production rate by both homogeneous (gas-phase) and heterogeneous (surface) reactions. For the surface species there is (by assumption) no transport, so the net production rate is set equal to zero. The gas-phase momentum equation expresses the axial acceleration in terms of both pressure and viscous forces. This is supplemented by an ideal gas equation of state in which the electrons have a separate temperature. The overall gas-phase energy equation relates changes in enthalpy and kinetic energy to the rate of heat loss to the surroundings. There is also a separate electron energy balance which shows how the enthalpy and kinetic energy fluxes of the electrons are affected by the chemical production rates and the rates of energy loss via both elastic and inelastic collisions, and surface losses.

The foregoing model allows one to find the axial profiles of the gas-phase density, velocity, pressure, temperature, and composition, as well as the electron temperature and the species site fractions on the tube surface. Initial values for the gas properties are obtained from the output of the plasma source model. The differential/algebraic system describing the remainder of the tube can then be solved using the standard DASSL ${ }^{23}$ routines.

\section{Downstream Chamber Model}

Exit conditions from the transport tube model provide the inlet species mass fractions for the downstream-etch chamber analysis. The purpose of the showerhead manifold at the chamber inlet is to redistribute the flow from the transport tube into the process chamber, providing radially uniform inlet mass flux. For the purposes of the analysis here, we assume an optimal showerhead design.

A chemically reacting flow model then addresses transport of neutral radicals to the wafer surface. The 2-D reacting-flow model solves the axisymmetric, incompressible Navier-Stokes equations using finite-volume methods, coupled to solution of the gas energy equation and species conservation equations including multicomponent transport and surface chemistry. The model employs a semi-implicit solution method based on the TEACH code, ${ }^{24}$ and the SIMPLER algorithm ${ }^{25}$ for determining the pressure field. The simulation acquires transport and thermodynamic properties from the CHEMKIN Transport-property routines and Thermodynamic Database. ${ }^{26,6}$ This chemically reacting flow software has been described previously in the 
context of chemical vapor deposition analysis. 27,28

In the downstream chamber, the only etchant species considered here is atomic fluorine. For this reason, the primary role of the 2-D simulation is to predict the transport of $F$ to the wafer surface and the etch product $\mathrm{SiF}_{4}$ away from the wafer. It is therefore necessary to solve speciesconservation equations only for the dominant neutral species, and to include the effects of multicomponent diffusion and gas-phase radical recombination. 1-D simulations determined that the gas-phase radical recombination was negligible for the conditions considered here, so that the dominant mechanisms are convection and diffusion of the etchant species to the wafer surface.

\section{RESULTS AND DISCUSSION}

The chemical kinetics described in the previous section is admittedly complex and involves a fair number of uncertain parameters. Rather than trying to determine each of these parameters in detail, however, our objective was to develop a chemistry mechanism that, as a whole, could predict experimental observations in the $\mathrm{NF}_{3}$ plasma system being studied. For this reason, comparisons with experimental data are required to obtain confidence in the predictive capabilities of the kinetics mechanism. Figure I-2 shows an example of comparisons made for the plasma source model applied to the experimental conditions of Perrin, et al. ${ }^{29}$ Perrin's

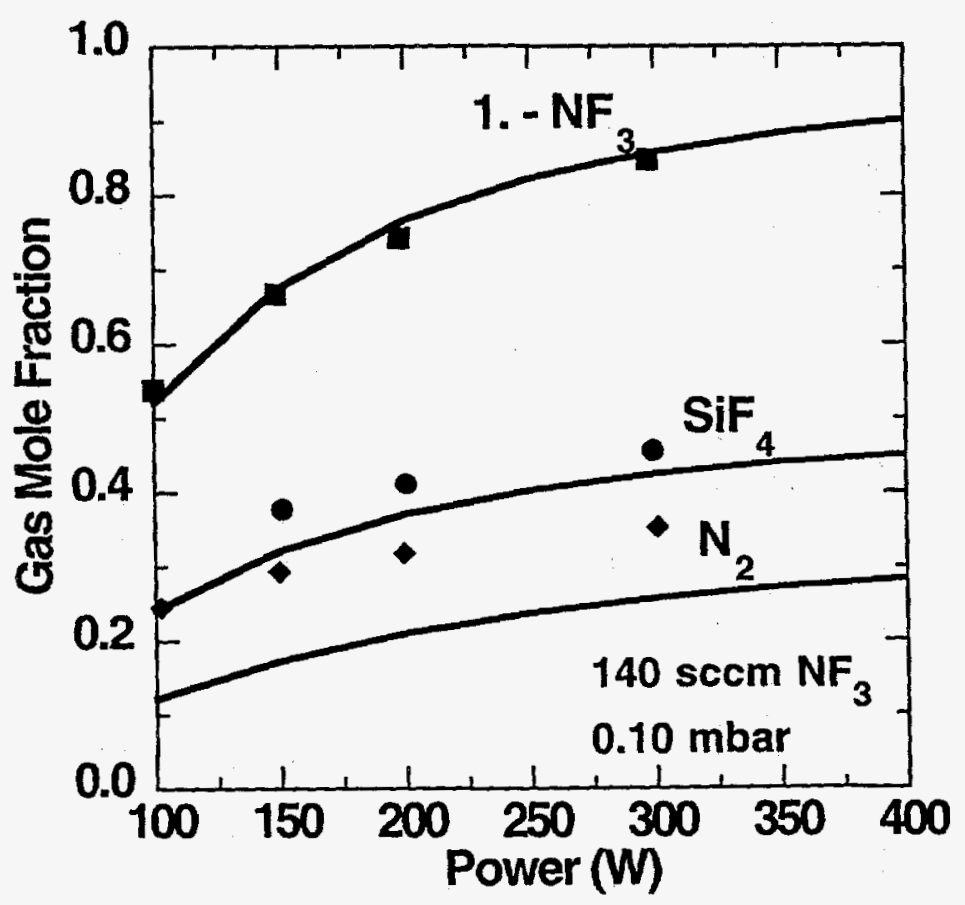

Figure I-2. Comparison of plasma source model results with experimental data for the rf plasma system of Perrin. ${ }^{29}$ 
system consisted of a cylindrical radio-frequency plasma chamber with silicon dioxide covering the chamber walls. Species concentrations were measured using mass spectrometry. The plasma source model for these conditions used a chamber volume of $12800 \mathrm{~cm}^{3}$, a surface area of 4480 $\mathrm{cm}^{2}$, and a flow rate of $140 \mathrm{sccm} \mathrm{NF} 3$ at $75 \mathrm{mTorr}$, while the rf power was varied. Results in Figure I-2 show quantitative agreement between the model and the observed $\mathrm{NF}_{3}$ dissociation rate, as well as prediction of the $\mathrm{SiF}_{4}$ production through etching of the quartz walls.

With confidence gained in the model chemistry, we then apply the linked-model simulations to the study of parameter variations in the CDE system shown in Figure I-1. Nominal conditions for this study were $75 \mathrm{sccm}$ flow of $\mathrm{NF}_{3}$ through the system at a reactor pressure of $525 \mathrm{mTorr}$, and $500 \mathrm{~W}$ microwave power applied in the plasma source. The plasma in the source region is taken to be $2.8 \mathrm{~cm}$ in diameter and about $30 \mathrm{~cm}$ in length. The nominal inner radius of the transport tube is also $2.8 \mathrm{~cm}$ with a total length of about $75 \mathrm{~cm}$ between the source region and the downstream chamber.

Results of varying power, gas flow rate, oxygen addition, and pressure in the plasma source region are shown in Figure I-3. The results show a high degree of $\mathrm{NF}_{3}$ dissociation in all cases. Results also indicate the magnitude of the quartz-tube etch rate as a function of the operating parameters through the evolution of $\mathrm{SiF}_{4}$ and $\mathrm{O}_{2}$. In these simulations the $\mathrm{SiF}_{4}$ is not allowed to dissociate once it is formed, while the oxygen does participate in the plasma reactions. This assumption avoids further complexity of the already lengthy reaction list and will not significantly affect the composition results. The effect of increasing the flow rate and thereby decreasing the plasma residence time is shown in Figure I-3(b). The primary effects of increased flow rate for these conditions are to decrease the $\mathrm{NF}_{3}$ dissociation level and decrease the quartz etch rate. Figure I-3(c) shows results for oxygen added to the system while the total gas flow rate is held constant. For this case the fractional dissociation of $\mathrm{NF}_{3}$ remains nearly constant, and the $\mathrm{F}$ mole-fraction decrease reflects the replacement of $\mathrm{NF}_{3}$ in the inlet stream. Figure I3 (d) shows the effects of reactor pressure on plasma composition in the source region. Here, although the mole fraction of $F$ remains nearly constant as the pressure is increased, the atomic fluorine concentration increases due to the increase in total gas density. The plasma source simulation also provides ion densities and composition. In all cases the plasma is highly electronegative and the dominant negative ion is $\mathrm{F}^{-}$. With oxygen addition, $\mathrm{O}^{-}$also becomes important. The positive ion composition changes upon the addition of oxygen: $\mathrm{NF}_{2}{ }^{+}$and $\mathrm{NF}_{3}{ }^{+}$ are dominant for $\mathrm{NF}_{3}$ alone, while $\mathrm{O}_{2}{ }^{+}$becomes dominant and $\mathrm{NO}^{+}$becomes significant as more oxygen flows through the system. The total positive-ion density stays near $2 \times 10^{12} / \mathrm{cm}^{3}$ in the source region for all of the conditions considered here. The predicted electron density is about $7.7 \times 10^{10} / \mathrm{cm}^{3}$ for the nominal conditions, increasing with decreasing flow rate and increasing power. 


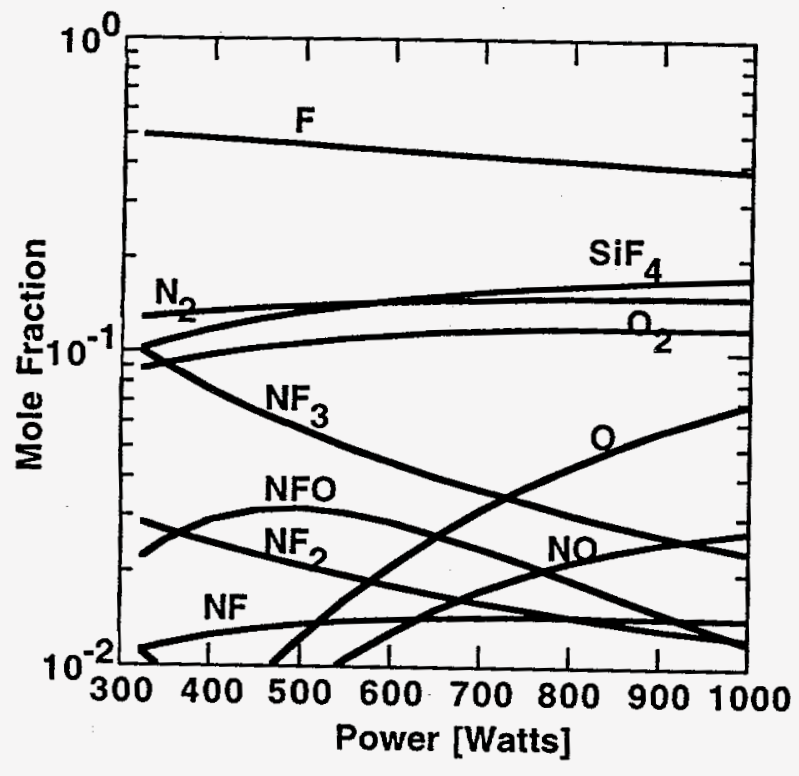

(a)

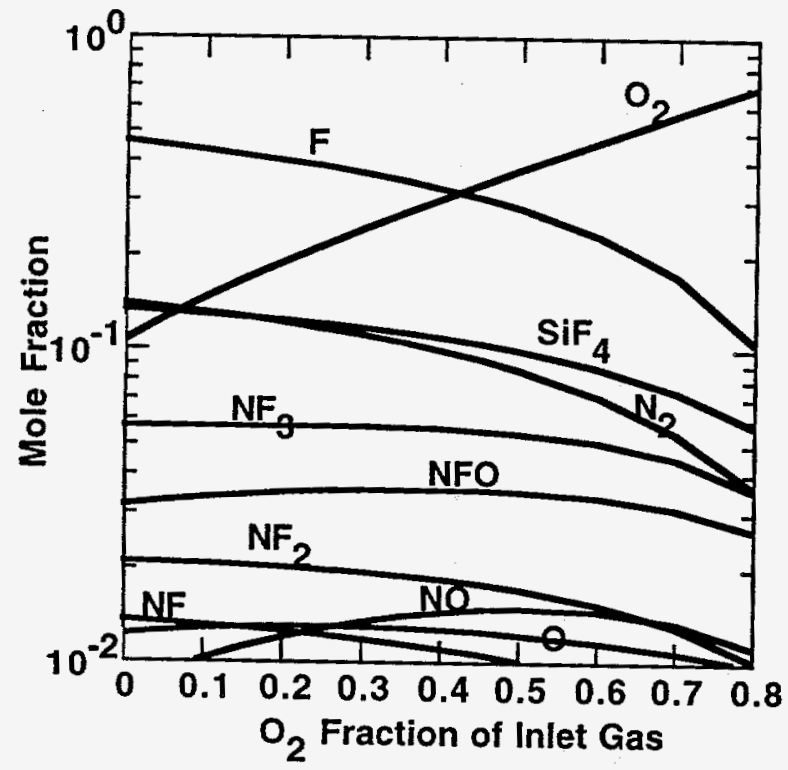

(c)

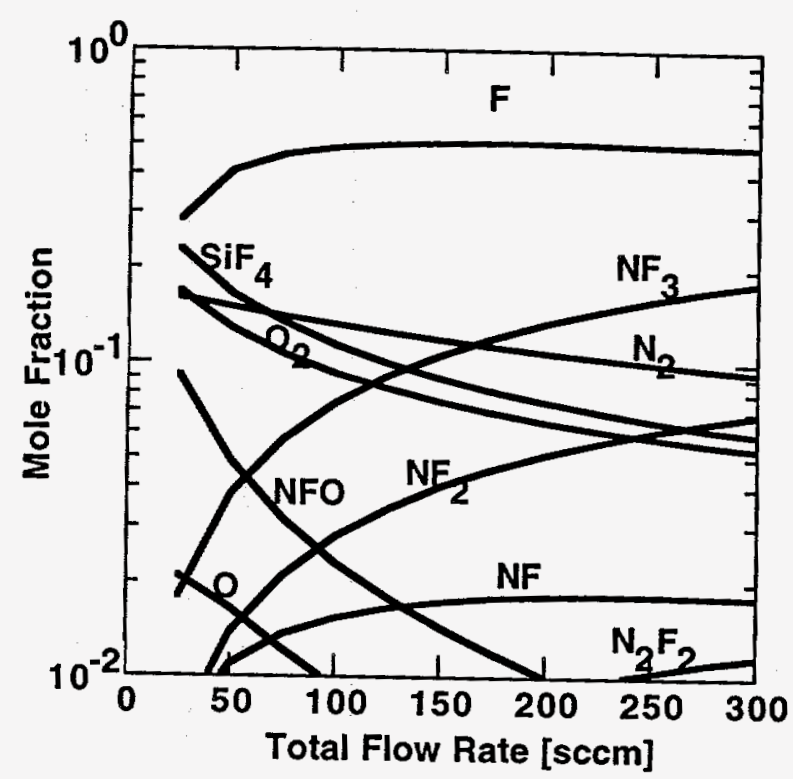

(b)

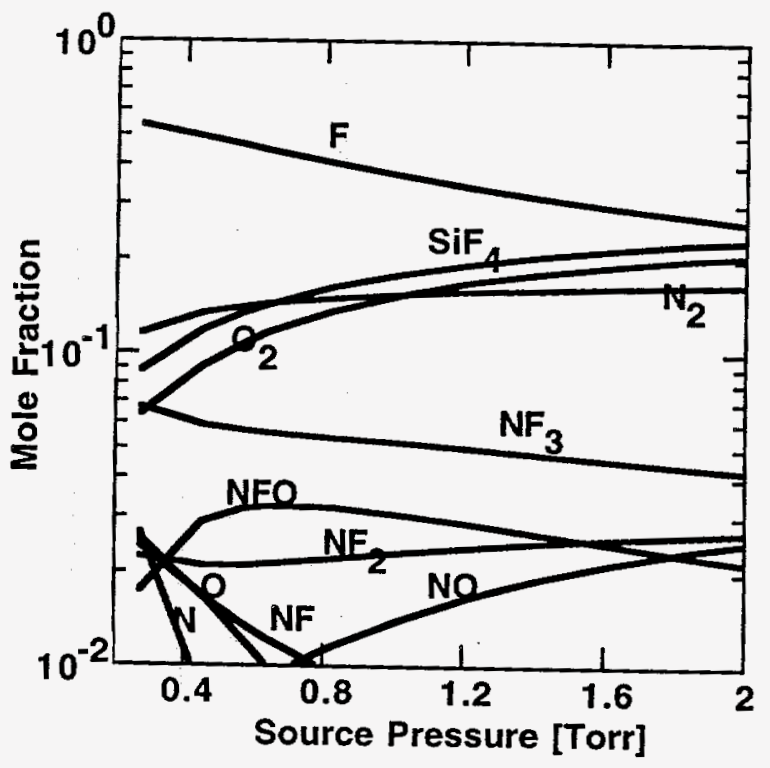

(d)

Figure I-3. Plasma source model predictions of neutral densities in the CDE-80 source region as functions of a) power b) gas flow rate, c) percent oxygen with constant total flow rate, and d) pressure. Nominal conditions are $75 \mathrm{sccm}$ total flow rate, $0 \%$ $\mathrm{O}_{2}, 0.525$ Torr, and $500 \mathrm{~W}$ deposited power. 
Figure I-4 shows results from the transport tube simulations for the nominal reactor conditions. Here the effect of transport-tube length is apparent from the axial dependence of the species mole fractions. In all cases run, the F concentration remains high despite recombination on the tube's inner teflon surface. Electron density drops off rapidly due to wall interactions with ions. The positive ion density remains significant farther into the transport tube, due to the predominance

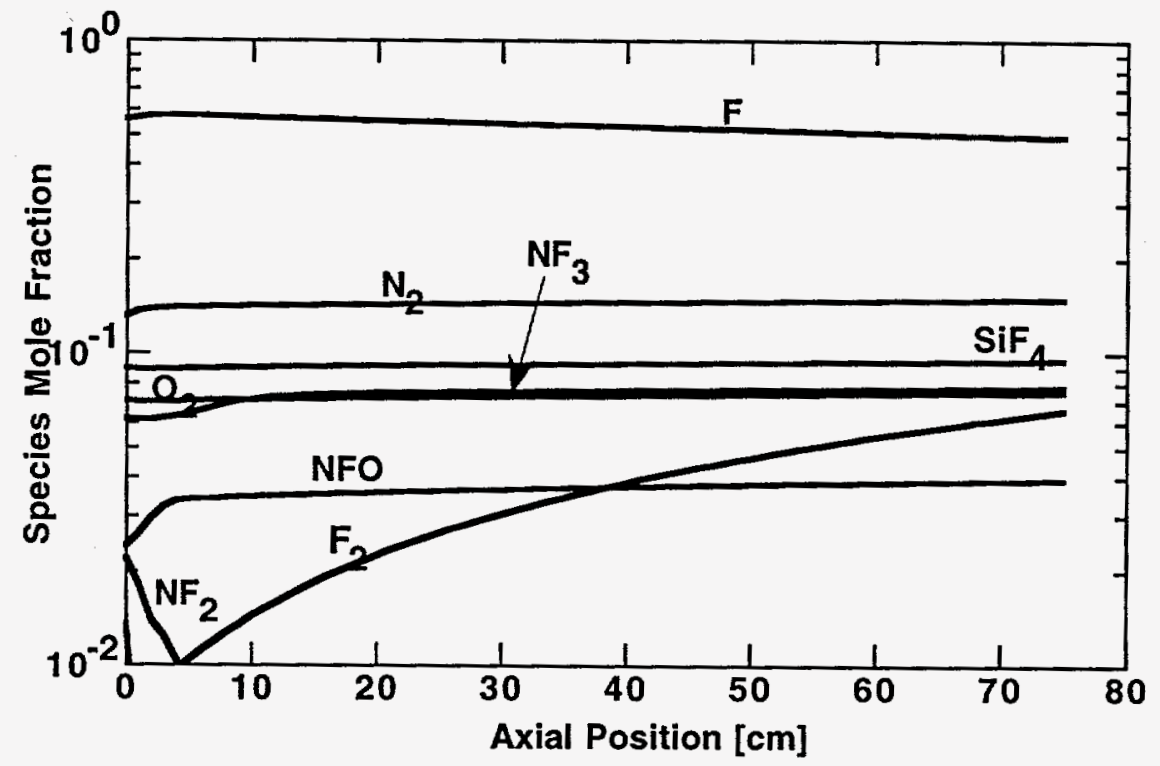

(a)

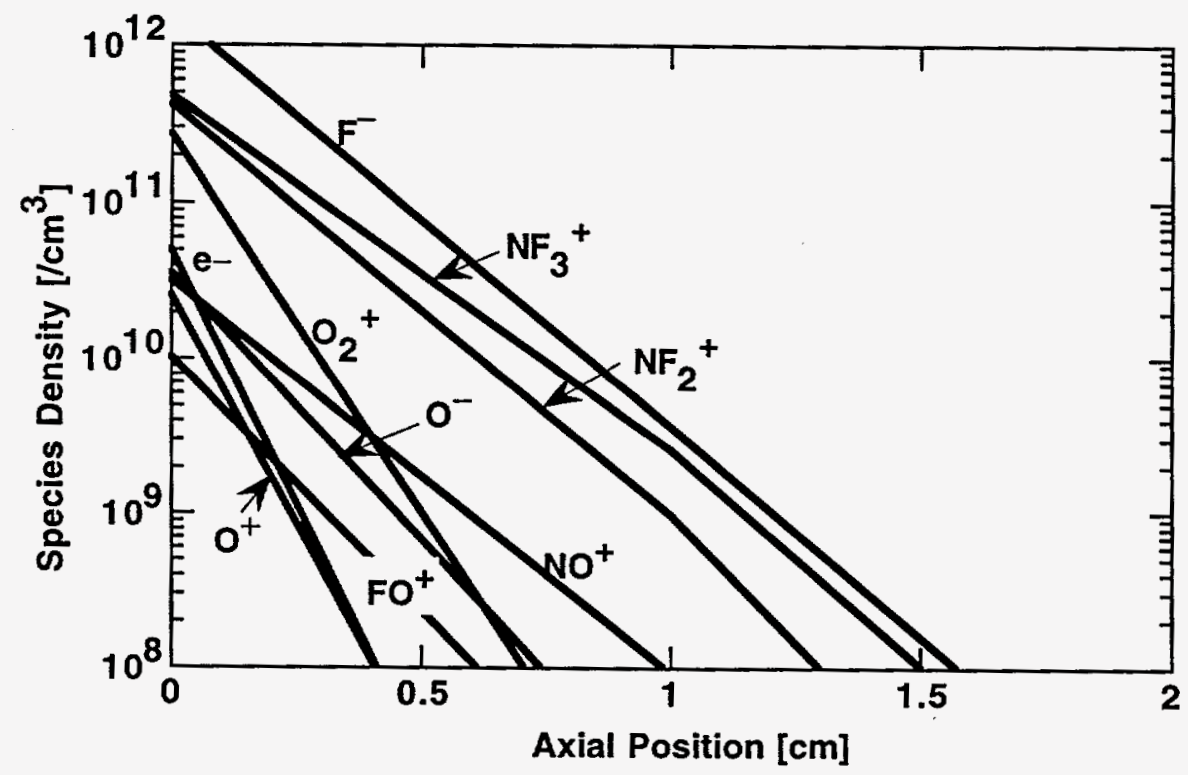

(b)

Figure I-4. Transport tube axial density profiles predicted for nominal conditions for a) neutral species and b) ions. 
of negative ions. Positive and negative ions recombine as they proceed down the transport tube through two mechanisms: gas-phase neutralization and the exchange of electrons through wall interactions. The latter mechanism is enabled once the electron density decays and the plasma sheath remaining near the tube walls is negligible. This surface neutralization mechanism dominates and causes the charge density to drop below $10^{7}$ within a few centimeters from the transport tube inlet. Below this density, the ion mole fractions cannot be accurately determined due to the resolution limits of the transport-tube model solution. The absence of significant charge density downstream of the transport tube is, however, consistent with measurements performed on the CDE- 80 tool. $^{30}$ In these measurements, the charge densities downstream of $\mathrm{N}_{2} / \mathrm{O}_{2}$ plasmas were less than about $10^{6} / \mathrm{cm}^{3}$ when the $\mathrm{N}_{2} / \mathrm{O}_{2}$ ratio was less than 9 , although a peak in charge density of $10^{7}$ is apparent at $5 \% \mathrm{O}_{2}$ in $\mathrm{N}_{2} \cdot{ }^{30}$ In the $\mathrm{NF}_{3}$ plasma simulations, the ratio of $\mathrm{N}_{2}$ to $\mathrm{O}_{2}$ downstream of the plasma is between 0.2 and 6 for the conditions reported here. The model results suggest that the $75 \mathrm{~cm}$ transport-tube length greatly exceeds that necessary to remove the ions from the plasma in the CDE system. Also, the optimal transport tube design, including tube length and material, depends on the process chemistry and the electronegativity of the source plasma.

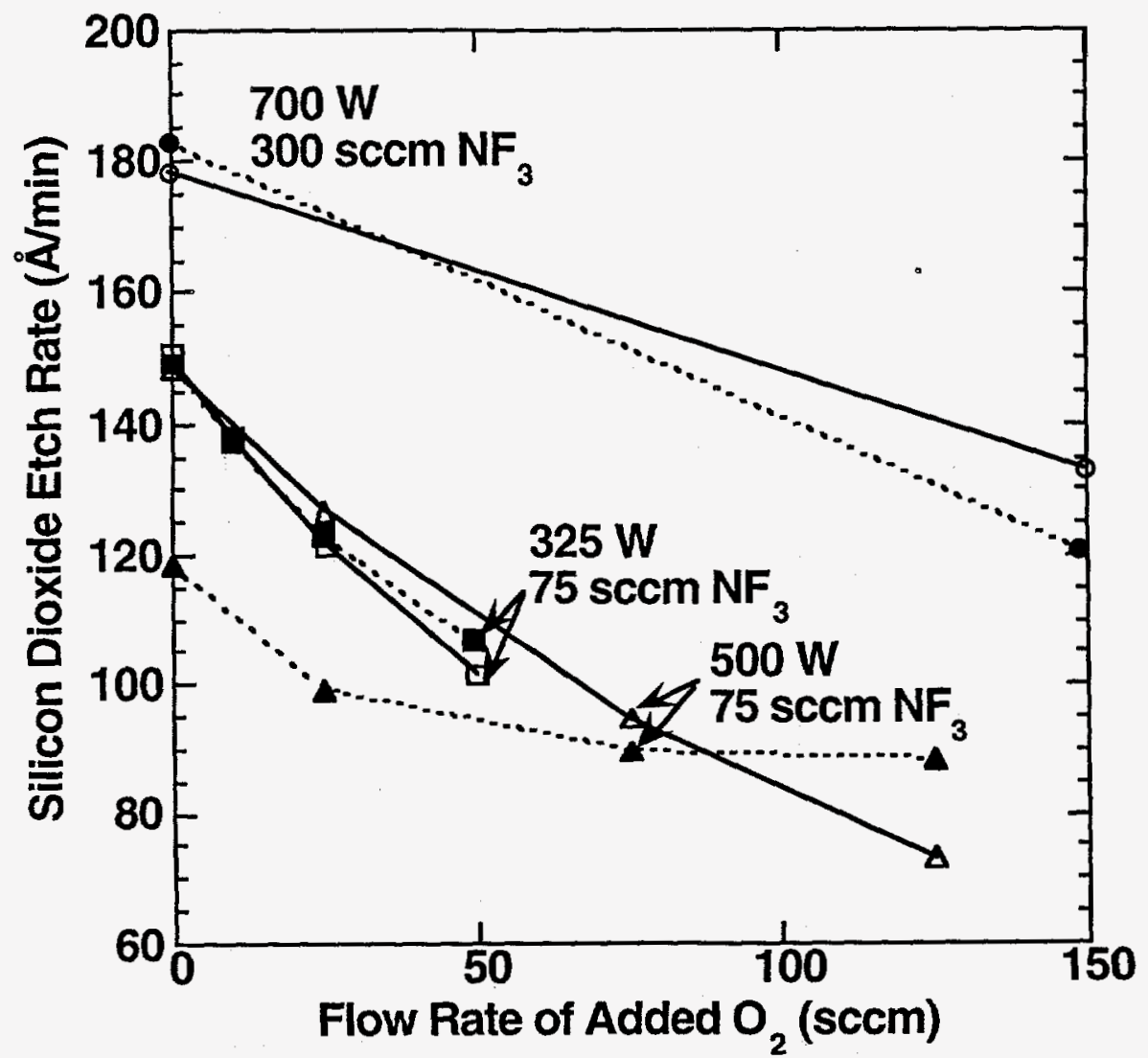

Figure I-5. Comparison of model predictions of silicon dioxide etch rates in the downstream chamber with experimental measurements in the CDE-80 tool. ${ }^{30}$ Dashed lines with closed symbols are the experimental data, while solid lines and open symbols are the simulation results. 
Figure I-5 shows a comparison of predicted downstream wafer etch rates for etching of silicon dioxide with measured etch rates ${ }^{30}$ on the CDE-80 tool. For these comparisons we used the 1-D Stagnation flow code ${ }^{5}$ for the downstream chamber simulation. However, each of the model etch rates represents a full simulation from the plasma source through the transport tube to the downstream chamber, including iteration between the plasma source and the transport-tube model to arrive at the appropriate plasma source pressure. In all cases the downstream chamber pressure is fixed at 525 mtorr. Figure I-5 shows excellent agreement between the model and experiments for the $325 \mathrm{~W}$ power cases and for the $700 \mathrm{~W} / 300 \mathrm{sccm}$ cases.

For the $500 \mathrm{~W}$ power, $75 \mathrm{sccm}$ cases, the model predicts higher etch rates and a sharper decline in oxide etch rate with added oxygen flow rate than observed. The source of this discrepancy lies in our inability to fully capture the effects of increased source power on the etch rate of the upstream quartz microwave applicator. Intuitively one would expect that increasing the power in the microwave source from $325 \mathrm{~W}$ to $500 \mathrm{~W}$, keeping flow rate and pressure constant, would have the effect of increasing the dissociation in the plasma and therefore increase the mole fraction of fluorine atoms. However, this effect must compete with the increased heating of the plasma gas and the applicator walls. As the source walls heat up, the quartz etching increases due to the exponential dependence of the etch rate on surface temperature. The quartz etch provides a sink for fluorine atoms through the production of the etch product $\mathrm{SiF}_{4}$. Although the model results shown in Fig. I-5 do illustrate this competition, the effect of increased quartz etching is not as strong as indicated by the measured results. In the source model, the heating of the quartz tube is modeled through specification of an internal and external heat transfer coefficient and a heat balance for the bulk gas in the plasma. The resulting surface temperatures calculated are between 450 and $1000 \mathrm{~K}$ as the power is varied from 325 $1000 \mathrm{~W}$. While the effect of surface temperature on thermal etch rate is captured in the measured etch rate employed in the simulation, the measurement was for etching thermal oxide, rather than quartz. In addition, there may be a significant non-thermal effect of increasing the source power on etch rate. Our model does include ion-enhanced etch reactions, but does not include any dependence on ion energy, nor any measure of the ion energy as a function of source power. We found that increasing the thermal-etch reaction rate in the model does cause the fluorine mole fraction calculated in the $500 \mathrm{~W}$ case to drop significantly below the $325 \mathrm{~W}$ case, more in agreement with the measured downstream etch rates. It should also be noted that the experimental data was taken from patterned wafers, where the oxide is a fraction of the total wafer area, while the model simulates etching of blanket oxide wafers. Even with the discrepancy in the power effect on etch rate, however, the model predictions are well within $25 \%$ for the $500 \mathrm{~W}$ case, and within $10 \%$ for the $300 \mathrm{~W}$ and $700 \mathrm{~W} / 300 \mathrm{sccm}$ cases.

Results from the 2-D reacting flow analysis in the downstream chamber are shown for the nominal case $(500 \mathrm{~W}, 75 \mathrm{sccm})$ in Figures I-6 and I-7. Figure I-6 shows the mole fraction contours for the $\mathrm{F}$ and $\mathrm{SiF}_{4}$ species. Diffusive transport has only a minor effect in this region 
due to the relatively low reaction probability of the atomic fluorine on the silicon dioxide. With this etch rate, radical transport to the surface becomes surface-kinetic limited, and surface temperature may play the dominant role in determining etch uniformity. For high reaction probabilities, such as fluorine etch of polysilicon, the process becomes transport limited and the uniformity depends strongly on the uniformity of species fluxes delivered to the surface. Figure 1-7 also demonstrates the role of species diffusion. On the left-hand-side of Fig. I-7 are streamlines for total mass flux, showing the flow of gas through the reactor chamber. On the right-hand-side, however, we plot fluorine-atom streamlines calculated from the addition of the convective flux vector and diffusive flux vector for $F$. If the surface-reaction probability of the fluorine atoms were very small, the $F$ streamlines would coincide with the mass streamlines. In this case, however, the diffusive flux does affect the fluorine flux profile, but does not entirely dominate convection.

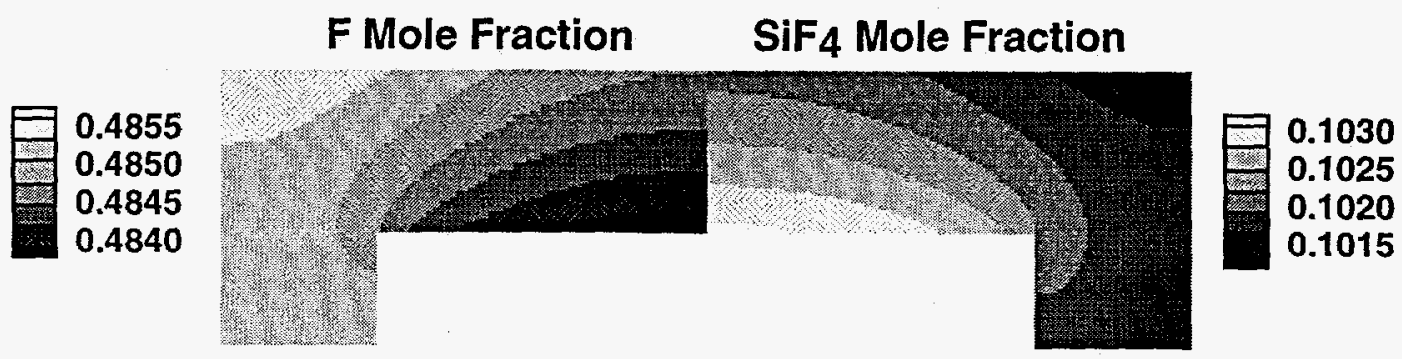

Figure I-6. Mole fraction contours for $\mathrm{F}$ and $\mathrm{SiF}_{4}$ for nominal conditions in the downstream chamber.

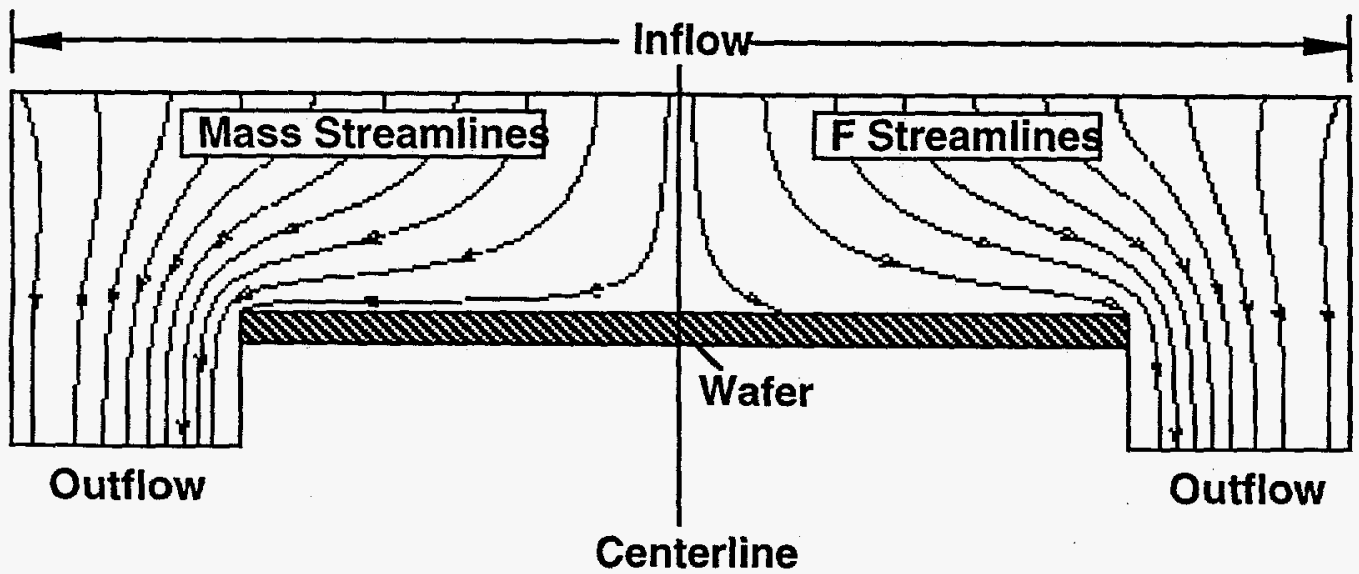

Figure I-7. Mass-flow streamlines compared to streamlines for the fluorine atoms calculated from the addition of convective and diffusive fluxes, for the nominal conditions.

The predicted silicon dioxide etch rate is faster at the wafer edge than at the center. This enhanced etching at the wafer edge is due to acceleration of the flow around the wafer, which results in enhanced radial diffusion of $F$ to the wafer corner. The average etch rate predicted by 
the 2 -D simulation is $172 \AA / \mathrm{min}$ (compared with the $1-\mathrm{D}$ prediction of $148 \AA / \mathrm{min}$ ) with a $3 \sigma$ non-uniformity of $0.15 \%$. The $13 \%$ underprediction by the $1-\mathrm{D}$ simulation is due to the neglect of radial diffusion in the 1-D model. This effect is illustrated by the species contours shown in Fig. I-6. Here the fluorine atom concentration is depleted in the center of the reactor due to the etching reactions. This gradient and the fact that the gas-inlet area is larger than the wafer area drive diffusion of the fluorine atoms in from the edges of the reactor, replenishing the etchant at the wafer.

\section{CONCLUSIONS}

The combination of the three modeling approaches presented here provides a coherent view of the chemistry interactions in a CDE process. The use of the models in tandem allows investigation into the impact of varying plasma source operating parameters on downstream etch results, as well as the role of the transport tube in delivering ions and radicals to the wafer surface. The downstream chamber calculations show the importance of competing processes under different etch conditions, and allow optimization of etch rate uniformity through reactor and process modifications. Comparisons of model predictions with available experimental data show good agreement for every portion of the model, including downstream etch performance results. These comparisons provide validation of the chemical reaction mechanisms employed in the model segments. With these chemistry mechanisms and the linked-model methodology, we can examine tradeoffs in achieving process objectives, reduce reactor design time, and understand the future impact of process modifications. 


\section{REFERENCES}

1. Park, S.-K. and Economou, D. J.: J. Appl. Phys., 663256 (1989).

2. Kushner, M. J.: J. Appl. Phys., 714173 (1992).

3. Deshmukh, S. C. and Economou, D. J.: J. Appl. Phys., 11206 (1993).

4. Coltrin, M. E., Kee, R. J. and Evans, G. H.: J. Electrochem. Soc., 136819 (1989).

5. Coltrin, M. E., Kee, R. J., Evans, G. H., Meeks, E., Rupley, F. M. and Grcar, J. F.: “SPIN (Version 3.83): A Fortran Program for Modeling One-Dimensional RotatingDisk/Stagnation-Flow Chemical Vapor Deposition Reactors," Sandia National Laboratories Report SAND91-8003 (1991).

6. Kee, R. J., Rupley, F. M. and Miller, J. A.: "The Chemkin Thermodynamic Data Base," Sandia National Laboratories Report SAND87-8215B (1990).

7. Coltrin, M. E., Kee, R. J. and Rupley, F. M.: Int. J. Chem. Kinet., 231111 (1991).

8. Coltrin, M. E., Kee, R. J., Rupley, F. M. and Meeks, E.: "SURFACE CHEMKIN III: A Fortran Package for Analyzing Heterogeneous Chemical Kinetics at a Solid-Surface - GasPhase Interface," Sandia National Laboratories Report SAND96-8217 (1996).

9. Kee, R. J., Rupley, F. M., Meeks, E. and Miller, J. A.: "CHEMKIN-III: A Fortran Chemical Kinetics Package for the Analysis of Gas-Phase Chemical and Plasma Kinetics," Sandia National Laboratories Report SAND96-8216 (1996).

10. Liu, X., MacDonald, M. A. and Coombe, R. D.: J. Phys. Chem., 964907 (1992).

11. Deshmukh, S. C. and Economou, D. J.: J. Appl. Phys., 724597 (1992).

12. von Engel, A.: Ionized Gases, AIP Press, New York (1965).

13. Flamm, D. L., Mogab, C. J. and Sklaver, E. R.: J. Appl. Phys., 506211 (1979).

14. Butterbaugh, J. W., Gray, D. C. and Sawin, H. H.: J. Vac. Sci. Tech. B, 91461 (1991).

15. Greaves, J. C. and Linnett, J. W.: Trans. Faraday Soc., 541323 (1958).

16. Ganguli, P. S. and Kaufman, M.: Chem. Phys. Lett., 25221 (1974).

17. Meeks, E. and Shon, J.: IEEE Trans. Plasma Sci., 23539 (1994). 
18. Meeks, E., Moffat, H. K., Grcar, J. F. and Kee, R. J.: "AURORA: A Fortran Program for Modeling Well Stirred Plasma and Thermal Reactors with Gas and Surface Reactions," Sandia National Laboratories Report SAND96-8218 (1996).

19. Holman, J. P.: Heat Transfer, McGraw-Hill Publishing Company, New York (1990).

20. Blain, M. Personal Communication: February, 1995.

21. Holber, W. Personal Communication:

22. Bird, R. B., Stewart, W. E. and Lightfoot, E. N.: Transport Phenomena, Wiley, New York (1960).

23. Petzold, L. R.: Sandia National Laboratories Report SAND82-8637 (1982).

24. Gosman, A. D. and Pun, W. M.: "Calculation of recirculating flow," Imperial College of Science and Technology Report (1973).

25. Patankar, S. V.: Numerical Heat Transfer and Fluid Flow, McGraw-Hill, New York (1980).

26. Kee, R. J., Dixon-Lewis, G., Warnatz, J., Coltrin, M. E. and Miller, J. A.: “A Fortran Computer Code Package for the Evaluation of Gas-Phase Multicomponent Transport Properties," Sandia National Laboratories Report SAND86-8246 (1986).

27. Evans, G. and Greif, R.: Int. J. Heat Mass Trans., 342039 (1991).

28. Evans, G. and Greif, R.: Int. J. Heat Mass Trans., 371535 (1994).

29. Perrin, J., Meot, J., Siefert, J.-M. and Schmitt, J.: Plasma Chemistry and Plasma Processing, 10571 (1990).

30. Stevens, J., Blain, M. and Meisenheimer, T.: "SEMATECH/Sandia Chemical Downstream Etch (CDE) Benchmark Project (S73)--Process Diagnostics and Hardware Analysis," SEMATECH Report 95042781A-ENG (1995).

31. Rescigno, T. N.: Phys. Rev. A, 52329 (1995).

32. Ushivoda, S., Kajita, S. and Kondo, Y.: Journal of Physics D, 2347 (1990).

33. Tarnovsky, V., Levin, A., Becker, K., Basner, R. and Schmidt, M.: International Journal of Mass Spectroscopy and Ion Processes, 133175 (1994).

34. Phelps, A. V.: J. Phys. Chem. Ref. Data, 20557 (1991).

35. Fox, R. E.: Westinghouse Electric Corporation Report 60-94439-4-R2 (1956). 
36. Morgan, W. L.: Plasma Chemistry and Plasma Processing, 12449 (1992).

37. Hayes, T. R., Wetzel, R. C. and Freund, R. S.: Phys. Rev. A, 35578 (1987).

38. Itikawa, Y., Ichimura, A., Onda, K., Sakimoto, K. and Takayanagi, K.: J. Phys. Chem. Ref. Data, 1823 (1989).

39. Itikawa, Y. and Ichimura, A.: J. Phys. Chem. Ref. Data, 19637 (1990).

40. Baulch, D. L., Duxbury, J., Grant, S. J. and Montague, D. C.: J. Phys. Chem. Ref. Data, 10 1 (1981).

41. Lloyd, A. C.: Int. J. Chem. Kinet., 339 (1971).

42. Levy, J. B. and Copeland, B. K. W.: J. Phys. Chem., 693700 (1965).

43. Kondratiev, V. N.: Rate Constants of Gas Phase Reactions (COM-72-10014), U. S. Department of Commerce, Washington, DC (1972).

44. Weiller, B. H., Heidner, R. F., Holloway, J. S. and Koffend, J. B.: J. Phys. Chem., 969321 (1992).

45. Heidner, R. F., Helvajian, H., Holloway, J. S. and Koffend, J. B.: J. Phys. Chem., 937813 (1989).

46. Rozenshtein, V. B., Bedzhanyan, Y. R. and Gershenson, Y. M.: Kinet. Catal., 2922 (1988).

47. Cheah, C. T., Clyne, M. A. A. and Whitefield, P. D.: J. Chem. Soc. Faraday Trans. 2,76 711 (1980).

48. Koffend, J. B., Gardner, C. E. and Heidner, R. F.: J. Chem. Phys., 832904 (1985).

49. Doroshchenko, V. M., Kudriavtsev, N. N., Suknov, A. M. and Shamshev, D. P.: Chem. Phys. Lett., 193258 (1992).

50. Westley, F., Herron, J. T. and Cvetanovic, R. J.: Compilation of Chemical Kinetic Data for Combustion Chemistry (NSRDS-NBS 73, Parts 1 and 2), U. S. Government Printing Office, Washington, DC (1987).

51. Atkinson, R., Baulch, D. L., Cox, R. A., Hampson, R. F., Kerr, J. A. and Troe, J.: J. Phys. Chem. Ref. Data, 211125 (1992).

52. Atkinson, R., Baulch, D. L., Cox, R. A., Hampson, R. F., Kerr, J. A. and Troe, J.: J. Phys. Chem. Ref. Data, 18881 (1989).

53. Rubinstein, M., Sicre, J. E. and Schumacher, H. J.: Z. Phys. Chem., 196451 (1964). 
54. Bedzhanyan, Y. G., Gershenson, Y. M., Il'in, S. D., Kishkovic, O. P. and Rozenshtein, V. B.: Sov. J. Chem. Phys., 6610 (1990).

55. Bedzhanyan, Y. G., Gershenson, Y. M. and Rozenshtein, V. B.: Kinet. Catal., 311291 (1990).

56. DeMore, W. B., Golden, D. M., Hampson, R. F., Howard, C. J., Kurylo, M. J., Molina, M. J., Ravishankara, A. R. and Sander, S. P.: Jet Propulsion Laboratory Report 87-41 (1987).

57. Rahman, M. M., Becker, E., Benter, T. and Schindler, R. N.: Ber. Bunsenges. Phys. Chem., 9291 (1988).

58. Lyman, J. L. and Holland, R.: J. Phys. Chem., 927232 (1988).

59. Campbell, G. M.: J. Fluor. Chem., 46357 (1990).

60. Timakov, A. A. and Prusakov, V. N.: Kinet. Catal., 30472 (1989).

61. Niles, F. E.: J. Chem. Phys., 52408 (1970).

62. Trotman-Dickenson, A. F. and Milne, G. S.: Tables of Bimolecular Gas Reactions (NSRDSNBS 9), U. S. Government Printing Office, Washington, DC (1967).

63. Kerr, J. A. and Moss, S. J.: CRC Handbook of Bimolecular and Termolecular Gas Reactions, CRC Press, Boca Raton, FL (1981).

64. Tsang, W. and Herron, J. T.: J. Phys. Chem. Ref. Data, 20609 (1991).

65. Anicich, V. G.: J. Phys. Chem. Ref. Data, 221469 (1993).

66. Touzeau, M., Gousset, G., Jolly, J., Pagnon, D. and Vialle, M.: Spectroscopy and Kinetics of an Oxygen Glow Discharge. Nonequilibrium Processes in Partially Ionized Gases. Plenum Press, New York, (1990). 571.

67. Steinfeld, J. I., Adler-Golden, S. M. and Gallagher, J. W.: J. Phys. Chem. Ref. Data, 16911 (1987).

68. Lifshitz, C., Wu, R. L. C., Tiernan, T. O. and Terwilliger, D. T.: J. Chem. Phys., 68247 (1978). 
Table I-1. Gas-Phase Reactions and Reaction Rate Coefficients for $\mathrm{NF}_{\mathbf{3}} / \mathrm{O}_{\mathbf{2}}$ Rate coefficients are in the form: $k_{f}=A T^{B} \exp (-C / T)$. Units are molecules, cubic centimeters, seconds, and Kelvin.

\begin{tabular}{|c|c|c|c|c|c|}
\hline & Reaction & $A$ & $B$ & $C$ & Reference \\
\hline 1. & $E+N F_{3} \Rightarrow N_{2}+F+E$ & $2.06 \mathrm{E}-17$ & 1.72 & 37274. & $31^{\ddagger}$ \\
\hline 2. & $E+N F_{3} \Rightarrow N F+2 F+E$ & $1.35 \mathrm{E}-30$ & 4.45 & 34210. & $31^{\frac{1}{t}}$ \\
\hline 3. & $\mathrm{E}+\mathrm{NF}_{3} \Rightarrow \mathrm{NF}_{2}+\mathrm{F}^{-}$ & $1.49 \mathrm{E}-08$ & -0.14 & 3751. & $32^{\ddagger}$ \\
\hline 4. & $\mathrm{NF}_{3}+\mathrm{E} \Rightarrow \mathrm{NF}_{3}{ }^{+}+2 \mathrm{E}$ & 7.39E-34 & 5.00 & 38111. & $33^{\ddagger}$ \\
\hline 5. & $\mathrm{NF}_{3}+\mathrm{E} \Rightarrow \mathrm{NF}_{2}^{+}+2 \mathrm{E}+\mathrm{F}$ & $2.25 \mathrm{E}-40$ & 6.46 & 34184. & $33^{\ddagger}$ \\
\hline 6. & $\mathrm{NF}_{3}+\mathrm{E} \Rightarrow \mathrm{NF}^{+}+2 \mathrm{E}+2 \mathrm{~F}$ & $3.93 \mathrm{E}-63$ & 11.04 & 39849. & $33^{\ddagger}$ \\
\hline 7. & $E+N F_{2} \Rightarrow N F+F+E$ & $1.57 \mathrm{E}-17$ & 1.84 & 27565. & $\dagger \ddagger$ \\
\hline 8. & $E+N F_{2} \Rightarrow N+2 F+E$ & $1.69 \mathrm{E}-23$ & 2.99 & 37652. & $\dagger \ddagger$ \\
\hline 9. & $\mathrm{NF}_{2}+\mathrm{E} \Rightarrow \mathrm{NF}_{2}^{+}+2 \mathrm{E}$ & $2.21 \mathrm{E}-33$ & 4.94 & 31902. & $33^{\ddagger}$ \\
\hline 10. & $E+N F \Rightarrow N+F+E$ & $1.57 \mathrm{E}-17$ & 1.84 & 27565. & $\dagger \ddagger$ \\
\hline 11. & $\mathrm{NF}+\mathrm{E} \Rightarrow \mathrm{NF}^{+}+2 \mathrm{E}$ & $1.94 \mathrm{E}-42$ & 6.80 & 33586. & $33^{\ddagger}$ \\
\hline 12. & $\begin{aligned} E+N F_{3} \Rightarrow E+N F_{3} & \text { excitation energy: }\end{aligned}$ & $\begin{array}{l}1.72 \mathrm{E}-12 \\
0.06 \mathrm{eV}\end{array}$ & $\begin{array}{l}0.42 \\
\text { (vibrational) }\end{array}$ & 3199. & $\dagger \ddagger$ \\
\hline 13. & $\begin{aligned} E+N F_{3} \Rightarrow E+ & N F_{3} \\
& \text { excitation energy: }\end{aligned}$ & $\begin{array}{c}4.10 \mathrm{E}-09 \\
0.14 \mathrm{eV}\end{array}$ & $\begin{array}{l}0.16 \\
\text { (vibrational) }\end{array}$ & 1670. & $\dagger \ddagger$ \\
\hline 14. & $\begin{aligned} & E+N F_{3} \Rightarrow E+N F_{3} \\
& \text { excitation energy: }\end{aligned}$ & $\begin{array}{l}3.42 \mathrm{E}-21 \\
7.70 \mathrm{eV}\end{array}$ & $\begin{array}{l}2.52 \\
\text { (electronic) }\end{array}$ & 33296. & + \\
\hline 15. & $\mathrm{E}+\mathrm{N}_{2} \Rightarrow \mathrm{N}_{2}{ }^{+}+2 \mathrm{E}$ & $2.56 \mathrm{E}-43$ & 7.07 & 31481. & $34 \ddagger$ \\
\hline 16. & $E+N \Rightarrow N^{+}+2 E$ & $5.11 \mathrm{E}-37$ & 5.78 & 47602. & 35 \\
\hline 17. & $\mathrm{E}+\mathrm{N}_{2}{ }^{+} \Rightarrow \mathrm{N}+\mathrm{N}$ & $2.25 \mathrm{E}-01$ & -2.50 & 0. & $34 \ddagger$ \\
\hline 18. & $\mathrm{E}+\mathrm{N}_{2}{ }^{+} \Rightarrow \mathrm{N}_{2}$ & $2.25 \mathrm{E}-01$ & -2.50 & 0. & $34^{\ddagger}$ \\
\hline 19. & $\mathrm{E}+\mathrm{N}^{+} \Rightarrow \mathrm{N}$ & $2.25 \mathrm{E}-01$ & -2.50 & 0. & $35^{\ddagger}$ \\
\hline 20. & $\begin{array}{r}E+N_{2} \Rightarrow N_{2}+E \\
\text { excitation energy: }\end{array}$ & $\begin{array}{l}5.65 \mathrm{E}-21 \\
6.17 \mathrm{eV}\end{array}$ & $\begin{array}{l}2.17 \\
\left(\mathrm{~N}_{2}\left(\mathrm{~A}^{3} \mathrm{\Sigma}^{+}\right)\right.\end{array}$ & 29055. & $34 \div$ \\
\hline 21. & $\mathrm{E}+\mathrm{F}_{2} \Rightarrow \mathrm{F}+\mathrm{F}^{-}$ & $1.02 \mathrm{E}-05$ & -0.90 & 1082. & $36^{\ddagger}$ \\
\hline 22. & $\mathrm{E}+\mathrm{F}_{2} \Rightarrow \mathrm{F}_{2}^{+}+2 \mathrm{E}$ & 1.64E-44 & 7.25 & 32883. & $36^{\ddagger}$ \\
\hline 23. & $E+F \Rightarrow F^{+}+2 E$ & $2.24 \mathrm{E}-47$ & 7.81 & 34076. & $37^{\ddagger}$ \\
\hline 24. & $\mathrm{E}+\mathrm{O}_{2} \Rightarrow 2 \mathrm{O}+\mathrm{E}$ & $9.06 \mathrm{E}-38$ & 5.58 & 45474. & $38^{\ddagger}$ \\
\hline 25. & $\mathrm{E}+\mathrm{O}_{2} \Rightarrow \mathrm{O}_{2}^{+}+2 \mathrm{E}$ & $4.64 \mathrm{E}-34$ & 5.16 & 33264. & $38 \mp$ \\
\hline 26. & $\mathrm{E}+\mathrm{O}_{2} \Rightarrow \mathrm{O}+\mathrm{O}^{-}$ & 3.39E-04 & -1.47 & 46608. & $38^{\ddagger}$ \\
\hline 27. & $\mathrm{E}+\mathrm{O} \Rightarrow \mathrm{O}^{+}+2 \mathrm{E}$ & $9.88 \mathrm{E}-35$ & 5.29 & 38669. & $39 \ddagger$ \\
\hline 28. & $\begin{aligned} \mathrm{E}+\mathrm{O}_{2} \Rightarrow \mathrm{O}_{2}{ }^{*}+\mathrm{E} & \\
& \text { excitation energy: }\end{aligned}$ & $\begin{array}{l}4.24 \mathrm{E}-11 \\
0.98 \mathrm{eV}\end{array}$ & $\begin{array}{l}0.26 \\
\left(\mathrm{O}_{2}\left(\mathrm{a}^{1} \Delta \mathrm{g}\right)\right)\end{array}$ & 14283. & $38^{\ddagger}$ \\
\hline 29. & $\begin{aligned} \mathrm{E}+\mathrm{O}_{2} \Rightarrow \mathrm{O}_{2}{ }^{* *}+\mathrm{E} & \text { excitation energy: }\end{aligned}$ & $\begin{array}{l}1.05 \mathrm{E}-09 \\
1.63 \mathrm{eV}\end{array}$ & $\begin{array}{l}-0.17 \\
\left(\mathrm{O}_{2}\left(\mathrm{~b}^{1} \Sigma \mathrm{g}^{+}\right)\right)\end{array}$ & 19499. & $38^{\ddagger}$ \\
\hline 30. & $\begin{aligned} E+O \Rightarrow O^{*}+E & \text { excitation energy: }\end{aligned}$ & $\begin{array}{l}7.58 \mathrm{E}-08 \\
1.96 \mathrm{eV}\end{array}$ & $\begin{array}{l}-0.32 \\
\left(O\left({ }^{1} D\right)\right)\end{array}$ & 22243. & $39^{\ddagger}$ \\
\hline
\end{tabular}

$\ddagger$ Rate coefficients are estimates or are derived from estimates of electron-impact cross sections.

$\dagger$ Rate coefficients are functions of electron temperature; references are for collision cross sections. 


\begin{tabular}{|c|c|c|c|c|c|}
\hline & Reaction & $A$ & $B$ & $C$ & Reference \\
\hline 31. & $\begin{aligned} \mathrm{E}+\mathrm{O} \Rightarrow \mathrm{O}^{* *}+\mathrm{E} \\
\quad \text { excitation energy: }\end{aligned}$ & $\begin{array}{c}3.46 \mathrm{E}-06 \\
4.18 \mathrm{eV}\end{array}$ & $\begin{array}{l}-0.67 \\
\left(O\left({ }^{1} S\right)\right)\end{array}$ & 39354. & $39 \ddagger$ \\
\hline 32. & $\mathrm{E}+\mathrm{N}_{2} \mathrm{~F}_{2} \Rightarrow 2 \mathrm{~N}+2 \mathrm{~F}+\mathrm{E}$ & $2.28 \mathrm{E}-17$ & 1.70 & 36391. & $\dagger \ddagger$ \\
\hline 33. & $\mathrm{E}+\mathrm{N}_{2} \mathrm{~F}_{4} \Rightarrow 2 \mathrm{~N}+4 \mathrm{~F}+\mathrm{E}$ & $2.28 \mathrm{E}-17$ & 1.70 & 36391. & $\dagger \ddagger$ \\
\hline 34. & $\mathrm{NF}_{2}+\mathrm{M} \Leftrightarrow \mathrm{NF}+\mathrm{F}+\mathrm{M}$ & $1.26 \mathrm{E}-09$ & 0.00 & 25700. & 40 \\
\hline 35. & $\mathrm{NF}_{2}+\mathrm{NF}_{2}+\mathrm{M} \Leftrightarrow \mathrm{N}_{2} \mathrm{~F}_{4}+\mathrm{M}$ & $1.50 \mathrm{E}-32$ & 0.00 & 0. & 40 \\
\hline \multirow[t]{2}{*}{36.} & $\mathrm{~F}+\mathrm{F}+\mathrm{M} \Leftrightarrow \mathrm{F}_{2}+\mathrm{M}$ & $2.80 \mathrm{E}-34$ & 0.00 & 0. & 41 \\
\hline & reverse parameters: & $7.60 \mathrm{E}-12$ & 0.00 & 14300. & 41 \\
\hline 37. & $\mathrm{NF}_{2}+\mathrm{F}_{2} \Leftrightarrow \mathrm{NF}_{3}+\mathrm{F}$ & $3.00 \mathrm{E}-14$ & 0.00 & 4860. & 42 \\
\hline 38. & $N F+N F \Leftrightarrow N_{2}+F+F$ & $6.88 \mathrm{E}-11$ & 0.00 & 1251. & 43 \\
\hline 39. & $\mathrm{NF}+\mathrm{NF} \Leftrightarrow \mathrm{F}_{2}+\mathrm{N}_{2}$ & $4.00 \mathrm{E}-12$ & 0.00 & 0. & 43,44 \\
\hline 40. & $\mathrm{NF}+\mathrm{N} 2 \mathrm{~F}_{2} \Leftrightarrow \mathrm{NF}_{2}+\mathrm{N}_{2}+\mathrm{F}$ & $2.00 \mathrm{E}-12$ & 0.00 & 0. & 44 \\
\hline 41. & $\mathrm{NF}+\mathrm{NF}_{2} \Leftrightarrow \mathrm{N}_{2} \mathrm{~F}_{2}+\mathrm{F}$ & $3.75 \mathrm{E}-12$ & 0.00 & 187. & 45,44 \\
\hline 42. & $\mathrm{NF}_{2}+\mathrm{N} \Leftrightarrow \mathrm{F}+\mathrm{F}+\mathrm{N}_{2}$ & $1.40 \mathrm{E}-11$ & 0.00 & 95. & 46 \\
\hline 43. & $\mathrm{NF}_{2}+\mathrm{N} \Leftrightarrow \mathrm{NF}+\mathrm{NF}$ & $3.00 \mathrm{E}-12$ & 0.00 & 0. & 47 \\
\hline \multirow[t]{2}{*}{44.} & $\mathrm{NF}_{2}+\mathrm{F}+\mathrm{M} \Leftrightarrow \mathrm{NF}_{3}+\mathrm{M}$ & $1.03 \mathrm{E}-30$ & 0.00 & 0. & 48 \\
\hline & reverse parameters: & $3.98 \mathrm{E}-10$ & 0.00 & 18417. & 49 \\
\hline 45. & $F+N_{3} \Leftrightarrow N F+N_{2}$ & $5.80 \mathrm{E}-11$ & 0.00 & 0. & 10 \\
\hline 46. & $\mathrm{NO}+\mathrm{NO}+\mathrm{NO} \Leftrightarrow \mathrm{NO}_{2}+\mathrm{N}_{2} \mathrm{O}$ & $2.95 \mathrm{E}-38$ & 0.00 & 13490. & 50 \\
\hline 47. & $\mathrm{NO}_{3}+\mathrm{NO}_{3} \Leftrightarrow \mathrm{NO}_{2}+\mathrm{NO}_{2}+\mathrm{O}_{2}$ & $8.50 \mathrm{E}-13$ & 0.00 & 2450. & 50 \\
\hline \multirow[t]{2}{*}{48.} & $\mathrm{O}_{3}+\mathrm{M} \Leftrightarrow \mathrm{O}+\mathrm{O}_{2}+\mathrm{M}$ & $7.17 \mathrm{E}-10$ & 0.00 & 11170. & 50 \\
\hline & reverse parameters: & $2.57 \mathrm{E}-35$ & 0.00 & 855. & 43 \\
\hline 49. & $\mathrm{~N}+\mathrm{NO}_{2} \Leftrightarrow \mathrm{NO}+\mathrm{NO}$ & $5.89 \mathrm{E}-12$ & 0.00 & 0. & 43 \\
\hline 50. & $\mathrm{~N}+\mathrm{NO}_{2} \Leftrightarrow \mathrm{N}_{2}+\mathrm{O}+\mathrm{O}$ & $1.12 \mathrm{E}-12$ & 0.00 & 0. & 43 \\
\hline 51. & $\mathrm{~N}_{2} \mathrm{O}+\mathrm{N}_{2} \mathrm{O} \Leftrightarrow \mathrm{N}_{2}+\mathrm{N}_{2}+\mathrm{O}_{2}$ & $6.17 \mathrm{E}-18$ & 0.00 & 0. & 43 \\
\hline 52. & $\mathrm{O}+\mathrm{FO} \Leftrightarrow \mathrm{O}_{2}+\mathrm{F}$ & $5.00 \mathrm{E}-11$ & 0.00 & 0. & 51 \\
\hline 53. & $\mathrm{O}+\mathrm{FO}_{2} \Leftrightarrow \mathrm{O}_{2}+\mathrm{FO}$ & $5.00 \mathrm{E}-11$ & 0.00 & 0. & 51 \\
\hline 54. & $\mathrm{FO}+\mathrm{NO} \Leftrightarrow \mathrm{F}+\mathrm{NO}_{2}$ & $2.60 \mathrm{E}-11$ & 0.00 & 0. & 51 \\
\hline 55. & $\mathrm{~F}+\mathrm{NO}_{2}+\mathrm{M} \Leftrightarrow \mathrm{NFO}_{2}+\mathrm{M}$ & $9.00 \mathrm{E}-26$ & -2.00 & 0. & 52 \\
\hline 56. & $\mathrm{FO}+\mathrm{NO}_{2}+\mathrm{M} \Leftrightarrow \mathrm{NFO}_{3}+\mathrm{M}$ & $4.23 \mathrm{E}-23$ & -3.40 & 0. & 52 \\
\hline 57. & $\mathrm{NF}_{2}+\mathrm{F}_{2} \mathrm{O} \Leftrightarrow \mathrm{NF}_{3}+\mathrm{FO}$ & $5.00 \mathrm{E}-12$ & 0.50 & 11100. & 53 \\
\hline 58. & $\mathrm{NF}_{2}+\mathrm{O} \Leftrightarrow \mathrm{NFO}+\mathrm{F}$ & $1.25 \mathrm{E}-11$ & 0.00 & 0. & 46 \\
\hline 59. & $\mathrm{NF}_{2}+\mathrm{O} \Leftrightarrow \mathrm{NF}+\mathrm{FO}$ & $1.80 \mathrm{E}-12$ & 0.00 & 0. & 47 \\
\hline 60. & $\mathrm{NF}_{2}+\mathrm{NO}_{2} \Leftrightarrow \mathrm{NFO}+\mathrm{NFO}$ & $8.60 \mathrm{E}-14$ & 0.00 & 2450. & 54 \\
\hline 61. & $\mathrm{NF}_{2}+\mathrm{FO} \Leftrightarrow \mathrm{F}+\mathrm{F}+\mathrm{NFO}$ & $3.80 \mathrm{E}-12$ & 0.00 & 0. & 55 \\
\hline 62. & $\mathrm{NO}+\mathrm{F}+\mathrm{M} \Leftrightarrow \mathrm{NFO}+\mathrm{M}$ & $9.47 \mathrm{E}-28$ & -1.70 & 0. & 56 \\
\hline 63. & $\mathrm{~F}_{2} \mathrm{O}+\mathrm{M} \Leftrightarrow \mathrm{F}+\mathrm{FO}+\mathrm{M}$ & $3.00 \mathrm{E}-09$ & 0.00 & 17500. & 40 \\
\hline 64. & $\mathrm{~F}+\mathrm{NO}_{3} \Leftrightarrow \mathrm{FO}+\mathrm{NO}_{2}$ & $3.00 \mathrm{E}-11$ & 0.00 & 0. & 57 \\
\hline \multirow[t]{2}{*}{65.} & $\mathrm{~F}_{2} \mathrm{O}_{2}+\mathrm{M} \Leftrightarrow \mathrm{F}+\mathrm{FO}_{2}+\mathrm{M}$ & $4.60 \mathrm{E}-03$ & -1.00 & 9900. & 58 \\
\hline & reverse parameters: & $3.00 \mathrm{E}-32$ & 0.00 & 0. & 58 \\
\hline \multirow[t]{2}{*}{66.} & $\mathrm{~F}+\mathrm{O}_{2}+\mathrm{M} \Leftrightarrow \mathrm{FO}_{2}+\mathrm{M}$ & $1.10 \mathrm{E}-30$ & -1.00 & 0. & 51 \\
\hline & reverse parameters: & $6.30 \mathrm{E}-09$ & 0.00 & 5800. & 51 \\
\hline \multirow[t]{2}{*}{67.} & $\mathrm{~F}_{2} \mathrm{O}_{2}+\mathrm{O}_{2} \Leftrightarrow \mathrm{FO}_{2}+\mathrm{FO}_{2}$ & $8.40 \mathrm{E}-08$ & 0.00 & 6520. & 59 \\
\hline & reverse parameters: & $2.00 \mathrm{E}-06$ & 0.00 & 6550. & 59 \\
\hline 68. & $\mathrm{~F}_{2} \mathrm{O}_{2}+\mathrm{F} \Leftrightarrow \mathrm{FO}_{2}+\mathrm{F}_{2}$ & $3.60 \mathrm{E}-14$ & 0.00 & 0. & 58 \\
\hline 69. & $\mathrm{FO}+\mathrm{NO}_{3} \Leftrightarrow \mathrm{FO}_{2}+\mathrm{NO}_{2}$ & $1.00 \mathrm{E}-12$ & 0.00 & 0. & 57 \\
\hline
\end{tabular}




\begin{tabular}{|c|c|c|c|c|c|}
\hline & Reaction & $A$ & $B$ & $C$ & Reference \\
\hline \multirow[t]{2}{*}{70.} & $\mathrm{~F}+\mathrm{FO}_{2} \Leftrightarrow \mathrm{F}_{2}+\mathrm{O}_{2}$ & $1.50 \mathrm{E}-11$ & 0.00 & 1500. & 58 \\
\hline & reverse parameters: & $5.20 \mathrm{E}-11$ & 0.00 & 10800. & 58 \\
\hline 71. & $\mathrm{FO}_{2}+\mathrm{FO}_{2}+\mathrm{M} \Leftrightarrow 2 \mathrm{O}_{2}+\mathrm{F}_{2}+\mathrm{M}$ & $2.40 \mathrm{E}-33$ & 0.00 & 0. & 60 \\
\hline 72. & $\mathrm{~N}+\mathrm{NO}+\mathrm{M} \Leftrightarrow \mathrm{N}_{2} \mathrm{O}+\mathrm{M}$ & $3.57 \mathrm{E}-36$ & 0.00 & 0. & 61 \\
\hline \multirow[t]{2}{*}{73.} & $\mathrm{NO}+\mathrm{NO} \Leftrightarrow \mathrm{N}_{2}+\mathrm{O}_{2}$ & $1.35 \mathrm{E}-11$ & 0.00 & 28680. & 62 \\
\hline & reverse parameters: & $1.51 \mathrm{E}+01$ & -2.50 & 64660. & 43 \\
\hline 74.. & $\mathrm{NO}+\mathrm{N}_{2} \mathrm{O} \Leftrightarrow \mathrm{N}_{2}+\mathrm{NO}_{2}$ & 4.17E-10 & 0.00 & 25160. & 62 \\
\hline 75. & $\mathrm{NO}_{2}+\mathrm{F}_{2} \Leftrightarrow \mathrm{NFO}_{2}+\mathrm{F}$ & $2.63 \mathrm{E}-12$ & 0.00 & 5284. & 62 \\
\hline 76. & $\mathrm{NO}_{2}+\mathrm{F}_{2} \mathrm{O} \Leftrightarrow \mathrm{NFO}_{2}+\mathrm{FO}$ & $2.14 \mathrm{E}-13$ & 0.00 & 7286. & 62 \\
\hline 77. & $\mathrm{O}_{3}+\mathrm{O}_{3} \Leftrightarrow \mathrm{O}_{2}+\mathrm{O}_{2}+\mathrm{O}_{2}$ & $7.42 \mathrm{E}-12$ & 0.00 & 9460. & 62 \\
\hline 78. & $\mathrm{~N}+\mathrm{NO}_{2} \Leftrightarrow \mathrm{N}_{2}+\mathrm{O}_{2}$ & $1.41 \mathrm{E}-12$ & 0.00 & 0. & 63 \\
\hline \multirow[t]{2}{*}{79.} & $\mathrm{~N}+\mathrm{NO} \Leftrightarrow \mathrm{N}_{2}+\mathrm{O}$ & $8.13 \mathrm{E}-11$ & 0.00 & 408. & 63 \\
\hline & reverse parameters: & $1.26 \mathrm{E}-10$ & 0.00 & 38040. & 63 \\
\hline \multirow[t]{2}{*}{80.} & $\mathrm{~N}+\mathrm{O}_{2} \Leftrightarrow \mathrm{NO}+\mathrm{O}$ & $1.05 \mathrm{E}-14$ & 1.00 & 3150. & 63 \\
\hline & reverse parameters: & $2.51 \mathrm{E}-15$ & 1.00 & 19500. & 63 \\
\hline 81. & $\mathrm{~N}+\mathrm{O}_{3} \Leftrightarrow \mathrm{NO}+\mathrm{O}_{2}$ & $5.50 \mathrm{E}-13$ & 0.00 & 0. & 63 \\
\hline 82. & $\mathrm{O}+\mathrm{O}_{3} \Leftrightarrow \mathrm{O}_{2}+\mathrm{O}_{2}$ & $8.71 \mathrm{E}-12$ & 0.00 & 2113. & 63 \\
\hline \multirow[t]{2}{*}{83.} & $\mathrm{O}+\mathrm{NO}_{2} \Leftrightarrow \mathrm{O}_{2}+\mathrm{NO}$ & $1.74 \mathrm{E}-10$ & -0.52 & 0. & 63 \\
\hline & reverse parameters: & 2.82E-12 & 0.00 & 23400 . & 63 \\
\hline \multirow[t]{2}{*}{84.} & $\mathrm{O}+\mathrm{N}_{2} \mathrm{O} \Leftrightarrow \mathrm{O}_{2}+\mathrm{N}_{2}$ & $1.66 \mathrm{E}-10$ & 0.00 & 14090. & 63 \\
\hline & reverse parameters: & $1.05 \mathrm{E}-10$ & 0.00 & 55350. & 63 \\
\hline \multirow[t]{2}{*}{85.} & $\mathrm{O}+\mathrm{N}_{2} \mathrm{O} \Leftrightarrow \mathrm{NO}+\mathrm{NO}$ & $1.66 \mathrm{E}-10$ & 0.00 & 14090. & 63 \\
\hline & reverse parameters: & $2.14 \mathrm{E}-12$ & 0.00 & 32100. & 63 \\
\hline \multirow[t]{2}{*}{86.} & $\mathrm{O}+\mathrm{F}_{2} \Leftrightarrow \mathrm{FO}+\mathrm{F}$ & $1.62 \mathrm{E}-11$ & 0.00 & 5233. & 63 \\
\hline & reverse parameters: & $6.61 \mathrm{E}-14$ & 0.00 & 9561. & 63 \\
\hline \multirow[t]{2}{*}{87.} & $\mathrm{FO}+\mathrm{F}_{2} \Leftrightarrow \mathrm{F}_{2} \mathrm{O}+\mathrm{F}$ & $1.66 \mathrm{E}-13$ & 0.00 & 5233. & 63 \\
\hline & reverse parameters: & $8.52 \mathrm{E}-14$ & 0.00 & 6894. & 63 \\
\hline 88. & $\mathrm{~F}+\mathrm{O}_{3} \Leftrightarrow \mathrm{FO}+\mathrm{O}_{2}$ & $2.82 \mathrm{E}-11$ & 0.00 & 252. & 63 \\
\hline \multirow[t]{2}{*}{89.} & $\mathrm{NO}_{3}+\mathrm{NO} \Leftrightarrow \mathrm{NO}_{2}+\mathrm{NO}_{2}$ & $6.92 \mathrm{E}-12$ & 0.00 & 855. & 63 \\
\hline & reverse parameters: & $5.37 \mathrm{E}-12$ & 0.00 & 12880. & 63 \\
\hline \multirow[t]{2}{*}{90.} & $\mathrm{NO}_{3}+\mathrm{NO}_{2} \Leftrightarrow \mathrm{NO}_{2}+\mathrm{NO}+\mathrm{O}_{2}$ & $1.95 \mathrm{E}-13$ & 0.00 & 1610. & 63 \\
\hline & reverse parameters: & $5.76 \mathrm{E}-41$ & 0.00 & -483 & 63 \\
\hline \multirow[t]{2}{*}{91.} & $\mathrm{NO}+\mathrm{NO}+\mathrm{O}_{2} \Leftrightarrow \mathrm{NO}_{2}+\mathrm{NO}_{2}$ & $6.61 \mathrm{E}-39$ & 0.00 & -528 & 63 \\
\hline & reverse parameters: & $2.63 \mathrm{E}-11$ & 0.00 & 13790. & 63 \\
\hline \multirow[t]{2}{*}{92.} & $\mathrm{~N}+\mathrm{N}+\mathrm{M} \Leftrightarrow \mathrm{N}_{2}+\mathrm{M}$ & $1.41 \mathrm{E}-32$ & 0.00 & 0. & 63 \\
\hline & reverse parameters: & $3.16 \mathrm{E}-07$ & -0.50 & 113200. & 43 \\
\hline \multirow[t]{2}{*}{93.} & $\mathrm{~N}+\mathrm{O}+\mathrm{M} \Leftrightarrow \mathrm{NO}+\mathrm{M}$ & $9.13 E-33$ & 0.00 & 0. & 63 \\
\hline & reverse parameters: & $2.28 \mathrm{E}-10$ & 0.00 & 74680. & 50 \\
\hline \multirow[t]{2}{*}{94.} & $\mathrm{O}+\mathrm{O}+\mathrm{M} \Leftrightarrow \mathrm{O}_{2}+\mathrm{M}$ & $5.25 \mathrm{E}-35$ & 0.00 & -906. & 63 \\
\hline & reverse parameters: & $1.31 \mathrm{E}-10$ & 0.00 & 52740. & 50 \\
\hline \multirow[t]{2}{*}{95.} & $\mathrm{O}+\mathrm{NO}+\mathrm{M} \Leftrightarrow \mathrm{NO}_{2}+\mathrm{M}$ & $7.25 \mathrm{E}-33$ & 0.00 & -805 & 63 \\
\hline & reverse parameters: & $4.10 \mathrm{E}+04$ & -3.37 & 37640. & 64 \\
\hline 96. & $\mathrm{O}+\mathrm{NO}_{2}+\mathrm{M} \Leftrightarrow \mathrm{NO}_{3}+\mathrm{M}$ & $6.32 \mathrm{E}-32$ & 0.00 & 0. & 63 \\
\hline 97. & $\mathrm{~N}+\mathrm{NO}_{2} \Leftrightarrow \mathrm{N}_{2} \mathrm{O}+\mathrm{O}$ & $1.41 \mathrm{E}-12$ & 0.00 & 0. & 63 \\
\hline 98. & $\mathrm{FO}+\mathrm{FO} \Leftrightarrow \mathrm{F}+\mathrm{F}+\mathrm{O}_{2}$ & $2.09 \mathrm{E}-12$ & 0.00 & 0. & 63 \\
\hline 99. & $\mathrm{FO}+\mathrm{FO} \Leftrightarrow \mathrm{F}_{2} \mathrm{O}+\mathrm{O}$ & $6.61 \mathrm{E}-14$ & 0.00 & 8051. & 63 \\
\hline
\end{tabular}




\begin{tabular}{|c|c|c|c|c|c|}
\hline & Reaction & $A$ & $B$ & $C$ & Reference \\
\hline 100. & $\mathrm{NO}+\mathrm{O}_{3} \Leftrightarrow \mathrm{NO}_{2}+\mathrm{O}_{2}$ & $2.35 \mathrm{E}-12$ & 0.00 & 1459. & 63 \\
\hline 101. & $\mathrm{NO}+\mathrm{F}_{2} \Leftrightarrow \mathrm{NFO}+\mathrm{F}$ & $6.92 \mathrm{E}-13$ & 0.00 & 1157. & 63 \\
\hline 102. & $\mathrm{~N}_{2} \mathrm{O}+\mathrm{M} \Leftrightarrow \mathrm{N}_{2}+\mathrm{O}+\mathrm{M}$ & $2.36 \mathrm{E}-10$ & 0.00 & 25810 & 50 \\
\hline 103. & $\mathrm{O}+\mathrm{N}_{3} \Leftrightarrow \mathrm{NO}+\mathrm{N}_{2}$ & $1.00 \mathrm{E}-11$ & 0.00 & 0. & 50 \\
\hline 104. & $\mathrm{O}+\mathrm{NO}_{3} \Leftrightarrow \mathrm{O}_{2}+\mathrm{NO}_{2}$ & $1.00 \mathrm{E}-11$ & 0.00 & 0 & 50 \\
\hline 105. & $\mathrm{O}_{3}+\mathrm{NO}_{2} \Leftrightarrow \mathrm{O}_{2}+\mathrm{NO}_{3}$ & $1.57 \mathrm{E}-13$ & 0.00 & 2509. & 50 \\
\hline 106. & $\mathrm{~N}^{+}+\mathrm{O}_{2} \Leftrightarrow \mathrm{O}^{+}+\mathrm{NO}$ & $4.64 \mathrm{E}-11$ & 0.00 & 0. & 65 \\
\hline 107. & $\mathrm{~N}^{+}+\mathrm{O}_{2} \Leftrightarrow \mathrm{NO}^{+}+\mathrm{O}$ & $2.32 \mathrm{E}-10$ & 0.00 & 0. & 65 \\
\hline 108. & $\mathrm{~N}^{+}+\mathrm{O}_{2} \Leftrightarrow \mathrm{O}_{2}^{+}+\mathrm{N}$ & $3.07 \mathrm{E}-10$ & 0.00 & 0. & 65 \\
\hline 109. & $\mathrm{~N}^{+}+\mathrm{NO} \Leftrightarrow \mathrm{NO}^{+}+\mathrm{N}$ & $4.72 \mathrm{E}-10$ & 0.00 & 0. & 65 \\
\hline 110. & $\mathrm{~N}^{+}+\mathrm{NO} \Leftrightarrow \mathrm{N}_{2}^{+}+\mathrm{O}$ & $8.33 \mathrm{E}-11$ & 0.00 & 0. & 65 \\
\hline 111. & $\mathrm{~N}^{+}+\mathrm{N}_{2} \mathrm{O} \Leftrightarrow \mathrm{NO}^{+}+\mathrm{N}_{2}$ & $5.55 \mathrm{E}-10$ & 0.00 & 0. & 65 \\
\hline 112. & $\mathrm{~N}_{2}^{+}+\mathrm{O} \Leftrightarrow \mathrm{O}^{+}+\mathrm{N}_{2}$ & $9.80 \mathrm{E}-12$ & 0.00 & 0. & 65 \\
\hline 113. & $\mathrm{~N}_{2}^{+}+\mathrm{O} \Leftrightarrow \mathrm{NO}^{+}+\mathrm{N}$ & $1.30 \mathrm{E}-10$ & 0.00 & 0. & 65 \\
\hline 114. & $\mathrm{~N}_{2}^{+}+\mathrm{O}_{2} \Leftrightarrow \mathrm{O}^{+}+\mathrm{N}_{2}$ & $5.00 \mathrm{E}-11$ & 0.00 & 0. & 65 \\
\hline 115. & $\mathrm{~N}_{2}^{+}+\mathrm{NO} \Leftrightarrow \mathrm{NO}^{+}+\mathrm{N}_{2}$ & $4.10 \mathrm{E}-10$ & 0.00 & 0. & 65 \\
\hline 116. & $\mathrm{~N}_{2}^{+}+\mathrm{N}_{2} \mathrm{O} \Leftrightarrow \mathrm{N}_{2} \mathrm{O}^{+}+\mathrm{N}_{2}$ & $6.00 \mathrm{E}-10$ & 0.00 & 0. & 65 \\
\hline 117. & $\mathrm{O}^{+}+\mathrm{N}_{2} \Leftrightarrow \mathrm{NO}^{+}+\mathrm{N}$ & $1.20 \mathrm{E}-12$ & 0.00 & 0. & 65 \\
\hline 118. & $\mathrm{O}^{+}+\mathrm{O}_{2} \Leftrightarrow \mathrm{O}_{2}^{+}+\mathrm{O}$ & $2.10 \mathrm{E}-11$ & 0.00 & 0. & 65 \\
\hline 119. & $\mathrm{O}^{+}+\mathrm{NO} \Leftrightarrow \mathrm{NO}^{+}+\mathrm{O}$ & $8.00 \mathrm{E}-13$ & 0.00 & 0. & 65 \\
\hline 120. & $\mathrm{O}^{+}+\mathrm{NO}_{2} \Leftrightarrow \mathrm{NO}_{2}^{+}+\mathrm{O}$ & $1.60 \mathrm{E}-09$ & 0.00 & 0. & 65 \\
\hline 121. & $\mathrm{O}^{+}+\mathrm{N}_{2} \mathrm{O} \Leftrightarrow \mathrm{N}_{2} \mathrm{O}^{+}+\mathrm{O}$ & $6.30 \mathrm{E}-10$ & 0.00 & 0. & 65 \\
\hline 122. & $\mathrm{O}_{2}^{+}+\mathrm{N} \Leftrightarrow \mathrm{NO}^{+}+\mathrm{O}$ & $1.50 \mathrm{E}-10$ & 0.00 & 0. & 65 \\
\hline 123. & $\mathrm{O}_{2}^{+}+\mathrm{NO} \Leftrightarrow \mathrm{NO}^{+}+\mathrm{O}_{2}$ & $4.60 \mathrm{E}-10$ & 0.00 & 0. & 65 \\
\hline 124. & $\mathrm{O}_{2}^{+}+\mathrm{NO}_{2} \Leftrightarrow \mathrm{NO}_{2}^{+}+\mathrm{O}_{2}$ & $6.60 \mathrm{E}-10$ & 0.00 & 0. & 65 \\
\hline 125. & $\mathrm{~F}^{+}+\mathrm{N}_{2} \Leftrightarrow \mathrm{N}_{2}^{+}+\mathrm{F}$ & $9.70 \mathrm{E}-10$ & 0.00 & 0. & 65 \\
\hline 126. & $\mathrm{~F}^{+}+\mathrm{O}_{2} \Leftrightarrow \mathrm{O}^{+}+\mathrm{FO}$ & $6.06 \mathrm{E}-11$ & 0.00 & 0. & 65 \\
\hline 127. & $\mathrm{~F}^{+}+\mathrm{O}_{2} \Leftrightarrow \mathrm{O}_{2}^{+}+\mathrm{F}$ & $7.01 \mathrm{E}-10$ & 0.00 & 0. & 65 \\
\hline 128. & $\mathrm{~F}^{+}+\mathrm{O}_{2} \Leftrightarrow \mathrm{FO}^{+}+\mathrm{O}$ & $1.04 \mathrm{E}-10$ & 0.00 & 0. & 65 \\
\hline 129. & $\mathrm{~F}^{+}+\mathrm{NO} \Leftrightarrow \mathrm{NO}^{+}+\mathrm{F}$ & $8.46 \mathrm{E}-10$ & 0.00 & 0. & 65 \\
\hline 130. & $\mathrm{~F}^{+}+\mathrm{NO} \Leftrightarrow \mathrm{NF}^{+}+\mathrm{O}$ & $9.40 \mathrm{E}-11$ & 0.00 & 0. & 65 \\
\hline 131. & $\mathrm{~F}^{+}+\mathrm{N}_{2} \mathrm{O} \Leftrightarrow \mathrm{NO}^{+}+\mathrm{NF}$ & $7.20 \mathrm{E}-10$ & 0.00 & 0. & 65 \\
\hline 132. & $\mathrm{NO}_{2}^{+}+\mathrm{NO} \Leftrightarrow \mathrm{NO}^{+}+\mathrm{NO}_{2}$ & $2.75 \mathrm{E}-10$ & 0.00 & 0. & 65 \\
\hline 133. & $\mathrm{~N}_{2} \mathrm{O}^{+}+\mathrm{O}_{2} \Leftrightarrow \mathrm{O}_{2}^{+}+\mathrm{N}_{2} \mathrm{O}$ & $2.24 \mathrm{E}-10$ & 0.00 & 0. & 65 \\
\hline 134. & $\mathrm{~N}_{2} \mathrm{O}^{+}+\mathrm{O}_{2} \Leftrightarrow \mathrm{NO}^{+}+\mathrm{NO}_{2}$ & $4.59 \mathrm{E}-11$ & 0.00 & 0. & 65 \\
\hline 135. & $\mathrm{~N}_{2} \mathrm{O}^{+}+\mathrm{NO} \Leftrightarrow \mathrm{NO}^{+}+\mathrm{N}_{2} \mathrm{O}$ & $2.30 \mathrm{E}-10$ & 0.00 & 0. & 65 \\
\hline 136. & $\mathrm{~N}_{2} \mathrm{O}^{+}+\mathrm{NO}_{2} \Leftrightarrow \mathrm{NO}^{+}+\mathrm{N}_{2}+\mathrm{O}_{2}$ & $4.29 \mathrm{E}-10$ & 0.00 & 0. & 65 \\
\hline 137. & $\mathrm{~N}_{2} \mathrm{O}^{+}+\mathrm{NO}_{2} \Leftrightarrow \mathrm{NO}_{2}^{+}+\mathrm{N}_{2} \mathrm{O}$ & $2.21 \mathrm{E}-10$ & 0.00 & 0. & 65 \\
\hline 138. & $\mathrm{~N}_{2} \mathrm{O}^{+}+\mathrm{N}_{2} \mathrm{O} \Leftrightarrow \mathrm{NO}^{+}+\mathrm{N}_{2}+\mathrm{NO}$ & $1.20 \mathrm{E}-11$ & 0.00 & 0. & 65 \\
\hline 139. & $\mathrm{O}^{-}+\mathrm{O} \Rightarrow \mathrm{O}_{2}+\mathrm{E}$ & $1.40 \mathrm{E}-10$ & 0.00 & 0. & 66 \\
\hline 140. & $\mathrm{O}^{-}+\mathrm{O}_{2}^{*} \Rightarrow \mathrm{O}_{3}+\mathrm{E}$ & $3.00 \mathrm{E}-10$ & 0.00 & 0. & 66 \\
\hline 141. & $\mathrm{O}+\mathrm{O}+\mathrm{O}_{2} \Rightarrow \mathrm{O}_{3}+\mathrm{O}$ & $2.10 \mathrm{E}-34$ & 0.00 & -345 & 66 \\
\hline 142. & $\mathrm{O}+\mathrm{O}_{2}+\mathrm{O}_{2} \Rightarrow \mathrm{O}_{3}+\mathrm{O}_{2}$ & $6.40 \mathrm{E}-34$ & 0.00 & -663 & 66 \\
\hline 143. & $\mathrm{O}_{3}+\mathrm{O} \Rightarrow \mathrm{O}_{2}^{*}+\mathrm{O}_{2}$ & $1.00 \mathrm{E}-11$ & 0.00 & 2300. & 66 \\
\hline 144. & $\mathrm{O}_{2}^{* *}+\mathrm{O}_{3} \Rightarrow 2 \mathrm{O}_{2}+\mathrm{O}$ & $1.50 \mathrm{E}-11$ & 0.00 & 0 & 66 \\
\hline
\end{tabular}




\begin{tabular}{|c|c|c|c|c|c|}
\hline & Reaction & $A$ & $B$ & $C$ & Reference \\
\hline 145. & $2 \mathrm{O}_{2}^{*}+\mathrm{O}_{2} \Rightarrow 2 \mathrm{O}_{3}$ & $1.00 \mathrm{E}-31$ & 0.00 & 0. & 66 \\
\hline 146. & $\mathrm{O}_{2}^{*}+\mathrm{O}_{3} \Rightarrow 2 \mathrm{O}_{2}+\mathrm{O}$ & $5.20 \mathrm{E}-11$ & 0.00 & 2840 . & 66 \\
\hline 147. & $\mathrm{O}^{-}+\mathrm{O}_{2} \Leftrightarrow \mathrm{O}_{3}+\mathrm{E}$ & $5.00 \mathrm{E}-15$ & 0.00 & 0. & 67 \\
\hline 148. & $\mathrm{O}^{-}+\mathrm{O}_{2}+\mathrm{M} \Leftrightarrow \mathrm{O}_{3}^{-}+\mathrm{M}$ & $1.10 \mathrm{E}-30$ & 0.00 & 0. & 67 \\
\hline 149. & $\mathrm{O}_{2}^{-}+\mathrm{O} \Leftrightarrow \mathrm{O}_{3}+\mathrm{E}$ & $1.50 \mathrm{E}-10$ & 0.00 & 0. & 67 \\
\hline 150. & $\mathrm{O}^{-}+\mathrm{O}_{2}^{+}+\mathrm{M} \Leftrightarrow \mathrm{O}+\mathrm{O}_{2}+\mathrm{M}$ & $2.00 \mathrm{E}-25$ & 0.00 & 0. & 67 \\
\hline 151. & $\mathrm{O}_{3}^{-}+\mathrm{O}^{+} \Leftrightarrow \mathrm{O}_{3}+\mathrm{O}$ & $1.73 \mathrm{E}-06$ & -0.50 & 0. & 67 \\
\hline 152. & $\mathrm{O}_{3}^{-}+\mathrm{O}_{2}^{+} \Leftrightarrow \mathrm{O}_{3}+\mathrm{O}_{2}$ & $3.46 \mathrm{E}-06$ & -0.50 & 0. & 67 \\
\hline 153. & $\mathrm{O}_{3}+\mathrm{E}+\mathrm{M} \Leftrightarrow \mathrm{O}_{3}^{-}+\mathrm{M}$ & $4.60 \mathrm{E}-28$ & 0.00 & 0. & 67 \\
\hline 154. & $\mathrm{O}_{3}^{-}+\mathrm{O} \Leftrightarrow \mathrm{O}_{2}^{-}+\mathrm{O}_{2}$ & $1.10 \mathrm{E}-11$ & 0.00 & 0. & 67 \\
\hline 155. & $\mathrm{O}_{3}^{-}+\mathrm{N}_{2} \Leftrightarrow \mathrm{NO}_{2}^{-}+\mathrm{NO}$ & $1.00 \mathrm{E}-20$ & 0.00 & 0. & 67 \\
\hline 156. & $\mathrm{O}_{3}^{-}+\mathrm{NO}_{2} \Leftrightarrow \mathrm{O}_{2}+\mathrm{NO}_{3}^{-}$ & $2.80 \mathrm{E}-10$ & 0.00 & 0. & 67 \\
\hline 157. & $\mathrm{NO}_{2}^{-}+\mathrm{O}_{3} \Leftrightarrow \mathrm{O}_{2}+\mathrm{NO}_{3}^{-}$ & $9.00 \mathrm{E}-11$ & 0.00 & 0. & 67 \\
\hline 158. & $\mathrm{O}^{-}+\mathrm{O}_{3} \Leftrightarrow \mathrm{O}_{3}^{-}+\mathrm{O}$ & $5.50 \mathrm{E}-10$ & 0.00 & 0. & 67 \\
\hline 159. & $\mathrm{O}^{-}+\mathrm{O}_{3} \Leftrightarrow \mathrm{O}_{2}^{-}+\mathrm{O}_{2}$ & $1.00 \mathrm{E}-11$ & 0.00 & 0. & 67 \\
\hline 160. & $\mathrm{O}_{2}^{-}+\mathrm{O}_{3} \Leftrightarrow \mathrm{O}_{3}^{-}+\mathrm{O}_{2}$ & $3.20 \mathrm{E}-10$ & 0.00 & 0. & 67 \\
\hline 161. & $\mathrm{O}_{3}^{-}+\mathrm{O} \Leftrightarrow \mathrm{O}_{2}+\mathrm{O}_{2}+\mathrm{E}$ & $1.10 \mathrm{E}-13$ & 0.00 & 0. & 67 \\
\hline 162. & $\mathrm{O}^{-}+\mathrm{O}_{3} \Leftrightarrow \mathrm{O}_{2}+\mathrm{O}_{2}+\mathrm{E}$ & $3.00 \mathrm{E}-10$ & 0.00 & 0. & 67 \\
\hline 163. & $\mathrm{~F}^{-}+\mathrm{O}_{3} \Leftrightarrow \mathrm{F}+\mathrm{O}_{3}^{-}$ & $2.00 \mathrm{E}-14$ & 0.00 & 0. & 68 \\
\hline
\end{tabular}




\title{
II. MODELING OF CHEMICAL DOWNSTREAM ETCHING USING $\mathrm{CF}_{4} / \mathrm{O}_{2}, \mathrm{AND} \mathrm{CF}_{4} / \mathrm{O}_{2} / \mathrm{N}_{2}$ GAS MIXTURES
}

\author{
J. W. Shon, E. Meeks, R. S. Larson, C. A. Fox, S. R. Vosen, and D. Buchenauer
}

\section{$\mathrm{CF}_{4} / \mathrm{O}_{2}$ MECHANISM DEVELOPMENT}

In this section, chemical downstream etch processes using $\mathrm{CF}_{4} / \mathrm{O}_{2}$ and $\mathrm{CF}_{4} / \mathrm{O}_{2} / \mathrm{N}_{2}$ feed gases are investigated. Modeling here focuses on the generation of charged species and radicals in a microwave-excited plasma source with etching of a quartz applicator tube, transport through a flow tube, and comparisons to experimental measurements using a molecular beam mass spectrometer. As in the previous section, perfectly stirred reactor approximations are used for the plasma source region. The model predicts spatially and temporally averaged plasma properties and has been described in detail. ${ }^{3,4} \mathrm{CF}_{4} / \mathrm{O}_{2}$ plasma has been studied by others. ${ }^{5-8}$ In this report, a more detailed mechanism for $\mathrm{CF}_{4} / \mathrm{O}_{2}$ plasmas, based on basic electron impact cross sections, and neutral gas chemistry is developed for use in modeling the microwave plasma source region of a CDE system. The model also includes plasma-surface interactions, including etching of the quartz-applicator in the source region.

\section{Electron Kinetics}

Electron impact cross sections are critical data for modeling CDE systems, since computing the number of ions and radicals generated in a plasma directly depends on these cross sections. Based on a literature survey, we have compiled a set of cross sections for the $\mathrm{CF}_{4} / \mathrm{O}_{2}$ system. There are two recent measurements of electron impact cross section sets for $\mathrm{CF}_{4}{ }^{9}, 10$ Electron impact cross sections for $\mathrm{CF}_{3}, \mathrm{CF}_{2}$ and $\mathrm{CF}$ are obtained from Tarnovsky et al. ${ }^{11}$ and Deutsch et al. ${ }^{12}$ Cross sections for $\mathrm{O}_{2}{ }^{13}$ and $\mathrm{O}^{14}$ and for $\mathrm{C}_{2} \mathrm{~F}_{6}{ }^{15}$ are also included in the comprehensive set. The $\mathrm{O}_{2}$ dissociation rate used here is $10 \%$ of that calculated with the referenced cross section data, based on prior work in modeling oxygen plasmas ${ }^{16}$ and comparisons to experimental data.

For the electron kinetics, a Boltzmann code, ELENDIF ${ }^{17}$ is used. The details of the usage of this Boltzmann code has been described previously. ${ }^{18,19}$ Electron impact rate constants are computed from the Boltzmann distributions. The rate constants for electron impact reactions are listed in Table II-1 in Arrhenius form, which are fitted from rate constants obtained from the 
Boltzmann code. The nominal pressure for the microwave source region is $0.5-2.0$ torr. Therefore, the plasma in the source region is dominated by collisions. The Boltzmann-code assumptions are valid as long as the power deposition is moderate.

Using ELENDIF, power losses due to various collision mechanisms can be obtained for typical conditions. Power loss percentages over a range of average electron energy are shown in Figure 2 for $\mathrm{CF}_{4} / \mathrm{O}_{2}=50 / 50$, at 0.5 torr. The applicator tube diameter is $25 \mathrm{~mm}$ O.D. The nominal average electron energy is between 3-4 eV for approximately $30 \mathrm{~W}$ of microwave power. Under these conditions, most of the input electromagnetic energy is dissipated through elastic collisions, dissociative excitation of oxygen, and vibrational excitation of $\mathrm{CF}_{4}$. Direct ionization and dissociation of $\mathrm{CF}_{4}$ consist of about one percent of the total power. Therefore, elastic collisions and excitations play an important role by providing an energy absorbing mechanism, even though they may not directly contribute to the production of radicals or ions.

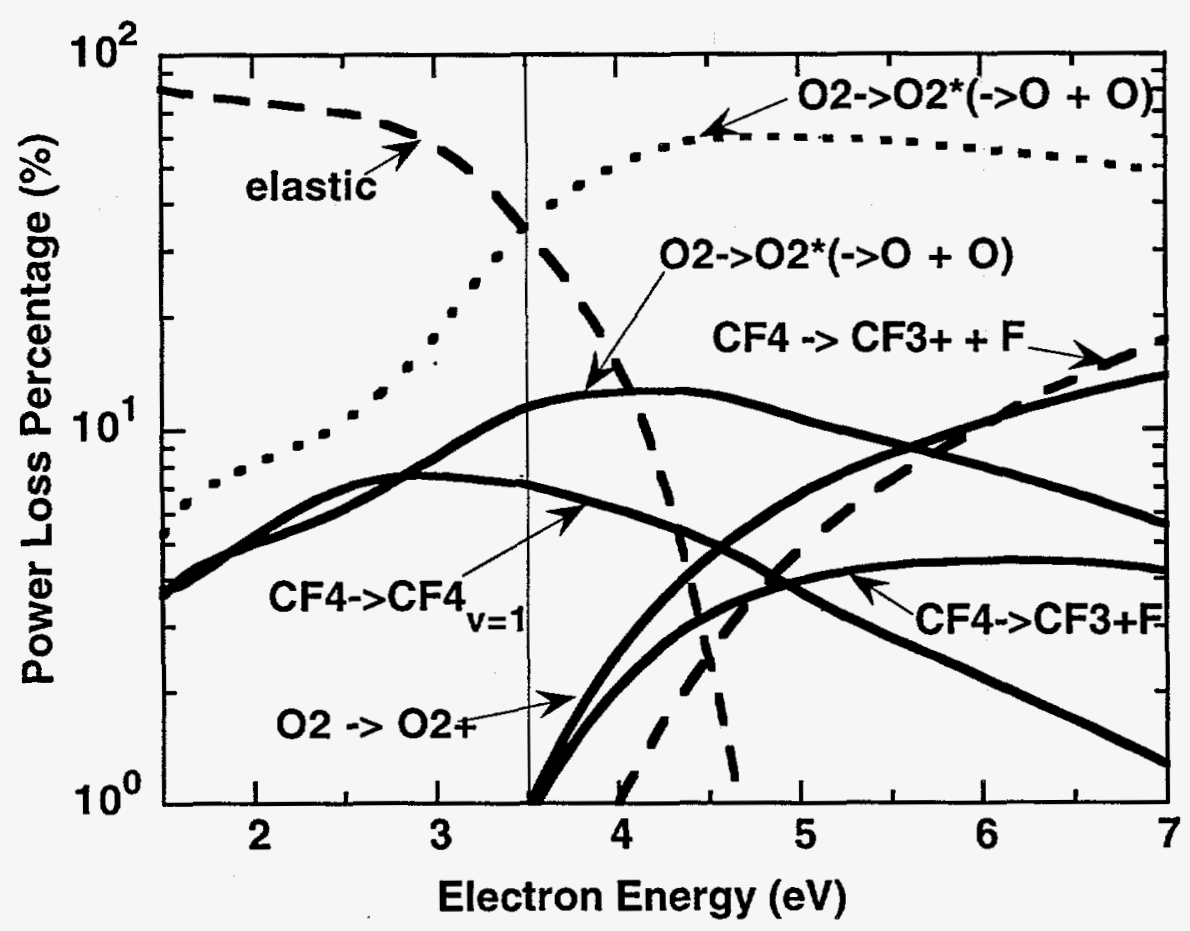

Figure II-1. Power loss percentages over a range of average electron energy for $\mathrm{CF}_{4} / \mathrm{O}_{2}=50 / 50 \%$ at 0.5 torr of pressure

\section{Neutral and Surface Reactions}

Downstream of the plasma source, neutral-neutral, ion-neutral and ion-ion collisions dominate the gas-phase chemistry. Deexcitation and recombination are also important at the surface. Even in the plasma source region, neutral and surface reactions can be very important. Energetic electrons in the plasma dissociate and ionize molecules. These reactions compete with 
gas-phase and surface recombination of radicals and ions. Therefore, the density of ions and radicals in the plasma are the result of dissociation and ionization rates, balanced by neutral and surface recombination rates. Neutral and ion reactions included in the model are listed in Table II-2. The dominant reactions in Table II-2 are recombination of $\mathrm{CF}_{3}, \mathrm{CF}_{2}$, and $\mathrm{CF}$ with $\mathrm{F}$; and $\mathrm{CF}_{2}$ and $\mathrm{CF}$ radicals reacting with $\mathrm{O}$ to form $\mathrm{COF}_{2}$ and $\mathrm{COF}^{20}$ The complete list of references and data used for the simulations is reported in Table II-2.

Four categories of plasma-surface interactions are considered in the plasma source model: ion recombination, radical recombination, excited-state de-excitation, and quartz-etch reactions. For ion-electron recombination at the surface, we assume that the ion flux to the surface is limited by the ion thermal velocity, rather than using a Bohm criterion, due to the high electronegativity of the gas. For example, the loss of $\mathrm{F}^{+}$ions at the tube walls is represented in the surface chemistry software, SURFACE CHEMKIN, ${ }^{21}$ by the surface reaction:

$$
\mathrm{F}^{+}+\mathrm{E}=>\mathrm{F}
$$

with a unity or near unity reaction probability. We include radical recombination on the quartz surface for $\mathrm{O}$ atoms combining to form $\mathrm{O}_{2}$ as follows:

$$
\mathrm{O}=>0.5 \mathrm{O}_{2} ; \quad \text { Reaction probability }=0.00071^{22}
$$

All excited species are assumed to be quenched to ground state with a unity reaction probability at the walls of the plasma source. For example,

$$
\mathrm{O}^{*} \Rightarrow \mathrm{O}
$$

The etching of the quartz tube has two reaction pathways. The first is thermal etching by $F$ atoms, for which we use the following two surface reactions:

$$
\begin{aligned}
\mathrm{F}+\mathrm{SiO}_{2}(\mathrm{~s}) \Rightarrow \mathrm{SiO}_{2} \mathrm{~F}(\mathrm{~s}) & \text { Reaction probability }=0.15 \\
\mathrm{~F}+\mathrm{SiO}_{2}(\mathrm{~b})+3 \mathrm{SiO}_{2} \mathrm{~F}(\mathrm{~s}) \Rightarrow & \mathrm{SIF}_{4}+\mathrm{O}_{2}+3 \mathrm{SiO}_{2}(\mathrm{~s}) \\
& \text { Reaction probability }=0.00429
\end{aligned}
$$

Here we have defined two types of surface sites, an open site $\mathrm{SiO}_{2}(\mathrm{~s})$ and a fluorinated surface site $\mathrm{SiO}_{2} \mathrm{~F}(\mathrm{~s})$. The first reaction represents $\mathrm{F}$-atom net adsorption, while the second reaction represents etching of the silicon dioxide bulk. In the second reaction, $\mathrm{SiO}_{2}(\mathrm{~b})$ represents the bulk material species and the rate of progress of the reaction is equivalent to the oxide etch rate. The reaction rate probabilities are based on the work of Butterbaugh, Gray, and Sawin ${ }^{23}$, and Flamm, Donnelly, and Mucha. ${ }^{24}$ The second quartz-etch pathway is ion-induced chemical etch. Again we base our reaction probabilities on the work of Butterbaugh, Gray, and Sawin ${ }^{23}$ for this 
process. As we do not know the energy of the ions impinging on the reaction wall, and suspect that it may be significantly lower than that assumed in the work of Butterbaugh, et al., the reaction probabilities for the ion-enhanced reactions are slightly lower in the simulations here. Also, for simplicity, each positive ion species is assumed to have the same probability of reaction with the fluorinated surface sites. An example of an ion induced reaction, is then:

$$
\mathrm{CF}_{2}{ }^{+}+\mathrm{E}+\mathrm{SiO}_{2}(\mathrm{~b})+4 \mathrm{SiO}_{2} \mathrm{~F}(\mathrm{~s}) \Rightarrow \mathrm{CF}_{2}+\mathrm{SiF}_{4}+\mathrm{O}_{2}+4 \mathrm{SiO}_{2}(\mathrm{~s})
$$

where the reaction rate is the ion thermal flux multiplied by a probability factor of 0.1 . The electron is included on the left-hand-side in order to maintain charge balance on the reaction, but does not contribute to the reaction-rate determination. In most cases of $\mathrm{CF}_{4}$ and $\mathrm{CF}_{4} / \mathrm{O}_{2}$ mixtures, we find that thermal etching dominates the ion-enhanced etching of the quartzapplicator tube.

\section{Dominant Reactions in the $\mathrm{CF}_{4} \underline{\mathrm{O}}_{2}$ Mechanism}

The dominant reaction paths in the plasma source region are identified by the investigation of sensitivities and rates of production of the comprehensive plasma chemistry. The dominant reactions for a $\mathrm{CF}_{4}$ plasma are depicted in Figure 3. The dominant reactions for a $\mathrm{CF}_{4} / \mathrm{O}_{2}$ plasma are shown in Figure 4. In a $\mathrm{CF}_{4}$ plasma, electron dissociation of $\mathrm{CF}_{4}$, creating $\mathrm{CF}_{3}$ and $\mathrm{F}$, is the dominant reaction for producing $\mathrm{F}$ radicals, and $\mathrm{CF}_{3}$ and $\mathrm{F}$ neutral recombination is the dominant reaction for the destruction of $\mathrm{F}$ radicals as well as for the production of $\mathrm{CF}_{4}$ molecules. Minor quantities of $\mathrm{F}$ atoms are also created from $\mathrm{CF}_{3}+$ ionization and $\mathrm{CF}_{2}$ dissociation. Overall $\mathrm{CF}_{4}$ dissociation is less than $20 \%$ due to the strong neutral recombination path to $\mathrm{CF}_{4}$. In a $\mathrm{CF}_{4} / \mathrm{O}_{2}$ plasma, $\mathrm{O}$ atoms react with $\mathrm{CF}_{3}$ and $\mathrm{CF}_{2}$ radicals efficiently, so that the $\mathrm{CF}_{4}$ recombination channel is partially blocked. Instead, a substantial amount of the recombination channel is diverted to making $\mathrm{COF}_{2}$ and $\mathrm{COF}$, which liberates more $\mathrm{F}$ atoms rather than consuming them by recombination. Therefore, the $\mathrm{F}$ density increases substantially with the addition of a small amount of $\mathrm{O}$ atoms. However, large amounts of $\mathrm{O}$ radicals produced by increasing the $\mathrm{O}_{2}$ percentage at the inlet can deplete $\mathrm{CF}_{3}$ and $\mathrm{CF}_{2}$ populations quickly. Fluorine sources are also reduced due to the larger $\mathrm{O}_{2}$ portion of the feed gas. In this case, the density of $\mathrm{F}$ atoms decreases with increasing $\mathrm{O}_{2}$. The densities of $\mathrm{CO}_{2}$ and $\mathrm{CO}$ are expected to be high due to the high conversion rate from $\mathrm{COF}$ and $\mathrm{CF}_{2}$. The dominant reactions shown in Figures 3 and 4 can explain major radical production channels for different feed gas mixtures. 


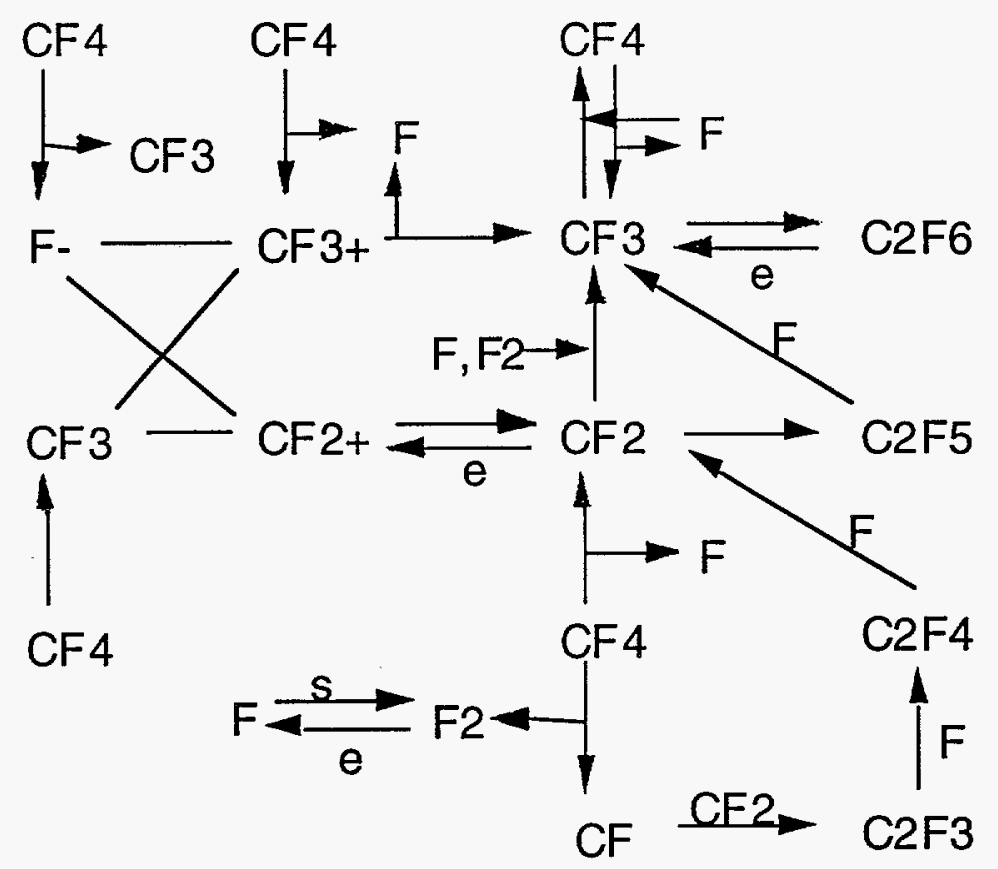

Figure II-2. Diagram of dominant $\mathrm{CF}_{4}$ plasma-chemistry mechanisms for 0.5 torr.

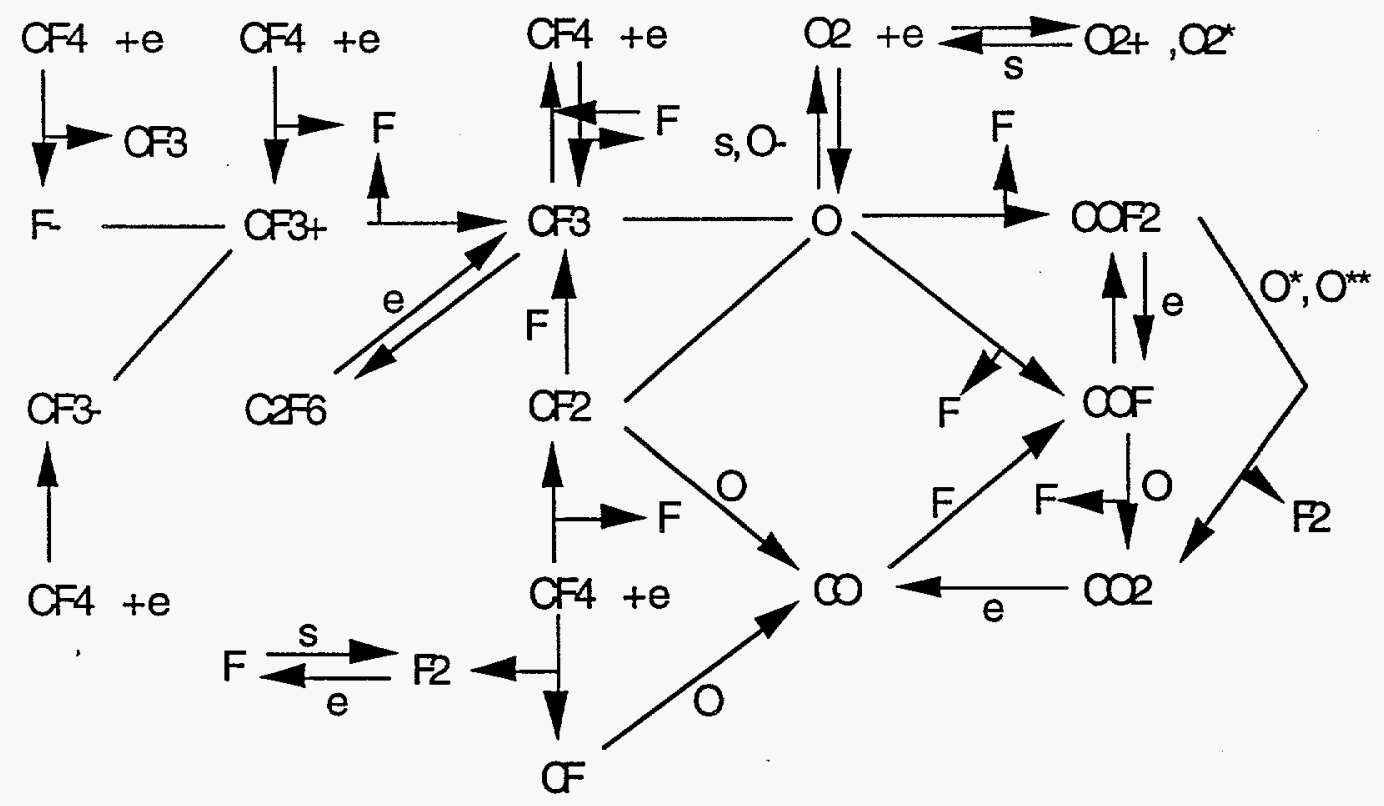

Figure II-3. Diagram of the dominant $\mathrm{CF}_{4} / \mathrm{O}_{2}$ reactions at 0.5 torr. 


\section{MODEL VALIDATION WITH EXPERIMENTS}

\section{Experimental Setup}

The experiments are performed using a $2.45 \mathrm{GHz}$ microwave generator with an Evensontype coupler to create a plasma in a $25 \mathrm{~mm}$ O.D. $x 70 \mathrm{~cm}$ long quartz discharge tube. We used a molecular beam mass spectrometer to identify the chemical species exiting the transport tube. The experimental apparatus is shown schematically in Figure 5.

In order to determine which species are present in the downstream portion of the discharge, a method must be employed that distinguishes the origin of each signal. To this end, threshold ionization techniques were used to determine the chemical composition of a $\mathrm{CF}_{4}$ microwave discharge at the downstream end of the applicator tube. This technique offers the capability of detecting neutral and radical species simultaneously to a mole fraction sensitivity of approximately $10^{-5}$.

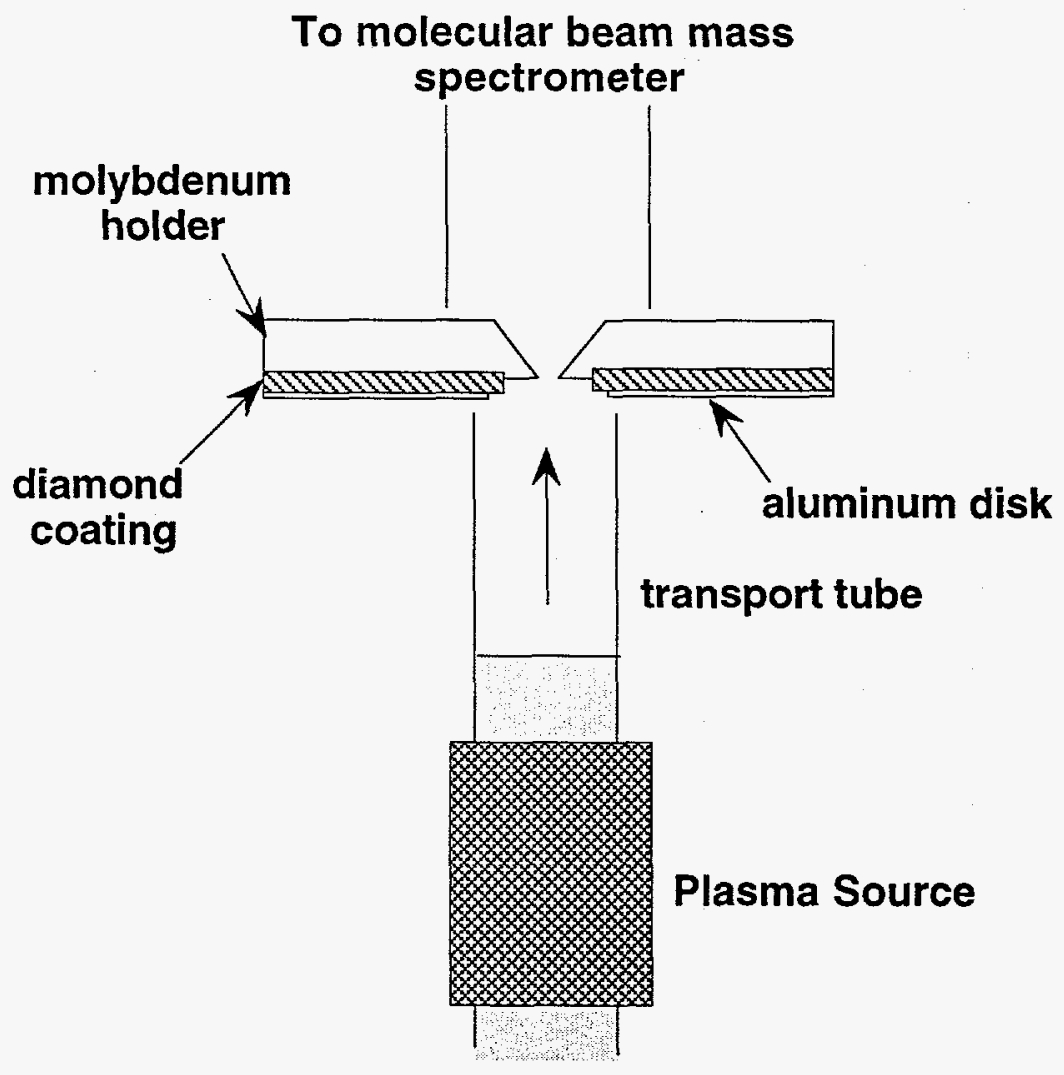

Figure II-4. Schematic of the molecular beam mass spectrometer (MBMS) system. 


\section{Model Results for $\mathrm{CF}_{4} / \mathrm{O}_{2}$ Plasmas}

The main function of the plasma is to dissociate and ionize feed molecular gases. For CDE systems, the fluorine radical is essential in etching wafers located in the downstream chamber. Thus, dissociation is the most important reaction in CDE plasma chemistry. The dissociation of $\mathrm{CF}_{4}$ and $\mathrm{O}_{2}$ is important for different reasons. $\mathrm{CF}_{4}$ dissociation is the major source of $\mathrm{F}$ and $\mathrm{CF}_{3}$ radicals. $\mathrm{O}_{2}$ dissociation is the major source of $\mathrm{O}$ radicals. $\mathrm{O}$ atoms react with $\mathrm{CF}_{3}$ and $\mathrm{CF}_{2}$ radicals to produce $\mathrm{COF}, \mathrm{COF}_{2}$, and additional $\mathrm{F}$ radicals. Figure 6 shows the comparison of $\mathrm{CF}_{4}$ and $\mathrm{O}_{2}$ mole fractions with molecular beam mass spectrometry measurements for various inlet oxygen fractions. Results show good quantitative agreement. These results show more efficient dissociation of $\mathrm{O}_{2}$ than of $\mathrm{CF}_{4}$.

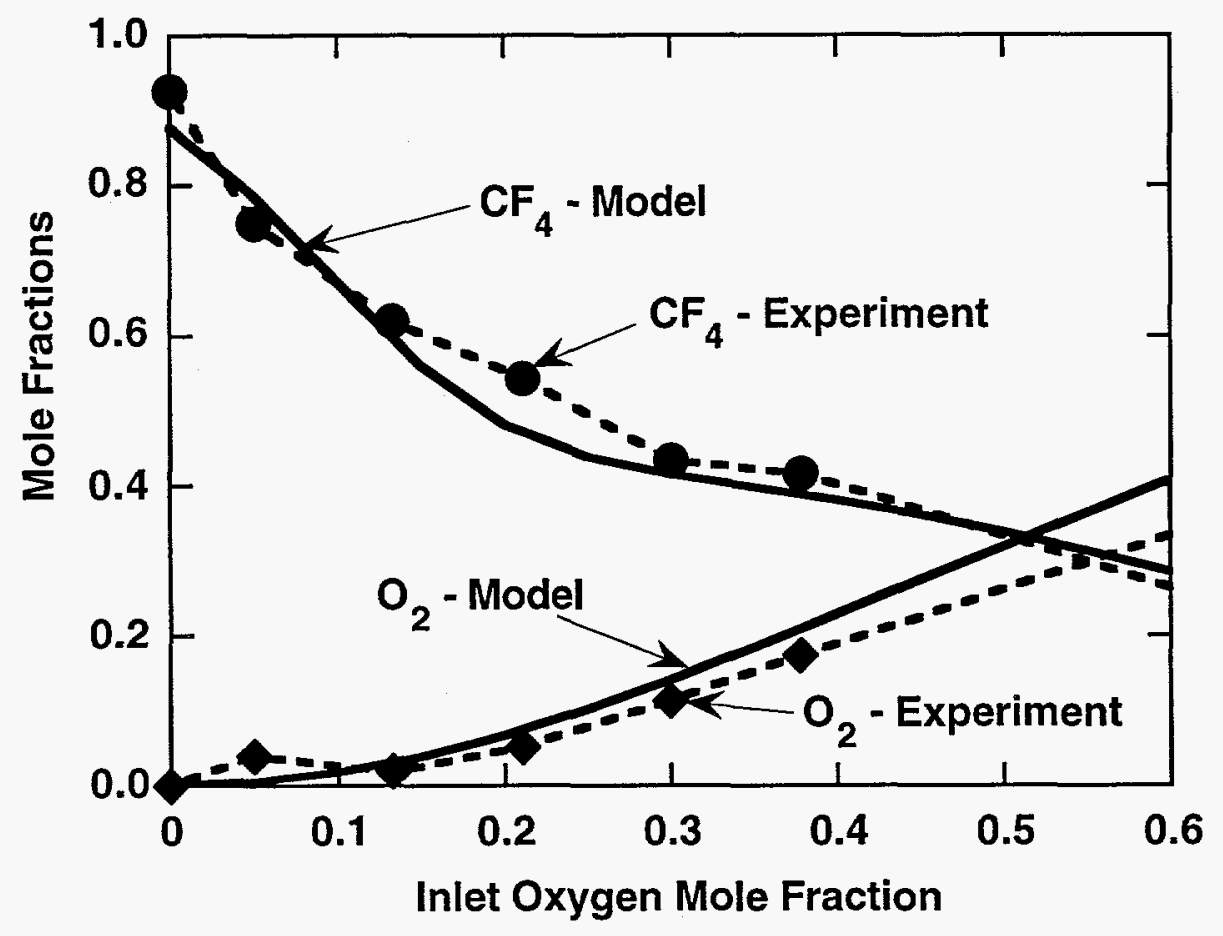

Figure II-5. Comparisons between model and experimental data of the mole fractions of $\mathrm{CF}_{4}$ and $\mathrm{O}_{2}$

$\mathrm{F}$ atoms are responsible for etching the wafer in the downstream chamber as well as etching the quartz-applicator tube. In $\mathrm{CF}_{4} / \mathrm{O}_{2}$ gas mixtures, the number density of $\mathrm{F}$ radicals is a strong function of $\mathrm{O}$ radical density. In Figure 7, mole fractions of $\mathrm{F}, \mathrm{O}$ and $\mathrm{SiF}_{4}$ are compared with the experimental data. As the percentage of $\mathrm{O}_{2}$ in the feed gases increases, the $\mathrm{F}$ mole fraction undergoes a maximum located at $20-25 \% \mathrm{O}_{2}$. The initial increase in $\mathrm{F}$ mole fraction is due to the interception of the neutral recombination channel to $\mathrm{CF}_{4}$ by the reactions between $\mathrm{CF}_{3}$ and $\mathrm{O}$ radicals. At higher percentages of $\mathrm{O}_{2}$, more $\mathrm{CF}_{4}$ is replaced by $\mathrm{O}_{2}$, which reduces the $\mathrm{F}$ radical source. $\mathrm{CF}_{3}$ and $\mathrm{CF}_{2}$ are also depleted through reaction with plentiful $\mathrm{O}$ radicals, preventing further reactions with $\mathrm{O}$ radicals to form $\mathrm{F}$ radicals. Therefore, $\mathrm{F}$ density decreases at 


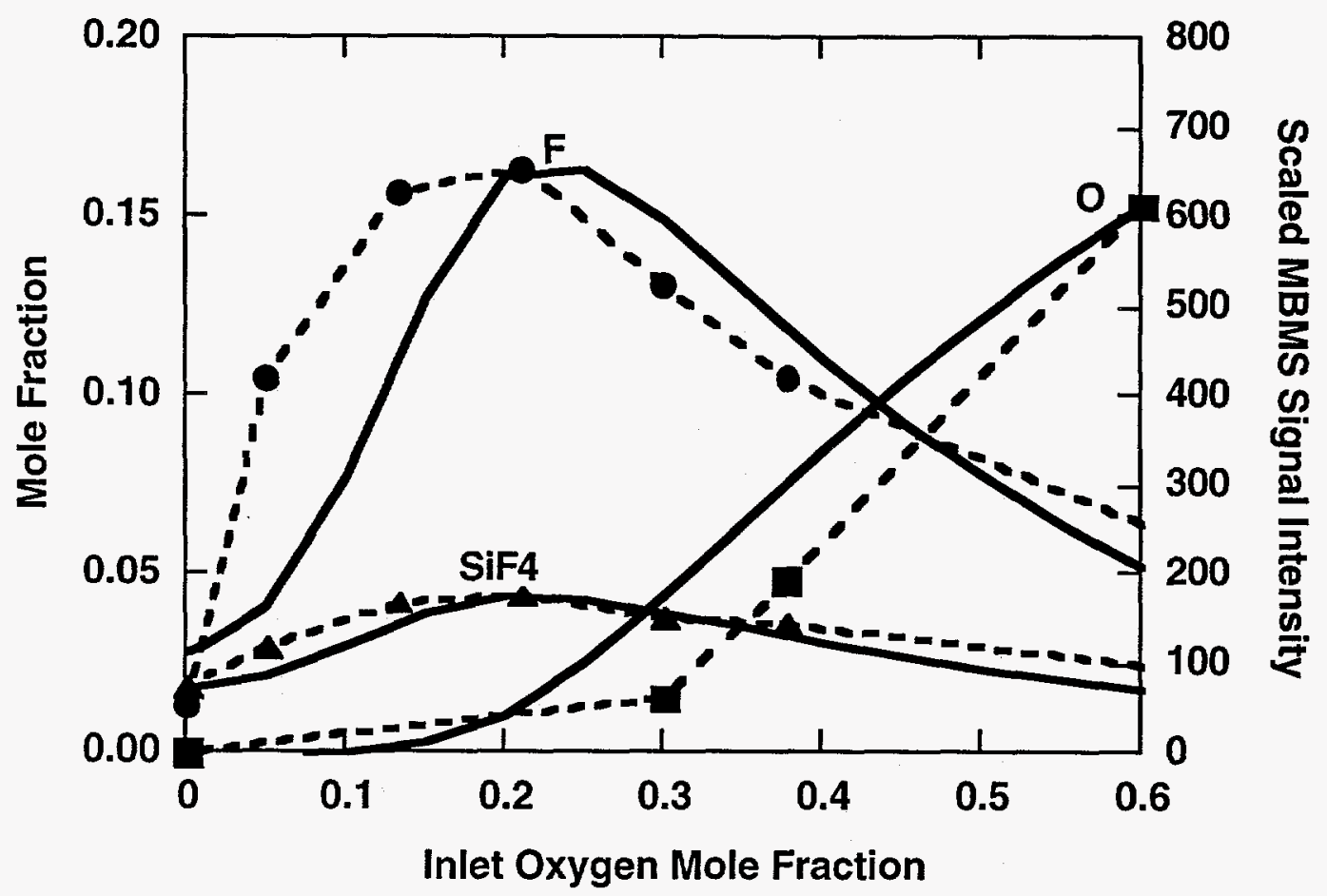

Figure II-6. Comparisons of the predicted mole fractions of $\mathrm{F}, \mathrm{O}$, and $\mathrm{SiF}_{4}$ with MBMS Signal Intensity versus inlet $\mathrm{O}_{2}$ mole fraction. The MBMS Signal intensity was scaled to match peak values of the predicted mole fractions and is shown with symbols and dashed lines, while the model predictions are solid lines.

higher inlet mole fractions of $\mathrm{O}_{2}$. Adding $20-25 \%$ of $\mathrm{O}_{2}$ will maximize the $\mathrm{F}$ number density, which is directly responsible for downstream etching. $\mathrm{SiF}_{4}$ number density is a direct indication of how much quartz etching is done by $\mathrm{F}$ radicals and other ions in the source region. The quartz wall is etched predominately by thermal reaction. The number density of $\mathrm{SiF}_{4}$ also has a maximum at $20-25 \%$ of $\mathrm{O}_{2}$ in the feed gas, consistent with the trends in $\mathrm{F}$ radical density.

The model can provide the number densities of all the major species formed in a $\mathrm{CF}_{4} / \mathrm{O}_{2}$ plasma. Both the model and the experiments show large fractions of $\mathrm{CO}_{2}, \mathrm{COF}_{2}$ and $\mathrm{CO}$, as well as small traces of $\mathrm{COF}, \mathrm{CF}_{3}, \mathrm{CF}_{2}$ and $\mathrm{CF}$ radicals. Figure 8 shows the mole fractions of other compounds and radicals computed. $\mathrm{CF}_{3}, \mathrm{CF}_{2}$ and $\mathrm{CF}$ densities decrease rapidly as the $\mathrm{O}$ radical density increases. $\mathrm{COF}_{2}, \mathrm{CO}_{2}$ and $\mathrm{CO}$ densities increase with the increase in $\mathrm{O}_{2}$ at the inlet, quickly reach a maximum and decreases gradually due to the depletion of carbon sources. 


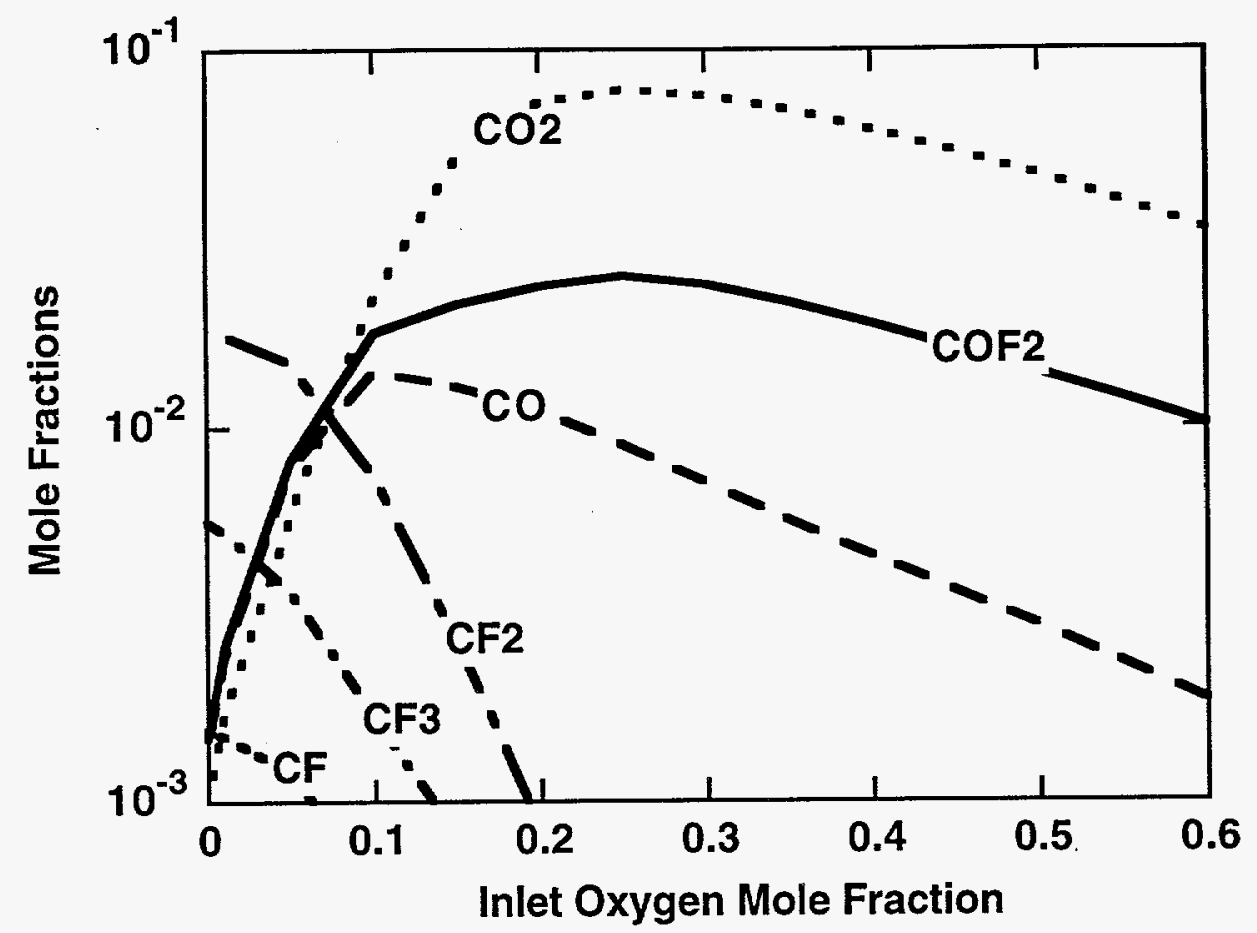

Figure II-7. Mole fractions of $\mathrm{CF}_{3}, \mathrm{CF}_{2}, \mathrm{CF}, \mathrm{CO}_{2}, \mathrm{CO}$, and $\mathrm{COF}_{2}$ versus inlet $\mathrm{O}_{2}$ mole fraction.

\section{Effects of Nitrogen Addition}

Observations in $\mathrm{CDE}$ systems show that, when $\mathrm{N}_{2}$ is added to $\mathrm{CF}_{4} / \mathrm{O}_{2}$ inlet gases, silicon nitride etch rate increases about seven fold in a downstream chamber. ${ }^{25}$ In order to investigate the causes of this phenomenon, a plasma-chemistry mechanism for $\mathrm{CF}_{4} / \mathrm{O}_{2} / \mathrm{N}_{2}$ gas mixtures was developed. The additional reactions for Nitrogen dissociation and N-O-F interactions are taken from previous work on the $\mathrm{NF}_{3} / \mathrm{O}_{2}$ chemistry in $\mathrm{CDE}$ systems. ${ }^{18,19}$ Figure 9 shows the experiment and model results for $\mathrm{F}$ and $\mathrm{F}_{2}$ mole fractions versus inlet $\mathrm{N}_{2}$ fraction. As the $\mathrm{N}_{2}$ inlet fraction increases, the $\mathrm{CF}_{4}$ and $\mathrm{O}_{2}$ mole fractions decrease, i.e. we are keeping the total flow rate constant. As a consequence, the source for $\mathrm{F}$ and $\mathrm{F}_{2}$ decreases as well as their number densities. This indicates that there is no other significant source of $F$ and $F_{2}$ other than ones already discussed, that would be triggered by adding $\mathrm{N}_{2}$. Therefore, if the quartz etching at the source region depends only on $\mathrm{F}$, then $\mathrm{SiF}_{4}$ number density should decrease in the same way as the $F$ radical density. However, both experiments and model show that this is not the case. Figure 10 shows the ratio of the $\mathrm{SiF}_{4}$ and $\mathrm{F}$ mole fractions compared to the molecular beam mass spectrometry signal ratio of $\mathrm{SiF}_{4}$ and $\mathrm{F}$. The trend in the $\mathrm{SiF}_{4} / \mathrm{F}$ ratio is increasing rather than remaining constant, as the $\mathrm{F}$ number density decreases. Further analysis in our model shows that, as $\mathrm{N}_{2}$ mole fraction increases, $\mathrm{NO}^{+}$ion density increases rapidly and become a dominant ion for the plasma. $\mathrm{NO}^{+}$ions are created from the $\mathrm{O}_{2}++\mathrm{N}=>\mathrm{NO}^{+}+\mathrm{O}$ atom exchange reaction, 
which has a high reaction probability. ${ }^{26}$ Figure 11 shows the normalized contributions to the rate of $\mathrm{SiF}_{4}$ production obtained from the model. The thermal etching of $\mathrm{F}$ atoms dominates the quartz etching at all conditions. However, when the $\mathrm{N}_{2}$ inlet mole fraction is larger than 0.3 , the production of $\mathrm{SiF}_{4}$ due to the ion enhanced etching by $\mathrm{NO}^{+}$becomes significant. This enhances the ratio of $\mathrm{SiF}_{4} / \mathrm{F}$ mole fraction. This effect does not explain why the downstream nitride etch rate increases by seven fold, but still provides us with important clues. As the $\mathrm{N}_{2}$ mole fraction increases, $\mathrm{NO}^{*}$ can be produced by similar atom exchange reactions, and this may contribute to nitride etching in the downstream chamber.

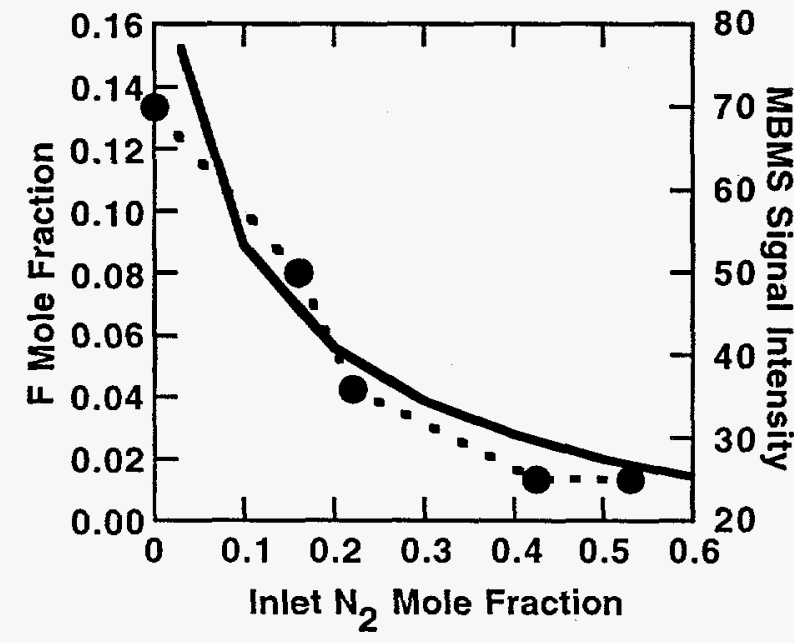

(a)

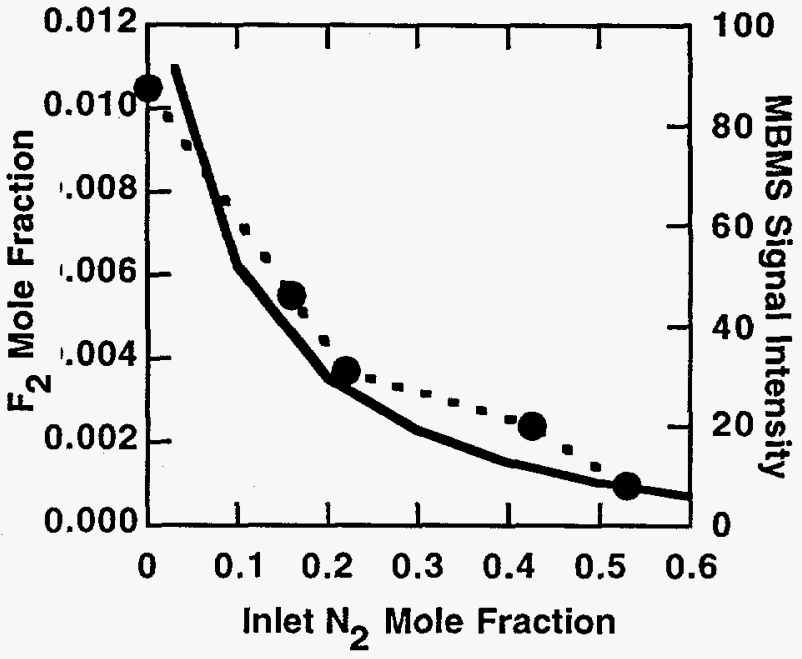

(b)

Figure II-8. Comparisons between model and experimental results of the mole fractions of a) $F$ and $b$ ) $F_{2}$, versus inlet $N_{2}$ mole fraction.

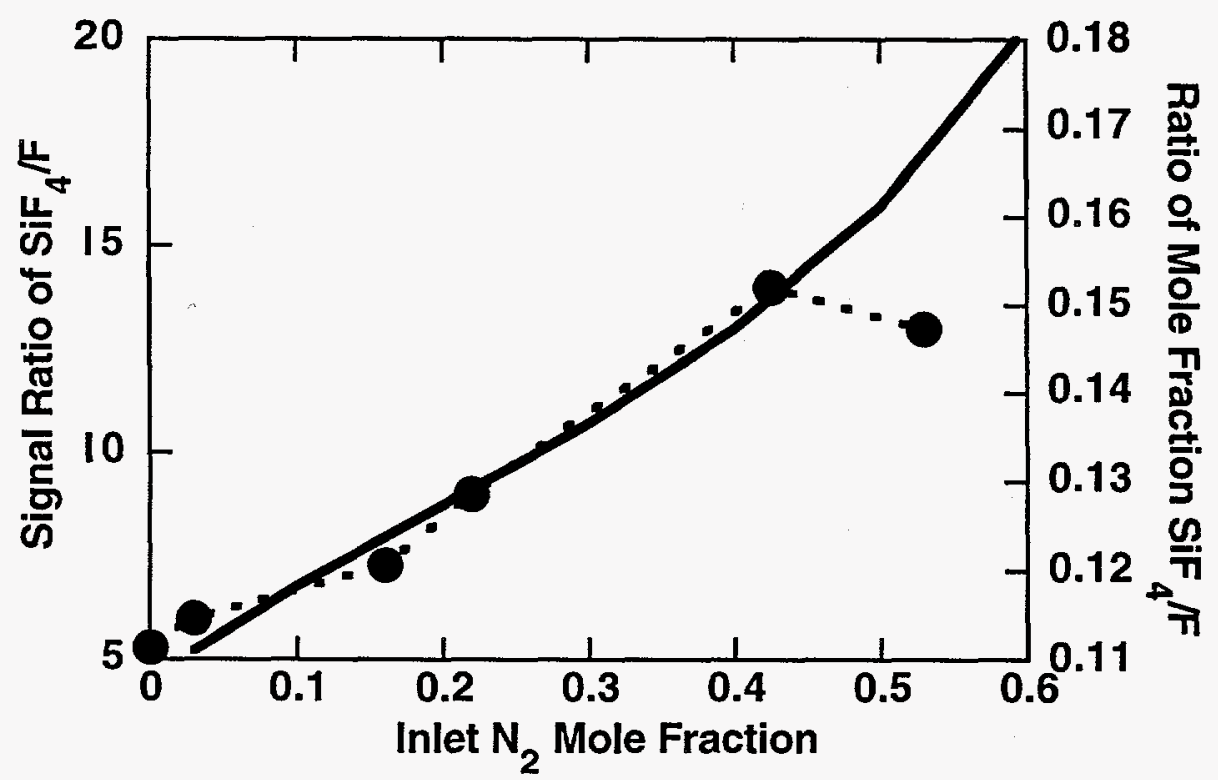

Figure II-9. Comparison between the ratio of $\mathrm{SiF}_{4} / \mathrm{F}$ mole fractions from the model and the corresponding ratio of MBMS signal ratio. 


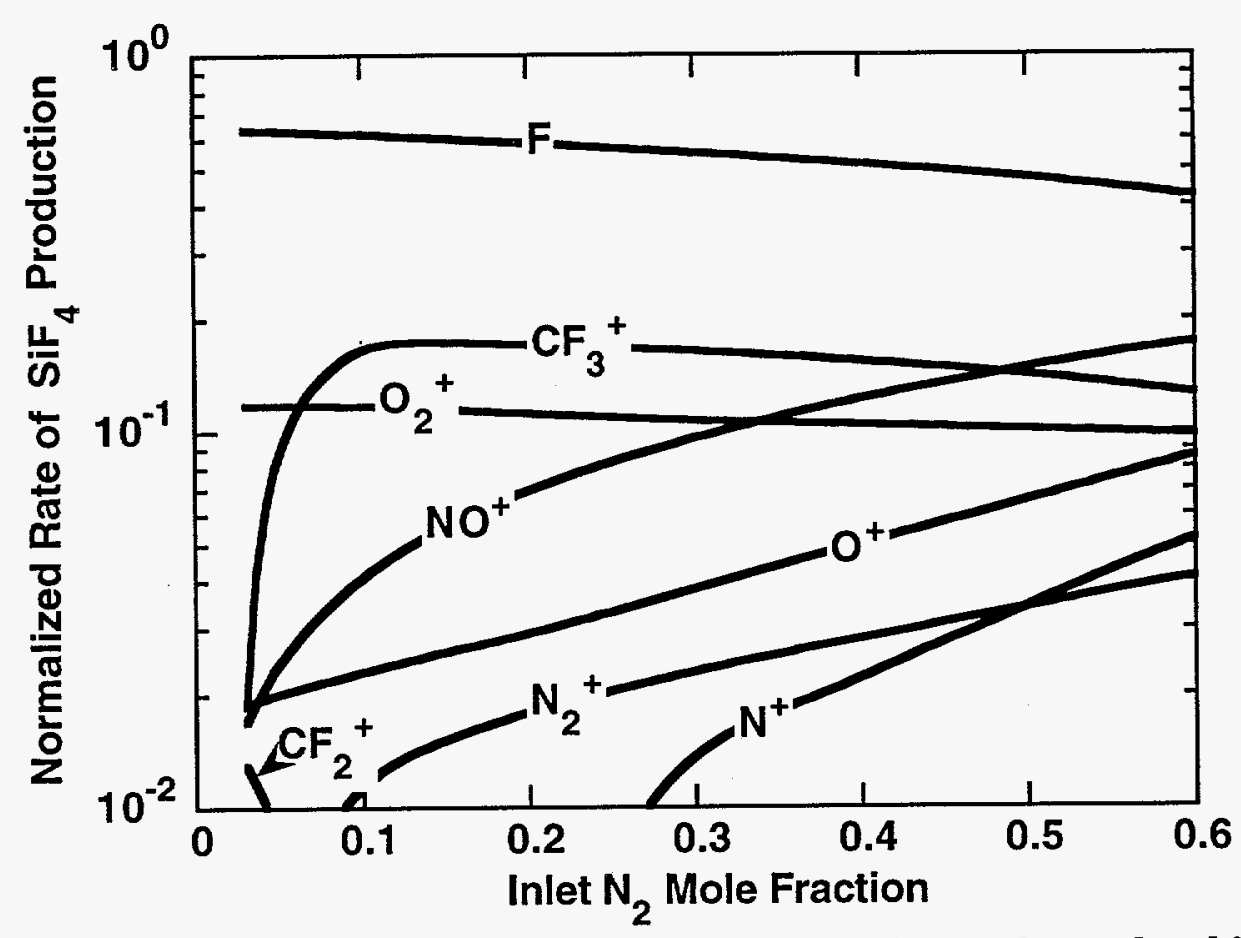

Figure II-10. Normalized rates of $\mathrm{SiF}_{4}$ production due to thermal etching by $F$ atoms and ion enhanced etching contributions. Etching of $\mathrm{SiF}_{4}$ is enhanced by the increase in $\mathrm{NO}^{+}$density for larger $\mathrm{N}_{2}$ inlet mole fractions.

\section{SUMMARY}

Comprehensive $\mathrm{CF}_{4} / \mathrm{O}_{2}$ and $\mathrm{CF}_{4} / \mathrm{O}_{2} / \mathrm{N}_{2}$ reaction mechanisms are developed with the latest values of electron impact cross sections. From the solutions of the Boltzmann transport equation, most of microwave power that is deposited in the $\mathrm{CF}_{4} / \mathrm{O}_{2}$ gas is dissipated through elastic collisions and dissociative excitation of oxygen molecules. The benchmark comparisons of the model with the molecular beam mass spectrometry experiments show good agreement for $\mathrm{CF}_{4}$ and $\mathrm{O}_{2}$ dissociation, as well as trends in mole fractions of the major radicals, $\mathrm{F}$ and $\mathrm{O}$. $\mathrm{CF}_{4} / \mathrm{O}_{2} / \mathrm{N}_{2}$ results are also compared to the data obtained from mass spectrometry and show good agreement. 


\section{REFERENCES}

1. Cheng, C. C. and Oncay, J.: Semiconductor International, 18185 (1995).

2. Shi, J., Kamarehi, M., Shaner, D., Rounds, S., Fink, S. and Ferris, D.: Solid State Technology, 3875 (1995).

3. Meeks, E. and Shon, J.: IEEE Trans. Plasma Sci., 23539 (1994).

4. Meeks, E., Moffat, H. K., Grcar, J. F. and Kee, R. J.: "AURORA: A Fortran Program for Modeling Well Stirred Plasma and Thermal Reactors with Gas and Surface Reactions," Sandia National Laboratories Report SAND96-8218 (1996).

5. Kushner, M. J.: J. Appl. Phys., 532939 (1982).

6. Plumb, I. C. and Ryan, K. R.: Plasma Chem. Plasma Process., 6205 (1986).

7. Schoenborn, P., Patrick, R. and Baltes, H. P.: J. Electrochem. Soc., 136199 (1989).

8. Gray, D. C., Tepermeister, I. and Sawin, H. H.: J. Vac. Sci. Technol. B, 111243 (1993).

9. Poll, H. U., Winkler, C., Margreiter, D., Grill, V. and Mark, T. D.: Int. J. Mass Spectrom. Ion Processes, 1121 (1992).

10. Bruce, M. R. and Bonham, R. A.: Int. J. Mass. Spectrom. Ion Processes, 12397 (1993).

11. Tarnovsky, V., Kurunczi, P., Rogozhnikov, D. and Becker, K.: Int. J. Mass. Spectrom. Ion Processes, 128181 (1993).

12. Deutsch, H., Mark, T. D., Tarnovsky, V., Becker, K., Cornelissen, C., Cespiva, L. and Bonacic-Koutecky, V.: Int. J. Mass. Spectrom. Ion Processes, 13777 (1994).

13. Itikawa, Y., Ichimura, A., Onda, K., Sakimoto, K. and Takayanagi, K.: J. Phys. Chem. Ref. Data, 1823 (1989).

14. Itikawa, Y. and Ichimura, A.: J. Phys. Chem. Ref. Data, 19637 (1990).

15. Hayashi, M.: Gaseous Dielectrics V, edited by L. Christophorou and D. Bouldin, Pergamon, New York (1987).

16. Penetrante, B. Personal Communication:

17. Morgan, L. W.: Computer Physics Communications, 58127 (1990). 
18. Meeks, E., Larson, R. S., Shon, J. W. and Vosen, S. R.: Symposium on Process Control, Diagnostics, and Modeling in Semiconductor Manufacturing, The Electrochemical Society (1995).

19. Meeks, E., Larson, R. S., Vosen, S. R. and Shon, J. W.: J. Electrochem. Soc., submitted (1996).

20. Herron, J. T.: J. Phys. Chem. Ref. Data, 17967 (1988).

21. Coltrin, M. E., Kee, R. J., Rupley, F. M. and Meeks, E.: "SURFACE CHEMKIN III: A Fortran Package for Analyzing Heterogeneous Chemical Kinetics at a Solid-Surface - GasPhase Interface," Sandia National Laboratories Report SAND96-8217 (1996).

22. Greaves, J. C. and Linnett, J. W.: Trans. Faraday Soc., 541323 (1958).

23. Butterbaugh, J. W., Gray, D. C. and Sawin, H. H.: J. Vac. Sci. Tech. B, 91461 (1991).

24. Flamm, D. L., Mogab, C. J. and Sklaver, E. R.: J. Appl. Phys., 506211 (1979).

25. Beulens, J. J., Kastenmeier, B. E. E., Matsuo, P. J. and Oehrlein, G. S.: Appl. Phys. Lett., 66 20 (1996).

26. Albritton, D. L.: Atomic Data and Nuclear Data Tables, 221 (1978).

27. Hayashi, M. and Nimura, T.: J. Appl. Phys., 544879 (1983).

28. Butkovskaya, N. I., Larichev, M. N., Leipunskii, I. O., Morozov, I. I. and Talroze, V. L.: Kinet. Catal., 21263 (1980).

29. Lloyd, A. C.: Int. J. Chem. Kinet., 339 (1971).

30. Atkinson, R., Baulch, D. L., Cox, R. A., Hampson, R. F., Kerr, J. A. and Troe, J.: J. Phys. Chem. Ref. Data, 211125 (1992).

31. DeMore, W. B., Sander, S. P., Golder, D. M., Molina, M. J., Hampson, R. F., Kurylo, M. J., Howard, C. J. and Ravishankara, A. R.: Jet Propulsion Laboratory Report JPL Pub. 90-1 (1990).

32. Tsai, C.-P. and McFadden, D. L.: Chem. Phys. Lett., 173241 (1990).

33. Cobos, C. J. and Troe, J.: Chem. Phys. Lett., 113419 (1985).

34. Vedeneer, V. I., Goldenberg, M. Y. and Teitelboim, M.: Kinet. Catal., 281055 (1987).

35. Nielsen, O. J., Ellermann, T., Sehested, J., Bartkiewicz, E., Wallington, T. J. and Hurley, M. D.: Int. J. Chem. Kinet., 241009 (1992). 
36. Kennedy, R. C. and Levy, J. B.: J. Phys. Chem., 927232 (1972).

37. Zhang, F., Francisco, J. S. and Steinfell, J. I.: J. Phys. Chem., 862402 (1982).

38. Lyman, J. L. and Holland, R.: J. Phys. Chem., 927232 (1988).

39. Tsang, W. and Hampson, R. F.: J. Phys. Chem. Ref. Data, 151087 (1986).

40. Warnatz, J.: Rate Coefficients in the $\mathrm{C} / \mathrm{H} / \mathrm{O}$ system combustion chemistry, Springer-Verlag, New York (1984).

41. Heras, J. M., Arvia, A. J. and Schmacher, H. J.: An. Asoc. Quim. Argent., 50120 (1962).

42. Croce, A. E., Tori, C. A. and Castellano, E.: Z. Phys. Chem. (Nene Folge), 162 (1989).

43. Baulch, D. L., Duxbury, J., Grant, S. J. and Montague, D. C.: J. Phys. Chem. Ref. Data, 10 1 (1981).

44. Bauer, S. H., Hou, K. C. and Jr., E. L. R.: The Phys. of Fluids, Suppl. 1125 (1969).

45. Modica, A. P. and Lagratt, J. E.: J. Chem. Phys., 433383 (1965).

46. Peters, J., Hoeymissen, J. V., Vanhaelemeersch, S. and D. Vermeylen: J. Phys. Chem., 96 1257 (1992).

47. Teitelboim, M. A. and Vedereev, V. I.: Kinet. Catal, 261119 (1986).

48. Gordiets, B., Ferreira, C., Guerra, V., Loureird, J., Nahorny, J., Pagnon, D., Toureau, M. and Vialle, M.: IEEE Trans. Plasma Sci., 23750 (1995).

49. Trotman-Dickenson, A. F. and Milne, G. S.: Tables of Bimolecular Gas Reactions (NSRDSNBS 9), U. S. Government Printing Office, Washington, DC (1967). 
Table II-1. Gas-phase electron impact reactions for $\mathrm{CF}_{4} / \mathrm{O}_{2}$.

Rate coefficients are in the form: $\mathrm{k}=\mathrm{AT}^{\mathrm{B}} \exp (-\mathrm{C} / \mathrm{T})$

Units are molecules, cubic centimeters, seconds, and Kelvins

\begin{tabular}{|c|c|c|c|c|c|}
\hline \multicolumn{2}{|c|}{ Reaction } & \multirow{2}{*}{$\frac{\text { A }}{3.0851 \mathrm{E}-02}$} & \multirow{2}{*}{$\frac{\text { B }}{-1.3002 \mathrm{E}+00}$} & \multicolumn{2}{|c|}{ C Reference } \\
\hline 1. & $E+C F 4 \Rightarrow C F 4+E$ & & & $7.7949 E+04$ & (15) \\
\hline 2. & $\mathrm{E}+\mathrm{CF} 4 \Rightarrow \mathrm{CF} 4+\mathrm{E}$ & $4.3973 \mathrm{E}-01$ & $-1.4136 \mathrm{E}+00$ & $5.9459 \mathrm{E}+04$ & (15) \\
\hline 3. & $\mathrm{E}+\mathrm{CF} 4 \Rightarrow \mathrm{CF} 3++\mathrm{F}-+\mathrm{E}$ & $4.7412 \mathrm{E}-03$ & $-1.9771 \mathrm{E}+00$ & $1.7721 \mathrm{E}+05$ & (10) \\
\hline 4. & $E+C F 4 \Rightarrow C F 3+F+E$ & $3.7563 \mathrm{E}-16$ & $1.4330 \mathrm{E}+00$ & $1.4946 \mathrm{E}+05$ & (15) \\
\hline 5. & $E+C F 4 \Rightarrow C F 2+2 F+E$ & $6.4123 \mathrm{E}-23$ & $2.7734 \mathrm{E}+00$ & $1.5710 \mathrm{E}+05$ & (15) \\
\hline 6. & $E+C F 4 \Rightarrow C F+F+F 2+E$ & $7.4700 \mathrm{E}-28$ & $3.7425 \mathrm{E}+00$ & $2.3844 \mathrm{E}+05$ & (15) \\
\hline 7. & $E+C F 4 \Rightarrow C F 3++F+2 E$ & $5.3173 \mathrm{E}-40$ & $6.3565 \mathrm{E}+00$ & $1.3415 \mathrm{E}+05$ & (10) \\
\hline 8. & $\mathrm{E}+\mathrm{CF} 4 \Rightarrow \mathrm{CF} 2++2 \mathrm{~F}+2 \mathrm{E}$ & $6.0972 \mathrm{E}-47$ & $7.5637 \mathrm{E}+00$ & $2.1140 \mathrm{E}+05$ & (10) \\
\hline 9. & $\mathrm{E}+\mathrm{CF} 4 \Rightarrow \mathrm{CF} 3+\mathrm{F}-$ & $1.0781 \mathrm{E}-02$ & $-1.6395 E+00$ & $8.3560 \mathrm{E}+04$ & (10) \\
\hline 10. & $\mathrm{E}+\mathrm{CF} 4 \Rightarrow \mathrm{CF} 3-+\mathrm{F}$ & $1.5663 \mathrm{E}-03$ & $-1.6056 \mathrm{E}+00$ & $8.6570 \mathrm{E}+04$ & (10) \\
\hline 11. & $\mathrm{E}+\mathrm{CF} 3 \Rightarrow \mathrm{CF} 3++2 \mathrm{E}$ & $1.0263 \mathrm{E}-25$ & $3.3220 \mathrm{E}+00$ & $4.8708 \mathrm{E}+04$ & (11) \\
\hline 12 . & $E+C F 3 \Rightarrow C F 2++F+2 E$ & $3.1202 \mathrm{E}-31$ & $4.5466 \mathrm{E}+00$ & $1.9376 \mathrm{E}+05$ & (11) \\
\hline 13. & $\mathrm{E}+\mathrm{CF} 3 \Rightarrow \mathrm{CF}++2 \mathrm{~F}+2 \mathrm{E}$ & $9.9390 \mathrm{E}-39$ & $6.0609 E+00$ & $2.9466 \mathrm{E}+05$ & (11) \\
\hline 14. & $\mathrm{E}+\mathrm{CF} 2=>\mathrm{CF} 2++2 \mathrm{E}$ & $2.3048 \mathrm{E}-24$ & $3.1418 \mathrm{E}+00$ & $5.3196 \mathrm{E}+04$ & (11) \\
\hline 15. & $E+C F 2 \Rightarrow C F++F+2 E$ & $1.3916 \mathrm{E}-28$ & $3.9837 E+00$ & $1.3289 \mathrm{E}+05$ & (11) \\
\hline 16. & $E+C 2 F 6 \Rightarrow C 2 F 6+E$ & $3.5522 \mathrm{E}-04$ & $-1.1502 \mathrm{E}+00$ & $4.8683 E+04$ & (15) \\
\hline 17. & $\mathrm{E}+\mathrm{C} 2 \mathrm{~F} 6 \Rightarrow \mathrm{C} 2 \mathrm{~F} 6+\mathrm{E}$ & $2.8896 \mathrm{E}-03$ & $-1.1267 \mathrm{E}+00$ & $4.8414 E+04$ & (15) \\
\hline 18. & $\mathrm{E}+\mathrm{C} 2 \mathrm{~F} 6 \Rightarrow \mathrm{C} 2 \mathrm{~F} 6+\mathrm{E}$ & $2.2073 \mathrm{E}+01$ & $-1.7073 E+00$ & $6.4565 \mathrm{E}+04$ & (15) \\
\hline 19. & $\mathrm{E}+\mathrm{C} 2 \mathrm{~F} 6 \Rightarrow \mathrm{C} 2 \mathrm{~F} 6+\mathrm{E}$ & $3.0825 \mathrm{E}-09$ & $1.0111 \mathrm{E}-01$ & $8.2981 \mathrm{E}+04$ & (15) \\
\hline 20 . & $\mathrm{E}+\mathrm{C} 2 \mathrm{~F} 6 \Rightarrow \mathrm{C} 2 \mathrm{~F} 6+\mathrm{E}$ & $1.6502 \mathrm{E}-25$ & $3.2623 \mathrm{E}+00$ & $7.5510 \mathrm{E}+04$ & (15) \\
\hline 21. & $\mathrm{E}+\mathrm{C} 2 \mathrm{~F} 6 \Rightarrow 2 \mathrm{CF} 3+\mathrm{E}$ & $6.3389 \mathrm{E}-24$ & $3.2025 \mathrm{E}+00$ & $1.1228 \mathrm{E}+05$ & (15) \\
\hline 22 . & $\mathrm{E}+\mathrm{C} 2 \mathrm{~F} 6=>\mathrm{CF} 3++\mathrm{CF} 3+2 \mathrm{E}$ & $1.0189 \mathrm{E}-34$ & $5.2829 \mathrm{E}+00$ & $1.0606 \mathrm{E}+05$ & (15) \\
\hline 23. & $\mathrm{E}+\mathrm{C} 2 \mathrm{~F} 6 \Rightarrow \mathrm{CF} 3-+\mathrm{CF} 3$ & $8.9508 \mathrm{E}+02$ & $-2.5040 \mathrm{E}+00$ & $8.2322 \mathrm{E}+04$ & (15) \\
\hline 24. & $E+O 2 \Rightarrow O 2+E$ & $4.7637 \mathrm{E}-06$ & $-6.3687 \mathrm{E}-01$ & $6.5885 \mathrm{E}+04$ & (13) \\
\hline 25. & $E+O 2 \Rightarrow O 2+E$ & $1.5576 \mathrm{E}-06$ & $-6.0983 \mathrm{E}-01$ & $6.4895 \mathrm{E}+04$ & (13) \\
\hline 26. & $E+O 2 \Rightarrow O 2+E$ & $3.2751 \mathrm{E}-08$ & $-3.2850 \mathrm{E}-01$ & $5.5318 \mathrm{E}+04$ & (13) \\
\hline 27. & $E+O 2 \Rightarrow O 2+E$ & $4.1267 \mathrm{E}-07$ & $-5.9054 \mathrm{E}-01$ & $6.7721 \mathrm{E}+04$ & (13) \\
\hline 28. & $E+O 2 \Rightarrow O 2^{\star}+E$ & $1.2077 \mathrm{E}-07$ & $-3.8616 \mathrm{E}-01$ & $4.1730 \mathrm{E}+04$ & (13) \\
\hline 29. & $\mathrm{E}+\mathrm{O} 2 \Rightarrow \mathrm{O} 2^{\star *}+\mathrm{E}$ & $9.3039 \mathrm{E}-09$ & $-2.8928 \mathrm{E}-01$ & $3.8775 \mathrm{E}+04$ & (13) \\
\hline 30. & $E+02=>02+E$ & $2.0078 \mathrm{E}-04$ & $-1.0519 \mathrm{E}+00$ & $7.4288 \mathrm{E}+04$ & (13) \\
\hline 31. & $E+O 2 \Rightarrow O+O+E$ & $1.0456 \mathrm{E}-09$ & $-9.3779 \mathrm{E}-02$ & $6.1178 \mathrm{E}+04$ & $(13) *$ \\
\hline & $E+O 2 \Rightarrow O+O^{*}+E$ & $2.4975 \mathrm{E}-16$ & $1.4136 \mathrm{E}+00$ & $5.7996 \mathrm{E}+04$ & (13) \\
\hline 33. & $E+O 2 \Rightarrow O 2+E$ & $6.3674 \mathrm{E}-28$ & $3.5286 \mathrm{E}+00$ & $5.1802 \mathrm{E}+04$ & (13) \\
\hline
\end{tabular}

* The $\mathrm{O}_{2}$ dissociation rate used here is $10 \%$ of that calculated with the referenced cross section data, based on prior work in modeling oxygen plasmas. ${ }^{16}$ 


\begin{tabular}{|c|c|c|c|c|c|}
\hline \multicolumn{2}{|c|}{ Reaction } & $\mathbf{A}$ & B & \multicolumn{2}{|c|}{ Reference } \\
\hline 34. & $E+O 2 \Rightarrow O 2+E$ & $4.5164 E-32$ & $4.4010 E+00$ & $1.3576 \mathrm{E}+05$ & (13) \\
\hline 35 . & $\mathrm{E}+\mathrm{O} 2 \Rightarrow \mathrm{O} 2++2 \mathrm{E}$ & $1.4737 \mathrm{E}-31$ & $4.5843 E+00$ & $7.2058 \mathrm{E}+04$ & (13) \\
\hline 36. & $E+O 2=>+O$ & $3.3246 \mathrm{E}-04$ & $-1.3254 \mathrm{E}+00$ & $7.3112 E+04$ & (13) \\
\hline 37. & $E+O \Rightarrow O^{*}+E$ & $4.1151 E-07$ & $-3.8845 \mathrm{E}-01$ & $4.1021 E+04$ & (14) \\
\hline 38. & $E+O=>O^{* *}+E$ & $3.7113 \mathrm{E}-10$ & $2.4720 \mathrm{E}-01$ & $3.8991 E+04$ & (14) \\
\hline 39. & $\mathrm{E}+\mathrm{O} \Rightarrow \mathrm{O}++2 \mathrm{E}$ & $1.8668 \mathrm{E}-27$ & $3.7786 \mathrm{E}+00$ & $1.2239 \mathrm{E}+05$ & (14) \\
\hline 40. & $E+F 2 \Rightarrow F 2+E$ & $3.8855 E-01$ & $-1.9423 \mathrm{E}+00$ & $2.9064 E+04$ & $(27)$ \\
\hline 41. & $E+F 2 \Rightarrow F 2+E$ & $3.6273 E+03$ & $-2.6754 \mathrm{E}+00$ & $7.1448 \mathrm{E}+04$ & (27) \\
\hline 42 . & $E+F 2 \Rightarrow F 2+E$ & $1.7215 \mathrm{E}+07$ & $-3.4049 E+00$ & $1.1167 \mathrm{E}+05$ & (27) \\
\hline 43. & $E+F 2 \Rightarrow F 2+E$ & $2.2830 E+09$ & $-3.9141 E+00$ & $1.3014 \mathrm{E}+05$ & $(27)$ \\
\hline 44. & $E+F 2 \Rightarrow 2 F+E$ & $7.7602 \mathrm{E}-09$ & $-5.9054 E-02$ & $3.9638 \mathrm{E}+04$ & (27) \\
\hline 45. & $E+F 2 \Rightarrow 2 F+E$ & $6.3050 \mathrm{E}-11$ & $2.7378 \mathrm{E}-01$ & $3.7597 \mathrm{E}+04$ & $(27)$ \\
\hline 46. & $E+F 2 \Rightarrow F 2+E$ & $1.0091 E-26$ & $3.5871 \mathrm{E}+00$ & $8.4644 \mathrm{E}+04$ & $(27)$ \\
\hline 47. & $E+F 2 \Rightarrow F 2+E$ & $1.5061 E-34$ & $5.0221 E+00$ & $2.2176 \mathrm{E}+05$ & (27) \\
\hline 48 . & $E+F 2 \Rightarrow F+F-$ & $2.1742 E-09$ & $-3.3003 E-01$ & $-5.5501 E+04$ & (27) \\
\hline 49. & $E+F 2 \Rightarrow F 2++2 E$ & $5.7468 E-34$ & $5.0532 \mathrm{E}+00$ & $1.5782 \mathrm{E}+05$ & (27) \\
\hline 50. & $E+F \Rightarrow F++2 E$ & $4.9548 \mathrm{E}-34$ & $5.0569 \mathrm{E}+00$ & $1.8660 \mathrm{E}+05$ & (6) \\
\hline 51. & $E+C 2 F 4 \Rightarrow 2 C F 2+E$ & $6.3389 \mathrm{E}-24$ & $3.2025 \mathrm{E}+00$ & $1.1228 \mathrm{E}+05$ & $(e)^{\dagger}$ \\
\hline 52 . & $E+C O F 2 \Rightarrow C O F+F+E$ & $3.7563 \mathrm{E}-16$ & $1.4330 \mathrm{E}+00$ & $1.4946 \mathrm{E}+05$ & $(e)^{\dagger}$ \\
\hline 53. & $E+C O F 2 \Rightarrow C O F+F+E$ & $6.4123 E-23$ & $2.7734 \mathrm{E}+00$ & $1.5710 \mathrm{E}+05$ & $(e)^{\dagger}$ \\
\hline 54. & $E+C F 3 O F \Rightarrow C F 3 O+E+E$ & $3.7563 E-16$ & $1.4330 \mathrm{E}+00$ & $1.4946 \mathrm{E}+05$ & $(e)^{\dagger}$ \\
\hline 55. & $E+C F 3 O 2 \Rightarrow C F 3+O 2+E$ & $3.7563 \mathrm{E}-16$ & $1.4330 \mathrm{E}+00$ & $1.4946 \mathrm{E}+05$ & $(e)^{\dagger}$ \\
\hline
\end{tabular}

$\dagger \mathrm{e}=$ estimated rate coefficients.

48. 
Table II-2. Gas-phase neutral reactions for $\mathrm{CF}_{4} / \mathrm{O}_{2}$.

Rate coefficients are in the form: $\mathrm{k}=\mathrm{ATB} \exp (-\mathrm{C} / \mathrm{T})$

Units are molecules, cubic centimeters, seconds, and Kelvins

\begin{tabular}{|c|c|c|c|c|c|}
\hline \multicolumn{2}{|c|}{ Reaction } & \multirow{2}{*}{$\frac{\text { A }}{8.300 \mathrm{E}-12}$} & \multirow{2}{*}{ B } & \multirow{2}{*}{$\frac{\mathrm{C}}{\mathrm{C} .}$} & \multirow{2}{*}{$\begin{array}{c}\text { Reference } \\
(6)\end{array}$} \\
\hline 1. & $\mathrm{CF} 3+\mathrm{CF} 3(+\mathrm{M})=\mathrm{C} 2 \mathrm{~F} 6(+\mathrm{M})$ & & & & \\
\hline & $C F 3+F(+M)=C F 4(+M)$ & $2.000 \mathrm{E}-11$ & 0 & 0. & $(6)$ \\
\hline 3. & $\mathrm{CF} 2+\mathrm{F}(+\mathrm{M})=\mathrm{CF} 3(+\mathrm{M})$ & $1.300 \mathrm{E}-11$ & 0 . & 0. & (6) \\
\hline 4. & $C F+F(+M)=C F 2(+M)$ & $1.000 \mathrm{E}-11$ & 0. & 0. & (6) \\
\hline 5. & $\mathrm{CF} 2+\mathrm{CF} 3(+\mathrm{M})=\mathrm{C} 2 \mathrm{~F} 5(+\mathrm{M})$ & $1.000 \mathrm{E}-12$ & 0 . & 0 & (6) \\
\hline 6. & $\mathrm{C} 2 \mathrm{~F} 4+\mathrm{M}=\mathrm{CF} 2+\mathrm{CF} 2+\mathrm{M}$ & $1.126 \mathrm{E}-07$ & 0 . & 27528.0 & (28) \\
\hline 7. & $F+C 2 F 4=C F 3+C F 2$ & $4.800 \mathrm{E}-11$ & 0. & 0 & (28) \\
\hline 8. & $\mathrm{C} 2 \mathrm{~F} 4+\mathrm{O}=\mathrm{COF} 2+\mathrm{CF} 2$ & $1.350 \mathrm{E}-11$ & 0. & 634.1 & (6) \\
\hline 9. & $\mathrm{C} 2 \mathrm{~F} 5+\mathrm{F}=\mathrm{CF} 3+\mathrm{CF} 3$ & $1.000 \mathrm{E}-11$ & 0 . & 0 & (6) \\
\hline 10. & $\mathrm{CF}+\mathrm{CF} 2=\mathrm{C} 2 \mathrm{~F} 3$ & $1.000 \mathrm{E}-12$ & 0. & 0. & (6) \\
\hline 11. & $\mathrm{C} 2 \mathrm{~F} 3+\mathrm{F}=\mathrm{C} 2 \mathrm{~F} 4$ & $1.000 \mathrm{E}-12$ & 0 . & 0 . & (6) \\
\hline \multirow{2}{*}{12.} & $F+F+M=F 2+M$ & $2.800 \mathrm{E}-34$ & 0. & 0 & (29) \\
\hline & Reverse Reaction rates & $/ 7.600 \mathrm{E}-12$ & 0. & 14300. & 1 \\
\hline 13. & $\mathrm{O}^{*}+\mathrm{O} 2 \Rightarrow \mathrm{O}+\mathrm{O} 2$ & $2.900 \mathrm{E}-11$ & 0. & -70.0 & (30) \\
\hline 14. & $\mathrm{O}^{*}+\mathrm{CF} 4=>\mathrm{O}+\mathrm{CF} 4$ & $1.000 \mathrm{E}-13$ & 0. & 0 & (31) \\
\hline 15. & $\mathrm{O}^{*}+\mathrm{COF} 2 \Rightarrow \mathrm{O}+\mathrm{COF} 2$ & $5.200 \mathrm{E}-11$ & 0. & 0. & (30) \\
\hline 16. & $\mathrm{O}^{\star}+\mathrm{COF} 2 \Rightarrow \mathrm{F} 2+\mathrm{CO} 2$ & $2.200 \mathrm{E}-11$ & 0. & 0 & (30) \\
\hline 17. & $\mathrm{O}^{\star}+\mathrm{CO} 2=>0+\mathrm{CO} 2$ & $7.400 \mathrm{E}-11$ & 0. & -120 & (30) \\
\hline 18. & $\mathrm{O}^{*}+03 \Rightarrow \mathrm{O}+\mathrm{O}+\mathrm{O} 2$ & $2.400 \mathrm{E}-10$ & 0. & 0 & $(e)^{\dagger}$ \\
\hline 19. & $\mathrm{O}^{\star *}+\mathrm{COF} 2=\mathrm{O}+\mathrm{COF} 2$ & $6.00 \mathrm{E}-11$ & 0. & 0. & $(e)^{\dagger}$ \\
\hline 20 . & $\mathrm{O}^{\star *}+\mathrm{COF} 2 \Rightarrow \mathrm{F} 2+\mathrm{CO} 2$ & $3.00 \mathrm{E}-11$ & 0 . & 0 . & $(e)^{\dagger}$ \\
\hline 21. & $\mathrm{O}^{* *}+\mathrm{COF} 2 \Rightarrow \mathrm{O}+\mathrm{COF}+\mathrm{F}$ & $1.00 \mathrm{E}-11$ & 0. & 0. & $(e)^{\dagger}$ \\
\hline 22 . & $\mathrm{O}^{* *}+\mathrm{CO} 2 \Rightarrow \mathrm{O}+\mathrm{CO} 2$ & $3.000 \mathrm{E}-11$ & 0. & 1320.0 & $(e)^{\dagger}$ \\
\hline 23. & $O^{* *}+C O=>O+C O$ & $9.400 \mathrm{E}-14$ & 0. & 0. & $(e)^{\dagger}$ \\
\hline & $\mathrm{O}^{* *}+02 \Rightarrow \mathrm{O}+\mathrm{O} 2$ & $4.800 \mathrm{E}-12$ & 0. & 850. & $(e)^{\dagger}$ \\
\hline & $0^{* *}+0 \Rightarrow 0+0$ & $5.000 \mathrm{E}-11$ & 0. & 300. & $(e)^{\dagger}$ \\
\hline & $\mathrm{O} 2 *+\mathrm{M} \Rightarrow \mathrm{O} 2+\mathrm{M}$ & $3.000 \mathrm{E}-18$ & 0. & 200.0 & $(e)^{\dagger}$ \\
\hline & $02^{\star}+02=>02+02$ & $1.470 \mathrm{E}-18$ & 0. & 0 & $(e)^{\dagger}$ \\
\hline & $\mathrm{O} 2^{\star}+\mathrm{O} 2^{*}=>\mathrm{O} 2+\mathrm{O} 2$ & $6.910 \mathrm{E}-17$ & 0. & 389. & $(\mathrm{e})^{\dagger}$ \\
\hline & $02^{\star}+02=>03+0$ & $2.950 \mathrm{E}-21$ & 0. & 0 & $(e)^{\dagger}$ \\
\hline & $02^{*}+03=>02+02+0$ & $6.00 \mathrm{E}-11$ & 0. & 2853.0 & $(\mathrm{e})^{\dagger}$ \\
\hline & $O-+O=O 2+E$ & $3.000 \mathrm{E}-10$ & 0. & 0. & $(26)$ \\
\hline & $\mathrm{O}-=>\mathrm{O}+\mathrm{E}$ & $5.000 \mathrm{E}+03$ & 0. & 0. & (26) \\
\hline
\end{tabular}

$\dagger \mathrm{e}=$ estimated rate coefficients. 


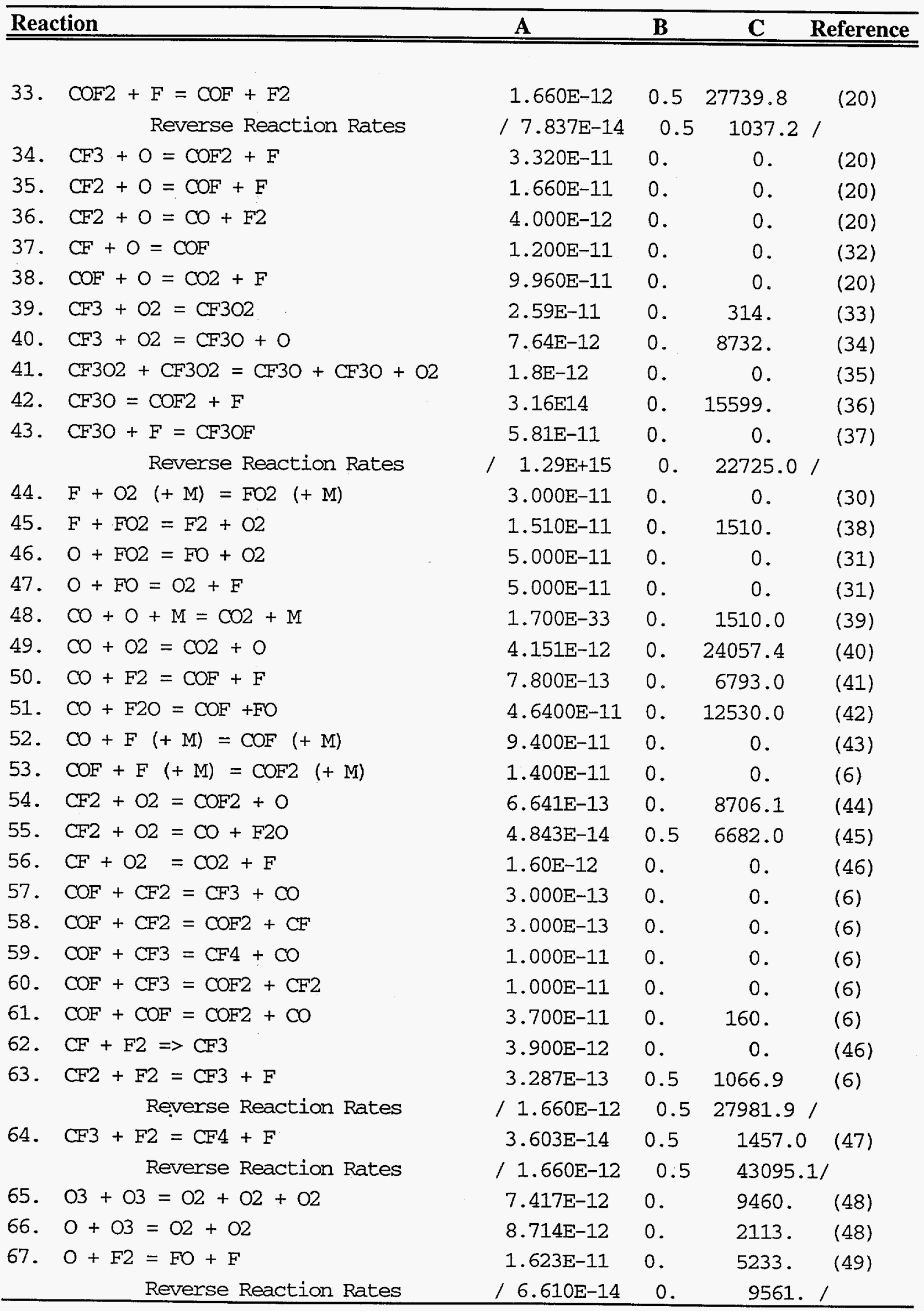


68. $F O+F 2=F 2 O+F$

Reverse Reaction Rates

69. $\mathrm{F}+\mathrm{O} 3=\mathrm{FO}+\mathrm{O} 2$

70. $\mathrm{O}+\mathrm{O}+\mathrm{M}=\mathrm{O} 2+\mathrm{M}$ Reverse Reaction Rates

71. $\mathrm{FO}+\mathrm{FO}=\mathrm{F}+\mathrm{F}+\mathrm{O} 2$

72. $\mathrm{FO}+\mathrm{FO}=\mathrm{F} 2 \mathrm{O}+\mathrm{O}$

73. $\mathrm{O} 3+\mathrm{M}=\mathrm{O}+\mathrm{O} 2+\mathrm{M}$

Reverse Reaction Rates

74. $\mathrm{F} 2 \mathrm{O}+\mathrm{M}=\mathrm{F}+\mathrm{FO}+\mathrm{M}$

75. $\mathrm{F} 2 \mathrm{O} 2+\mathrm{M}=\mathrm{F}+\mathrm{FO} 2+\mathrm{M}$

Reverse Reaction Rates

76. $\mathrm{F} 2 \mathrm{O} 2+\mathrm{O} 2=\mathrm{FO} 2+\mathrm{FO} 2$

Reverse Reaction Rates

77. $\mathrm{F} 2 \mathrm{O} 2+\mathrm{F}=\mathrm{FO} 2+\mathrm{F} 2$

78. $\mathrm{FO} 2+\mathrm{FO} 2+\mathrm{M}=\mathrm{O} 2+\mathrm{O} 2+\mathrm{F} 2+\mathrm{M}$

79. $\mathrm{O}+\mathrm{O} 2 \Rightarrow \mathrm{O} 2++\mathrm{O}$

80. $\mathrm{F}++\mathrm{O} 2 \Rightarrow \mathrm{O}++\mathrm{FO}$

81. $\mathrm{F}++\mathrm{O} 2 \Rightarrow \mathrm{O} 2++\mathrm{F}$

82. $\mathrm{O}-+\mathrm{O} 2=>\mathrm{O} 3+\mathrm{E}$

83. $\mathrm{O} 2-+\mathrm{O}=>\mathrm{O} 3+\mathrm{E}$

84. $\mathrm{O} 2-+\mathrm{O}=>\mathrm{O} 2+\mathrm{O}-$

85. $\mathrm{O}-+\mathrm{O} 2++\mathrm{M}=>\mathrm{O}+\mathrm{O} 2+\mathrm{M}$

86. $\mathrm{O}-+\mathrm{O} 3=\mathrm{O} 2-+\mathrm{O} 2$
$1.660 \mathrm{E}-13 \quad 0 . \quad 5233$.

(49)

/ 8.516E-14 0. 6894. /

$2.819 \mathrm{E}-1120.252$.

$5.252 \mathrm{E}-35 \quad 0 . \quad-906$.

$/ 1.307 \mathrm{E}-10 \quad 0 . \quad 52740 . /$

$2.090 \mathrm{E}-120.0$.

6.610E-14 $0 . \quad 8051$.

$7.173 \mathrm{E}-10 \quad 0 . \quad 11170$.

/ $4.742 \mathrm{E}-27-2.8 \quad 0 . /$

3.000E-09 0. 17500 .

$4.589 \mathrm{E}-03-1.0 \quad 9914$.

/ 3.000E-32 0. 0./

$8.400 \mathrm{E}-08 \quad 0.6520$.

(49)

$/ 2.000 \mathrm{E}-06 \quad 0.6550 . /$

3.600E-14 0. 0 .

2.400E-33 0. 0 .

$2.100 \mathrm{E}-110.0$.

$6.056 \mathrm{E}-110$.

0 .

7.007E-10 0 .

0 .

5.000E-15 0 .

0 .

$1.500 \mathrm{E}-10 \quad 0$.

0 .

$1.500 \mathrm{E}-10 \quad 0$.

0 .

2.000E-25 0 .

0 .

$1.000 \mathrm{E}-11 \quad 0$.

0 . 


\title{
III. MODELING THE EFFECTS OF ETCHANT CONCENTRATION AND TRANSPORT ON CHEMICAL DOWNSTREAM ETCH SYSTEM PERFORMANCE
}

\author{
S. R. Vosen, E. Meeks, R. S. Larson and J. W. Shon
}

INTRODUCTION

\begin{abstract}
In this chapter, the CDE system modeling is validated through comparison of etch rates and nonuniformity of blanket polysilicon and silicon dioxide wafers in a CDE tool from Matrix Integrated Systems, Inc., using $\mathrm{NF}_{3} / \mathrm{O}_{2}$ gas mixtures at conditions representative of normal tool use. This study is primarily concerned with the effects of operating parameters on the etch rate and nonuniformity, and thus focuses mainly on etch chamber calculations. It was the goal of this study to develop and apply a numerical model to aid in the design and operation of new CDE tools. To do this, we compiled a comprehensive plasma kinetics model for $\mathrm{NF}_{3} / \mathrm{O}_{2}$ gas, ${ }^{1,2}$ as described in Section I. This model is used in conjunction with chemically reacting flow models to predict conditions through the plasma source, transport tube, showerhead and etch chamber for a reactor in development at Matrix Integrated Systems, Inc. Model validation is achieved through comparison with experimental data. In addition, the model was used to determine operating characteristics of the CDE system by varying the total flow rate, pressure, plasma power, oxygen flow rate and transport tube diameter. Correlation of the etch rate and nonuniformity highlight the importance of system pressure, flow rate and atomic fluorine concentration on system performance.
\end{abstract}

\section{CDE MODEL}

A chemically reacting flow model was assembled to include important chemical and physical phenomena in each of the CDE components (see Fig. I-1). The CDE model consists of a chemically reacting flow model for each of the components -- plasma source, transport tube, showerhead and process chamber. The CDE model follows the gas flow from one component to the next, with the output from each component model being the input to the next model. The models incorporate the important physical and chemical phenomena in each component. In general the chemical complexity of the models becomes smaller as the flow travels from the 
plasma source to the process chamber (going from hundreds of chemical reactions to 4), while the physical dimensionality increases downstream (from 0-D in the plasma source to 2-D in the etch chamber). Inputs to the CDE model are the inlet gas flow rates, plasma source power and

process pressure, and the output is the wafer etch rate and nonuniformity and an estimate of the ion concentration at the wafer. Intermediate results include the plasma source applicator erosion rate, and gas-phase concentrations through the transport tube and process chamber.

The CDE model described here is tailored to a CDE tool that is currently under development at Matrix Integrated Systems, Inc. This system includes a microwave plasma source with a quartz applicator tube capable of running at 300 to 750 Watts of input power, $\mathrm{NF}_{3}$ flow rates of up to $67 \mathrm{sccm}, \mathrm{O}_{2}$ flow rates of up to $100 \mathrm{sccm}$, a transport tube that is $10 \mathrm{~s}$ of centimeters long and an etch chamber capable of handling $200 \mathrm{~mm}$ wafers. Several different showerhead designs were also analyzed. Plasma source pressures of 250 to 1,000 mTorr were considered.

Kinetics model

A plasma chemistry model was compiled for $\mathrm{NF}_{3} / \mathrm{O}_{2}$ gas systems. This model and its validation are described in detail in Meeks, et al., 1995. In summary, the model contains the important reactions between species resulting from a $\mathrm{NF}_{3} / \mathrm{O}_{2}$ plasma discharge and the interaction of the plasma with the quartz applicator tube. The plasma is generated by the energetic electrons, resulting from a given amount of input power, reacting with the inlet gases to form ions, radicals and excited state species. Included in the model are electron-impact, neutralneutral, ion-neutral and ion-ion kinetics. While most of the chemical data needed to compile the model is available in the literature, there was significant uncertainty in many of the reaction rates and some estimation was required. For this reason, measurements from plasmas, including species measurements and applicator tube consumption, were used to validate the plasma source model. Measurements of etch rate and nonuniformity validated the complete CDE model. Surface chemistry was included to account for the loss of etchant and charged species on the surfaces. Incorporation of chemical kinetics into the model employed CHEMKIN III ${ }^{3,4}$ and SURFACE CHEMKIN III ${ }^{5-7}$ software packages. In the source region, quartz etching by neutral and ion bombardment (each of nearly equal importance) were included, as well as surface recombination and charge exchange.

As the flow proceeds downstream, recombination and neutralization reactions are important in the transport tube, and wafer etching reactions are important in the etch chamber. Flow through the showerhead and process chamber is chemically simpler than that through the plasma source and transport tube. Because of the large amount of neutralization that occurs in the transport tube, the reaction set is reduced through a two step process. First, charged species are eliminated. Etch rates are predicted using a one-dimensional process chamber model. ${ }^{8,9}$ 
Species and reactions are systematically removed to give a reduced set of species and reactions that have nearly the same etch rate - to within $3 \%$ of the full chemistry calculation. Using this method, the large reaction set necessary to describe the source region and transport tube is reduced to a set manageable for the two-dimensional process chamber model. The species used in this reduced chemistry model are: $\mathrm{FO}_{2}, \mathrm{NO}, \mathrm{F}_{2}, \mathrm{~N}_{2} \mathrm{~F}_{2}, \mathrm{NF}_{2}, \mathrm{NFO}, \mathrm{SiF}_{4}, \mathrm{~N}_{2}, \mathrm{NF}_{3}, \mathrm{~F}$ and $\mathrm{O}_{2}$. Only three gas-phase reactions are needed to predict the etch rate:

$$
\begin{aligned}
\mathrm{NF}_{2}+\mathrm{F}+\mathrm{M} & \leftrightarrow \mathrm{NF}_{3}+\mathrm{M} \\
\mathrm{F}+\mathrm{O}_{2}+\mathrm{M} & \leftrightarrow \mathrm{FO}_{2}+\mathrm{M}, \text { and } \\
\mathrm{F}+\mathrm{FO}_{2} & \leftrightarrow \mathrm{F}_{2}+\mathrm{O}_{2},
\end{aligned}
$$

where $M$ is any species in third-body recombination reactions. For the off-baseline calculations, a simpler set is used: $\mathrm{F}_{2}, \mathrm{SiF}_{4}, \mathrm{~N}_{2}, \mathrm{~F}$ and $\mathrm{O}_{2}$ with no gas phase reactions. The use of the reduced reaction set changed the predicted etch rate by $\sim 3 \%$ for the baseline case.

Surface reactions are written in terms of temperature dependent sticking coefficients. In the process chamber quartz etch proceeds through the reaction: ${ }^{10}$

$$
\mathrm{F}(\mathrm{g})+0.25 \mathrm{SiO}_{2}(\mathrm{~s})=>0.25 \mathrm{SiF}_{4}(\mathrm{~g})+0.25 \mathrm{O}_{2}(\mathrm{~g})
$$

and polysilicon etching through (Flamm et al., 1981):

$$
\mathrm{F}(\mathrm{g})+0.25 \mathrm{Si}(\mathrm{s})=>0.25 \mathrm{SiF}_{4}(\mathrm{~g})
$$

On exposed non-wafer surfaces, atomic fluorine recombines to molecular fluorine: ${ }^{11}$

$$
\mathrm{F}=>0.5 \mathrm{~F}_{2}
$$

with a surface dependent sticking coefficient.

\section{Plasma Source Model}

The plasma source is modeled as a perfectly stirred reactor, including energy deposition to energetic electrons, neutral and charged gas phase reactions and etching of quartz applicator tube walls. ${ }^{12,2}$ In this model the conservation equations of species, mass, gas-energy and electron-energy are solved, giving steady-state gas and electron temperatures, and species concentrations for ions, electrons, and neutral species. The plasma power deposition is a source term of the electron energy equation, which results in the level of ionization and dissociation in the plasma. The gas temperature is obtained from a balance of heat losses to the external 
environment and gains from neutral third-body chemical recombination. In this study the plasma was assumed to have a volume of $184 \mathrm{~cm}^{3}$ and a surface area of $264 \mathrm{~cm}^{2}$.

Quartz applicator tubes in $\mathrm{NF}_{3} / \mathrm{O}_{2}$ discharges undergo erosion that is rapid enough to limit the tube lifetime and also result in a significant loss of the etchant $F$ atoms. This erosion results from both neutral and ion enhanced $F$ atom reaction with the quartz tube. Surface reactions were included to account for this significant loss of $\mathrm{F}$ atoms. With the addition of these reactions and a convective heat loss term to the tube walls, the observed applicator tube erosion rates for the Shibaura CDE- $80^{13}$ and the effect of tube temperature on erosion rates ${ }^{14}$ are predicted by the plasma source model to within a factor of two.

\section{Transport Tube Model}

The transport tube model solves the steady state plug flow formulation of the transport equations, including gas-phase reactions and gas-surface reactions, assuming that the radial transport is rapid and that axial diffusion is negligible. Using this model we predict changes in species through the transport tube, including the variation of charged species concentration with distance. Important phenomena occurring in the transport tube are the neutralization of charged species in the gas phase and on the surface and the effect of compressibility for larger flow rates. Since no energy deposition occurs in the transport tube, reactions with electrons become less important as the flow moves through the tube.

The transport tube equations consist of the usual mass, momentum and energy balances for plug flow, ${ }^{15}$ with certain modifications to account for plasma effects. The conservation equations for total mass and for each gas-phase species balance the convective transport with the net production rate by both homogenous and heterogeneous reactions. For the surface species there is, by assumption, no transport and the net production rate is set equal to zero. The gasphase momentum equation expresses the axial acceleration in terms of both pressure and viscous forces. This is supplemented by an ideal gas equation of state in which the electrons have a separate temperature. The overall gas-phase energy equation relates changes in enthalpy and kinetic energy to the rate of heat loss to the surroundings. There is also a separate electron energy balance which shows how the enthalpy and kinetic energy fluxes of the electrons are affected by the chemical production rates and the rates of energy loss via both elastic and inelastic collisions, and surface losses.

The foregoing model predicts the axial profiles of the gas-phase density, velocity, pressure, temperature, and composition, as well as the electron temperature and the species site fractions on the tube surface. Initial values for the gas properties are obtained from the output of the plasma source model. The differential/algebraic system describing the remainder of the tube is solved using the standard DASSL ${ }^{16}$ routines. 


\section{$\underline{\text { Showerhead Model }}$}

The purpose of the showerhead is to produce a uniform flow for the etch chamber inlet with a minimum pressure drop. The showerhead consists of a plenum region, followed by an obstruction consisting of a plate with holes. For the conditions of interest here, the flow through the showerhead holes is compressible, laminar, fully developed continuum flow with friction. While the flow on either side of the showerhead is incompressible $(M<1)$, forcing the flow though small holes may cause the flow to accelerate to sonic conditions ("choked flow"), producing a large pressure drop. ${ }^{17}$ Once the showerhead flow becomes choked, the ability to control the flow will be reduced because the flow rate through the CDE tool can no longer be adjusted by increasing the pumping capacity in the process chamber, but only by increasing the supply pressure. For these reasons, choked flow is to be avoided. This condition is satisfied when:

$$
L_{h}<L_{h}^{*}=\frac{\pi}{256} \frac{\left(\rho_{p} a_{p}\right)^{2}}{\gamma \mu_{p}} \frac{N D_{h}^{4}}{\dot{m}}
$$

where $L_{h}$ is the showerhead hole length, $L_{h}^{*}$ is the length corresponding to choked flow, $D_{h}$ is the showerhead hole diameter, $\rho_{p}, a_{p}, \mu_{p}$ and $\gamma$ are the stagnation gas density, sound speed, viscosity and specific heat ratio in the plenum region just upstream of the showerhead, $\mathrm{N}$ is the number of showerhead holes and $\dot{m}$ is the total mass flow rate. For non-choked showerhead flow, the etch chamber pressure, $P_{e}$, is:

$$
P_{e}=P_{p}\left[\sqrt{1-L_{h} / L_{h}^{*}}\right]
$$

For an axisymmetric flow pattern the uniformity of the gas velocity entering the showerhead has been shown to be: ${ }^{18}$

$$
\frac{U_{r m s}}{U_{\text {ave }}}=\frac{N \dot{m}}{4 \pi \mu_{o} L_{h}}\left[\frac{D_{h}}{D_{T T}}\right]^{4}\left(1+\frac{4 \pi \mu_{o} H}{\dot{m}}\right)^{-2}\left(.062+0.041\left[\frac{4 \pi \mu_{o} H}{\dot{m}}\right]^{1.373}\right)
$$

where $H$ is the plenum height and $D_{T T}$ is the transport tube diameter.

The gas composition is assumed to be constant through the plenum and showerhead. For steady flow the mass flow rate is constant, so the average gas velocity is given by balancing the flow out of the transport tube with the flow leaving the showerhead at the calculated etch chamber pressure. For the comparison calculations described below, the $U_{r m s}$ value is approximately $0.07 \%$ of the $U_{a v e}$ value, which suggests that the flow out of the showerhead is very uniform for this system. 


\section{Etch Chamber Model}

With the above conditions satisfied for the showerhead, a uniform flow will enter the etch chamber. No gas or surface reactions are assumed to occur from the exit of the transport tube to the entrance of the etch chamber. The actual loss of etchants in the region between the transport tube and etch chamber is estimated to be $\sim 2 \%$ due to gas-phase and surface reactions. The etch chamber input gas is assumed to have the same chemical composition as at the transport tube exit. Since the showerhead design considered here resulted in flow uniform to within $0.1 \%$, a radially invariant axial velocity was assumed.

A chemically reacting flow model was used to predict the transport of neutral species from the showerhead to the wafer and the resulting etch rate and nonuniformity. The twodimensional reacting flow model solves the axisymmetric, incompressible Navier-Stokes equations using finite-volume methods, coupled to the solution of species conservation equations including gas-phase and surface reactions. The model employs a semi-implicit solution method based on the TEACH code ${ }^{19}$ and the SIMPLER algorithm ${ }^{20}$ for determining the pressure field. The simulation acquires transport and thermodynamic properties from the CHEMKIN Transportproperty routines and Thermodynamic Database. ${ }^{21,22}$ This chemically reacting flow software has been described previously in the context of chemical vapor deposition analysis.

\section{RESULTS AND DISCUSSION}

Calculations were performed for a variety of operating conditions and transport tube diameters. The results will be presented in two parts. The first is direct comparison between calculations and measurements for two operating conditions and two wafer types. The second is a parametric study to determine the effect of operating conditions and geometric variations on CDE performance.

\section{Comparison}

A comparison between calculations and measurements of etch rate was made to provide confidence that the CDE model predicts the performance of the Matrix CDE tool. Direct comparisons between calculations and measurements were done for four conditions: two flow conditions each with two different wafer types. The two flow conditions were: 1) the baseline case of $67 \mathrm{sccm} \mathrm{NF} 3,100 \mathrm{sccm} \mathrm{O}$ with a source power of 320 Watts and an etch chamber pressure of $335 \mathrm{mTorr}$, and 2) $67 \mathrm{sccm} \mathrm{NF}, 0 \mathrm{sccm} \mathrm{O} \mathrm{O}_{2}$ with a source power of 320 Watts and an etch chamber pressure of $250 \mathrm{mTorr}$. The two wafer types were blanket polysilicon and silicon dioxide wafers. The etch rate and nonuniformity are presented in Table III-1. The model is 
most accurate for the $\mathrm{NF}_{3} / \mathrm{O}_{2}$ plasma, and in all cases predicts the etch rate to within $25 \%$. The model predictions for nonuniformity do not agree as well with measurements. One reason for this may be the small sample size - only one wafer was used in this comparison. It has been shown that an adequate comparison results for more detailed measurements of more wafers. In particular, this model has been used to compare etch rates and nonuniformities for poly etching in a different $\mathrm{CDE}$ tool, ${ }^{23}$ and values and trends in both etch rate and nonuniformity compared to within $25 \%$.

In addition to predicting etch rates, the model yields other information useful in understanding the behavior of CDE systems. For example, the plasma source model predicts a high degree of $\mathrm{NF}_{3}$ dissociation, and that the primary etchant species, $\mathrm{F}$, has a mole fraction of $37 \%$ for the $\mathrm{NF}_{3} / \mathrm{O}_{2}$ plasma and $67 \%$ for the $\mathrm{NF}_{3}$ plasma. The predicted positive ion concentration is $\sim 3 \times 10^{12} / \mathrm{cm}^{3}$, and the electron concentration is $\sim 2 \times 10^{10} / \mathrm{cm}^{3}$. The high degree of dissociation increases the total volumetric flow rate by roughly $50 \%$ as the flow enters the transport tube.

Table III-1. Comparison between CDE model predictions and experimental results.

\begin{tabular}{|c|c|c|c|c|c|c|c|}
\hline $\begin{array}{c}\text { Etch } \\
\text { Chamber } \\
\text { Pressure } \\
\text { [mTorr] }\end{array}$ & $\begin{array}{c}\text { Power } \\
\text { [W] }\end{array}$ & $\begin{array}{c}\mathrm{NF}_{3} \\
\text { Flow } \\
\text { Rate } \\
\text { [sccm] }\end{array}$ & $\begin{array}{c}\mathrm{O}_{2} \text { Flow } \\
\text { Rate } \\
{[\mathrm{sccm}]}\end{array}$ & $\begin{array}{l}\text { Wafer } \\
\text { Type }\end{array}$ & Result & $\begin{array}{c}\text { Etch Rate } \\
\text { [A/min] }\end{array}$ & $\begin{array}{c}1 \sigma \text { Non- } \\
\text { uniformity } \\
{[\%]}\end{array}$ \\
\hline \multirow{4}{*}{335} & \multirow{4}{*}{320} & \multirow{4}{*}{67} & \multirow{4}{*}{100} & \multirow[t]{2}{*}{ poly } & measurement & 1545 & 2 \\
\hline & & & & & calculation & 1394 & 3 \\
\hline & & & & \multirow[t]{2}{*}{ oxide } & measurement & 55 & 19 \\
\hline & & & & & calculation & 54 & 3 \\
\hline \multirow{4}{*}{250} & \multirow{4}{*}{320} & \multirow{4}{*}{67} & \multirow{4}{*}{0} & \multirow[t]{2}{*}{ poly } & measurement & 1697 & 5 \\
\hline & & & & & calculation & 2081 & 3 \\
\hline & & & & \multirow[t]{2}{*}{ oxide } & measurement & 62 & 5 \\
\hline & & & & & calculation & 81 & 1 \\
\hline
\end{tabular}

The transport tube calculations give the variation of species concentration, pressure and velocity along the tube length. Predicted major species variations down the transport tube are shown in Figure III-1(a) for the $\mathrm{NF}_{3} / \mathrm{O}_{2}$ conditions. The dominant species, in terms of mole fraction, are $\mathrm{O}_{2}$ and $\mathrm{F}$, at about $35 \%$ each, $\mathrm{NF}_{3}$ and $\mathrm{N}_{2}$ at about $8 \%$ each, $\mathrm{SiF}_{4}, \mathrm{NF}_{2}$ and $\mathrm{NFO}$ at about $3 \%$ each. All of these have concentrations that vary slightly down the transport tube. Only $\mathrm{F}_{2}$, at a mole fraction of less than $1 \%$, shows any significant variation down the length of the transport tube. 


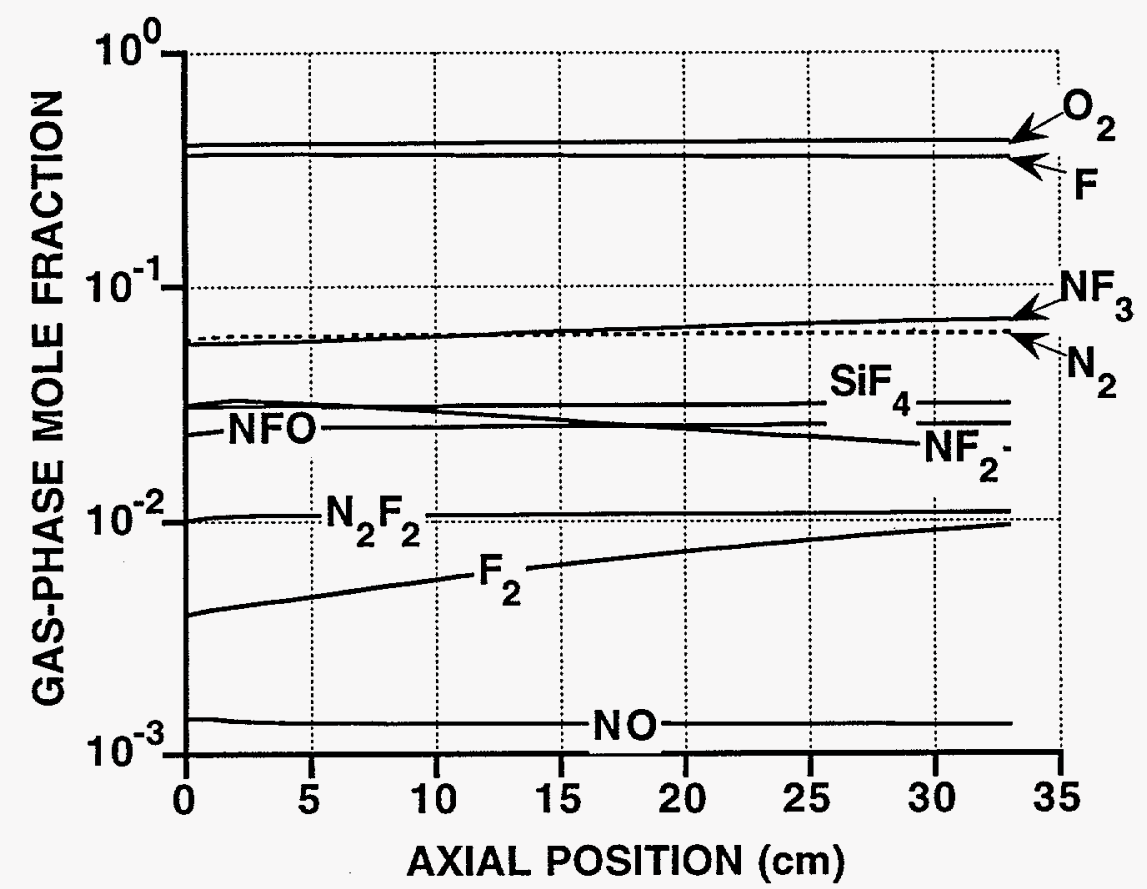

(a)

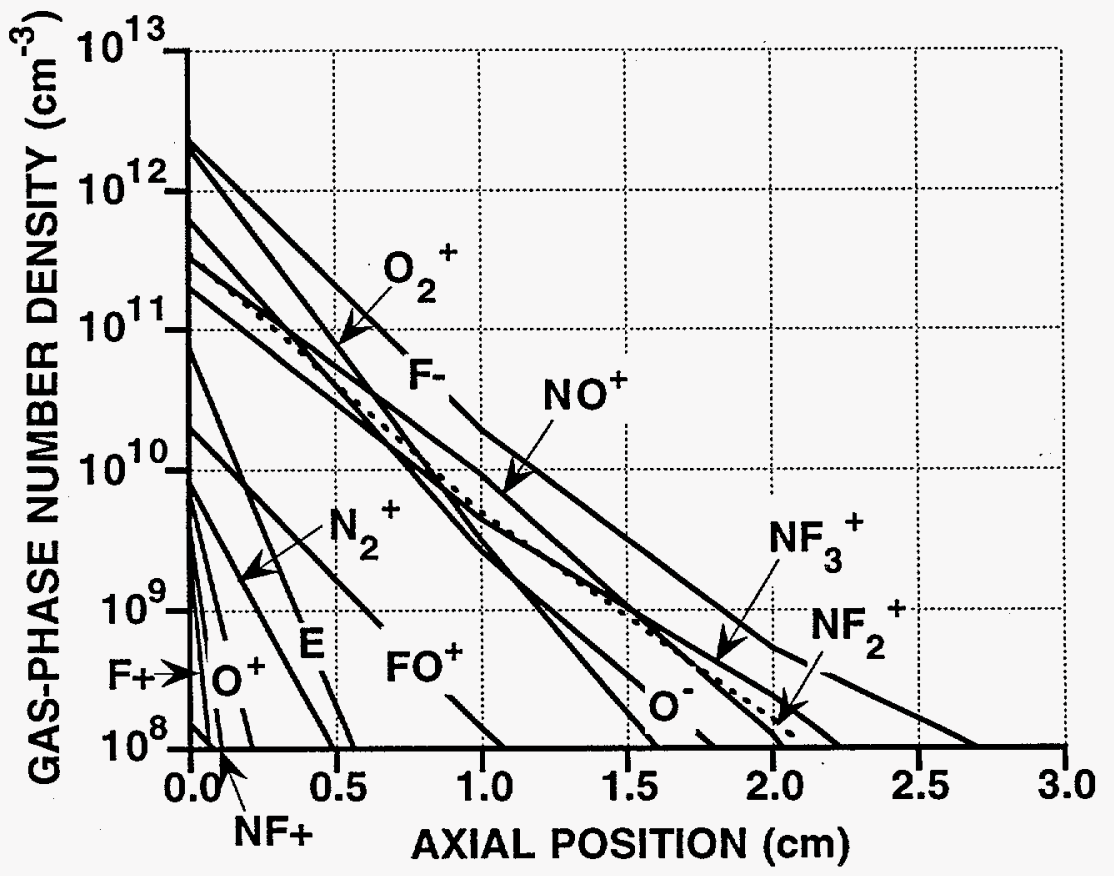

(b)

Figure III-1. Baseline Distribution of a) Neutral Species and b) Charged Species Down the Transport Tube. 
While the transport tube has only a small effect on the $\mathrm{F}$ atom concentration, the gasphase ion concentration is greatly reduced by the transport tube. The ion concentrations (Figure III-1(b)) diminish exponentially down the transport tube. The dominant ions emanating from the source are $\mathrm{F}^{-}$and $\mathrm{O}_{2}^{+}$, at concentrations of $\sim 2 \times 10^{12} / \mathrm{cm}^{3}$. At a distance of $2.7 \mathrm{~cm}$ the negative ion concentration is $\sim 10^{8} / \mathrm{cm}^{3}$, and the negative charge is balanced by the positive ions $\mathrm{NF}_{3}{ }^{+}, \mathrm{NF}_{2}{ }^{+}$and $\mathrm{NO}^{+}$. This concentration is on the order of parts per million, and is expected to be small enough that no wafer damage would be sustained. Since the transport tube is much longer than $3 \mathrm{~cm}$, the exponentially falling ion concentration can be seen to be of little concern. An extremely small ion content was found to result in all of the calculations presented here, so we conclude that the transport tube design is expected to eliminate the presence of ions while only slightly affecting the radical concentration.

Detailed results from a two-dimensional etch chamber calculation are shown in Figure III-2. Atomic fluorine recombination to $F_{2}$ occurs on all surfaces except for the wafer, where polysilicon is etched by fluorine atoms to form $\mathrm{SiF}_{4}$. Figure III-2(a) shows atomic fluorine concentrations and fluorine atom flux lines through the chamber. In Figure III-2(b) the resulting oxide etch rate profile is shown. If the etch rate were uniform across the wafer, the flux lines would intersect the wafer evenly spaced. The deflection of the flux lines toward the edge of the wafer results from the complex interaction of convection and diffusion in the etch chamber, resulting in a center-fast etch rate profile.
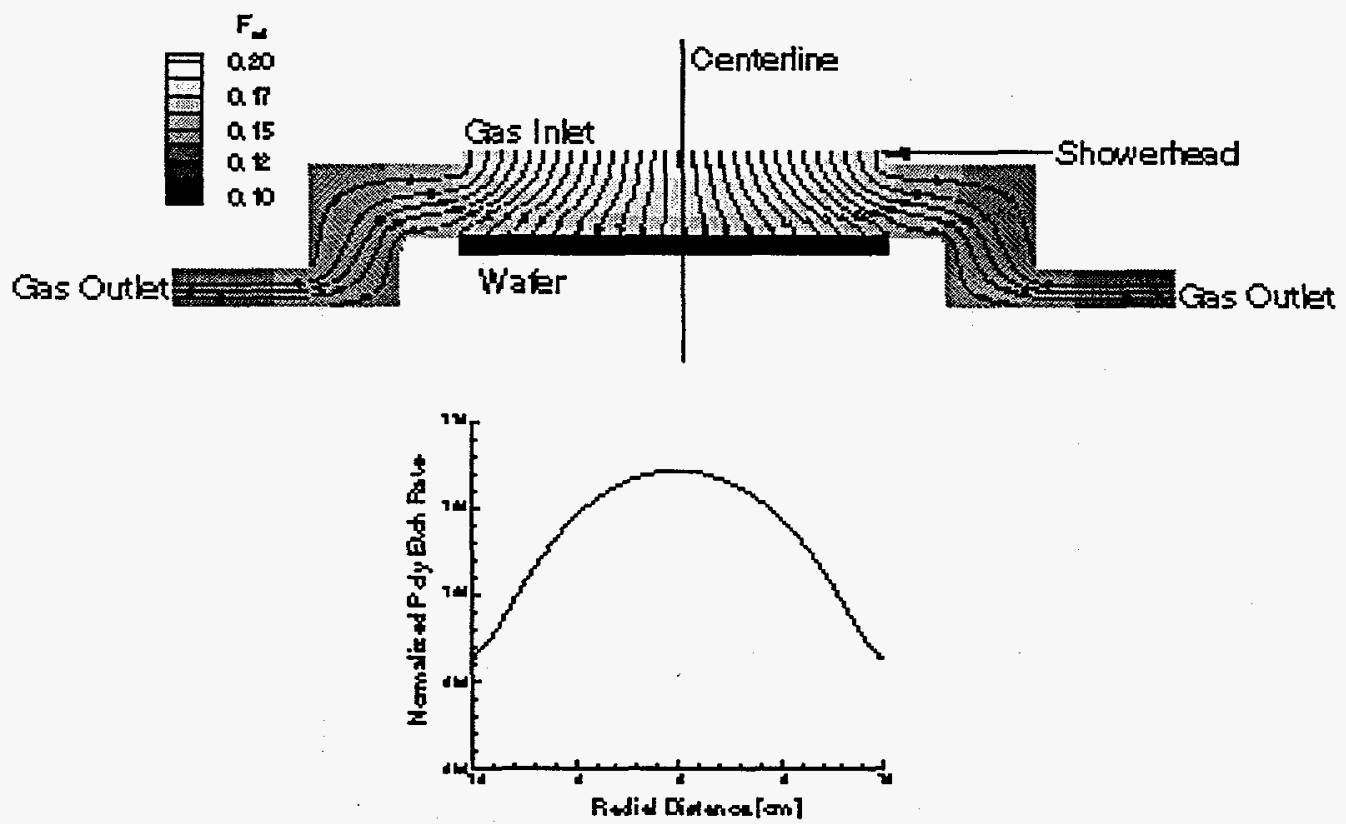

Figure III-2. Results of 2-D Calculation. 3a) (top) Fluorine atom concentration and flux lines, and $3 \mathrm{~b}$ ) (bottom) polysilicon etch rate profile - Baseline Case. 


\section{Off-Baseline Calculations}

The performance characteristics of the CDE system were calculated by predicting the etch rate and nonuniformity as a function of source power, pressure, flow rates and transport tube diameter. Off-baseline conditions were chosen based on their ability to change the production of atomic fluorine in the source. This was done through a parametric study of $\mathrm{NF}_{3} / \mathrm{O}_{2}$ plasmas to determine the effect of changing easily process variables (flow rate, pressure and source power), over a reasonable range, on the atomic fluorine exiting the plasma source. The showerhead design used for the comparison calculations has showerhead holes that produce nearly choked flow. To allow for process conditions to be varied over a wider range, the off-baseline predictions were done for a showerhead with slightly larger holes $\left(D_{h}\right.$ was increased from 0.152 to $0.185 \mathrm{~cm}$ ). This change in the showerhead design results in a slightly smaller pressure drop, but also allows for a greater and more useful variation in process conditions. With this change to the showerhead model, the effects of process variable changes on wafer etch rate were calculated using the full CDE model. A correlation of the predicted etch rate and nonuniformity with the process and calculated variables was then attempted.

Results for the parametric plasma source study are presented in Figure III-3. In each case one parameter was varied while the others were held constant at those of a "baseline case": 67 $\mathrm{sccm} \mathrm{NF}, 100 \mathrm{sccm} \mathrm{O}, 350 \mathrm{mTorr}$ source pressure, 320 Watts plasma power and a transport tube $2.54 \mathrm{~cm}$ in diameter. The dominant species exiting the plasma source are $\mathrm{F}$ and $\mathrm{O}_{2}$ with mole fractions generally in the range of $30 \%$ to $45 \%$. As the $\mathrm{O}_{2}$ flow approaches zero, atomic fluorine becomes the dominant species and $\mathrm{O}_{2}$ concentration decreases but does not go to zero due to oxygen release from etching of the quartz applicator tube. Another result of applicator tube etching is the presence of $\mathrm{SiF}_{4}$ as a minor species. Other minor species (with mole fractions greater than $1 \%$ ) are $\mathrm{N}_{2}, \mathrm{NF}_{3}, \mathrm{NF}_{2}$ and NF. Dissociation of $\mathrm{NF}_{3}$ increases for decreasing $\mathrm{O}_{2}$ flow, increasing plasma power and decreasing total flow rate. Pressure has little effect on $\mathrm{NF}_{3}$ dissociation. Atomic fluorine mole fraction increases for decreasing $\mathrm{O}_{2}$ flow rate and pressure, and has a maximum with varying power and total flow rate.

The off-baseline conditions, shown in Table III-2, are labeled "Baseline," "Power," "Pressure," Oxygen," "Flow Rate," and "Transport Tube." These names denote the parameter varied from the baseline in an attempt to increase etch rate through increased atomic fluorine production in the source. The exception to this was the pressure case. Atomic fluorine production is maximized by decreasing the pressure. Since the showerhead flow is nearly choked, this would have the effect of choking the flow. For this reason a higher pressure was chosen to study the effect of source pressure on etch rate. The power case has the plasma power increased to $700 \mathrm{~W}$, the pressure case has the source pressure increased to $472 \mathrm{mTorr}$, the oxygen case has no oxygen flow, the flow rate case has a decreased total flow rate of $150 \mathrm{sccm}$ with the same $\mathrm{NF}_{3} / \mathrm{O}_{2}$ flow-rate ratio as the baseline, and the transport tube case has a transport tube 

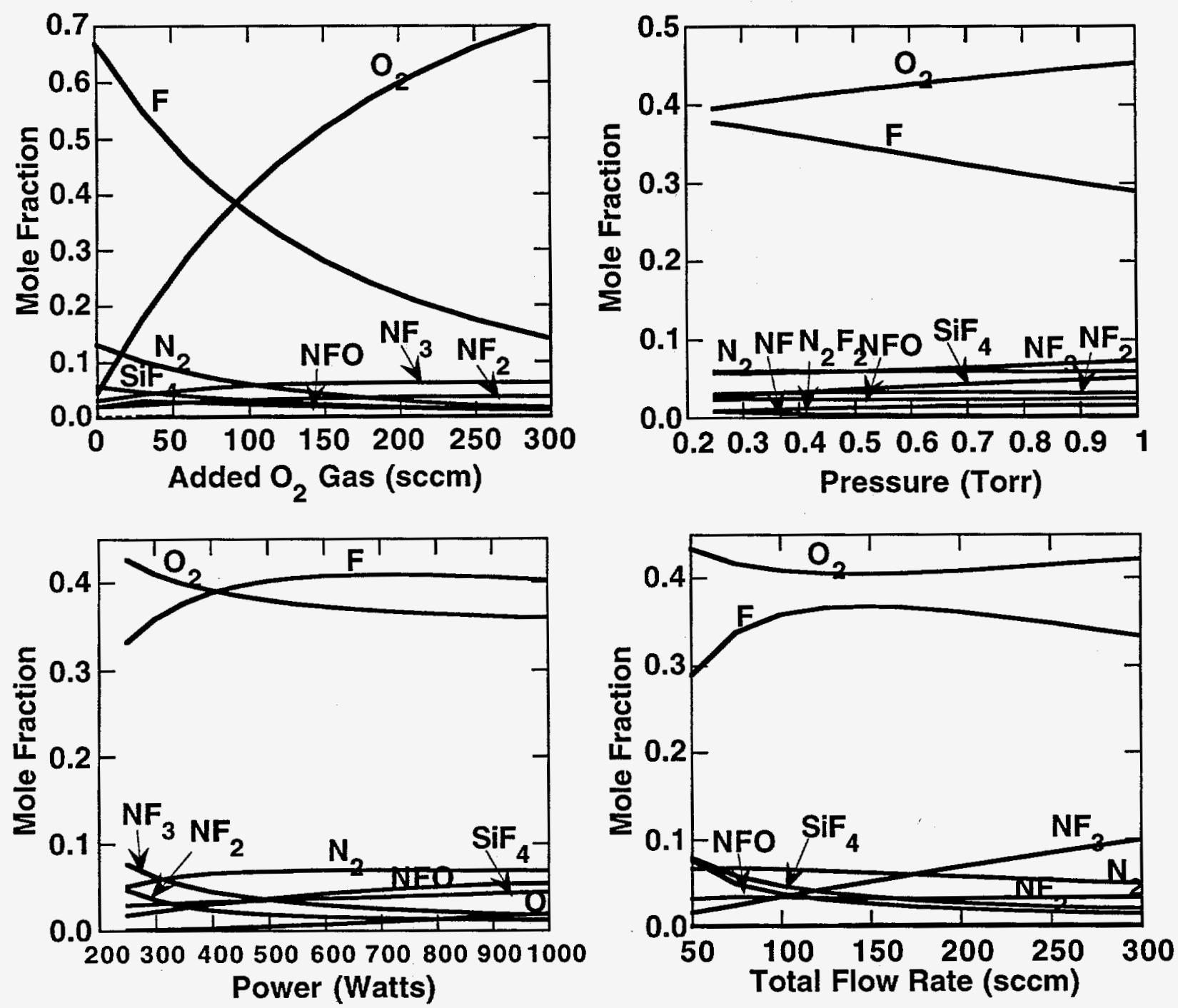

Figure III-3. Plasma Source Parametric Study. Effect of varying plasma source input $\mathrm{O}_{2}$ flow rate, pressure, power and total flow rate on plasma source output mole fractions.

diameter increased to $5.08 \mathrm{~cm}$. Also shown in Table III-2 are output pressures and atomic fluorine mole fractions at the exit of each model (rounded to the nearest percent), as well as the predicted etch rate and nonuniformity for both poly and oxide etching.

As noted, the off-baseline conditions were chosen to increase atomic fluorine production, with the exception of the pressure. However, each of the off-baseline conditions resulted in an increased etch rate. Even though increasing the source pressure decreases the source exit $\mathrm{X}_{\mathrm{F}}$ and the mass flow rate of $F$, the effect of increasing pressure on transport to the etch chamber was found to overcompensate for the loss of $F$. Maximizing etch rates therefore cannot be done solely through considering the source output. The etch rate is ultimately a function of the 
conditions at the wafer, and thus flow throughout the entire system must be considered.

The oxide and poly etch results follow similar trends in etch rate and nonuniformity with process conditions, though the dependence on process conditions is slightly different for the two wafer types. For example, changing the power increases the poly etch rate by $10 \%$ over the baseline case, while the oxide etch rate is increased by only $4 \%$. This trend is reversed in the $0 \%$ oxygen case, where the poly etch rate is increased by $85 \%$ over the baseline case, and the oxide etch rate increases more than poly etch, to $124 \%$. These differences in poly and oxide etch-rate response provide important information for optimizing etch selectivity in the CDE tool. Similar variations in etch rate response to plasma source conditions are observed for nonuniformity as well.

The largest increase in both oxide and poly etching occurs through changing the $\mathrm{O}_{2}$ flow rate. By decreasing $\mathrm{O}_{2}$ flow to zero, the etch rates are roughly doubled, with a $25 \%$ increase in nonuniformity. Increasing the pressure by a third increases the etch rate by $50 \%$, and increases the nonuniformity by nearly a factor of two. Increasing the power by a factor of two increases the etch rate only slightly. The smallest changes were observed in the power and flow rate cases. The transport tube case does not represent a process condition change, as it results from changing the transport tube dimensions. It does have a noticeable effect on system performance, increasing the etch rate and nonuniformity. 
Table III-2. Off-Baseline Calculation Results.

\begin{tabular}{|c|c|c|c|c|c|c|c|}
\hline & & & & & & \\
\hline & & Baseline & Power & Pressure & Oxygen & $\begin{array}{l}\text { Flow } \\
\text { Rate }\end{array}$ & $\begin{array}{c}\text { Transport } \\
\text { Tube } \\
\end{array}$ \\
\hline \multicolumn{8}{|c|}{ Source Inputs: } \\
\hline & $\mathrm{NF}_{3}$ Flow $(\mathrm{sccm})$ & 67. & 67. & 67. & 67. & 60. & 67. \\
\hline & $\mathrm{O}_{2}$ Flow $(\mathrm{sccm})$ & 100. & 100. & 100. & 0. & 90. & 100. \\
\hline & Power $(\mathrm{W})$ & 320. & 700. & 320. & 320. & 320. & 320. \\
\hline Sourc & e Pressure (mTorr) & 350. & 350. & 472. & 350. & 350. & 350. \\
\hline \multicolumn{8}{|c|}{\begin{tabular}{|l|} 
Source Model Output and \\
Transport Tube Input:
\end{tabular}} \\
\hline & Source exit $\mathrm{X}_{\mathrm{F}}(\%)$ & 37. & 41. & 36. & 67. & 37. & 37. \\
\hline \multicolumn{8}{|c|}{$\begin{array}{l}\text { Transport Tube Output and } \\
\text { Showerhead Input: }\end{array}$} \\
\hline & Pressure (mTorr) & 290. & 279. & 428. & 312. & 298. & 347. \\
\hline & $\mathrm{X}_{\mathrm{F}}(\%)$ & 35. & 41. & 35. & 65. & 35. & 33. \\
\hline \multicolumn{8}{|c|}{\begin{tabular}{|l|} 
Showerhead Output and \\
Etch Chamber Input:
\end{tabular}} \\
\hline & Pressure (mTorr) & 194. & 168. & 370. & 258. & 217. & 274. \\
\hline & Total Flow (sccm) & 238. & 254. & 237. & 159. & 213. & 231. \\
\hline & $\mathrm{X}_{\mathrm{F}}(\%)$ & 35. & 41. & 35. & 65. & 35. & 33. \\
\hline \multicolumn{8}{|c|}{ Etch Chamber Output: } \\
\hline \multirow[b]{2}{*}{ oxide } & etch rate $(\mathrm{A} / \mathrm{min})$ & 37.7 & 39.1 & 65.3 & 84.4 & 40.7 & 47.1 \\
\hline & \begin{tabular}{|c|}
$3 \sigma$ non- \\
uniformity $(\%)$ \\
\end{tabular} & 3.1 & 2.5 & 5.8 & 4.4 & 3.7 & 4.5 \\
\hline \multirow[b]{2}{*}{ poly } & etch rate $(\mathrm{A} / \mathrm{min})$ & 1147. & 1265. & 1580. & 2127. & 1161. & 1262. \\
\hline & $\begin{array}{c}3 \sigma \text { non- } \\
\text { uniformity }(\%)\end{array}$ & 4.3 & 3.6 & 8.2 & 7.1 & 5.1 & 6.2 \\
\hline
\end{tabular}




\section{CORRELATION OF CDE PERFORMANCE}

In addition to providing detailed information on the distribution of species throughout the $\mathrm{CDE}$ tool, the modeling can also be used to provide correlations of general system performance with operating parameters. This is the type of data obtained experimentally in process design. Because of the detailed information available, correlations can also be based on internal variables, such as etchant mole fraction entering the etch chamber. Since the CDE system is composed of physically separate components, this type of correlation is useful in determining the effect of component performance on total system performance.

Three sets of etch rate and nonuniformity correlations are presented. The first are correlations with the plasma source inlet conditions using plasma source pressure, $\mathrm{NF}_{3}$ inlet flow rate, total $\left(\mathrm{NF}_{3}+\mathrm{O}_{2}\right)$ inlet flow rate and power as independent variables in the form:

$$
\frac{\text { E.R. or } 3 \sigma}{\text { E.R. or } 3 \sigma_{\cdot}}=A\left(\frac{\text { Plasma Source Pr essure }}{\text { Plasma Source Pr } \text { essure }_{0}}\right)^{a}\left(\frac{N F_{3} \text { Flow Rate }}{N F_{3} \text { Flow Rate }}\right)^{b}\left(\frac{\text { Total Flow Rate }}{\text { Total Flow Rate }_{0}}\right)^{c}\left(\frac{\text { Power }}{\text { Power }_{0}}\right)^{d} \text {, }
$$

where the subscript " 0 " refers to the baseline case value. Since changes in transport tube diameter are not expected to be captured with this correlation, only results from 5 cases were used: baseline, pressure, power, flow rate and oxygen. With 5 variables and 5 unknowns, the correlation fits the data exactly, as shown in Table III-3(a). Etch rates increase with increasing plasma source pressure, $\mathrm{NF}_{3}$ flow and power, and with decreasing total flow. Nonuniformity increases with plasma source pressure and decreases with $\mathrm{NF}_{3}$ flow, total flow and power. In general the etch rate and nonuniformity vary greatest with plasma source pressure, total flow and $\mathrm{NF}_{3}$ flow, in decreasing order of importance. The plasma source power has the smallest effect on etch rate and uniformity, and also had the smallest effect on the plasma source output (see Figure III-3). A correlation with the 3 most important independent variables, as determined by the magnitude of the exponents in Table III-3, is shown using plasma source pressure and flow rates in Table III-3(b). This correlation predicts the etch rate to within $7 \%$ and the nonuniformity to within $14 \%$.

In practice the etch chamber pressure, as opposed to plasma source pressure, is a control parameter, so a second correlation was made with the chamber pressure replacing the plasma source pressure:

$$
\frac{\text { E.R.or } 3 \sigma}{\text { E.R. or } 3 \sigma_{\cdot 0}}=A\left(\frac{\text { Chamber Pr essure }}{\text { Chamber Pr } \text { essure }_{0}}\right)^{a}\left(\frac{N F_{3} \text { Flow Rate }}{N F_{3} \text { Flow Rate }_{0}}\right)^{b}\left(\frac{\text { Total Flow Rate }}{\text { Total Flow Rate }_{0}}\right)^{c}\left(\frac{\text { Power }_{\text {Power }}}{\text { Pow }^{d}}\right)^{d}
$$


where the subscript " 0 " refers to the baseline case value, again excluding the transport tube case. The results are shown in Table III-4(a). The importance of the variables, as determined by the exponents in Table III-4(a), show the same trends as for the previous correlation. The results of using the variables with the greatest effect on etch rate and nonuniformity (chamber pressure, and flow rates) is shown in Table III-4(b). Correlations based on the chamber pressure (Table III-4(b)), as opposed to the plasma source pressure (Table III-3(b)) have similar trends with the dependent variables, and also have smaller errors, with etch rate errors of $11 \%$ and nonuniformity errors of $3.5 \%$.

Table III-3(a). Correlation Based on Plasma Source Parameters. This correlation has the form: (Plasma Pressure) ${ }^{\mathrm{a}}\left(\right.$ NF3 Flow) $^{\mathrm{b}}$ (Total Flow) $^{\mathrm{c}}$ (Power) $^{\mathrm{d}}$. $^{\text {. }}$

\begin{tabular}{|l|cc|c|c|c|}
\cline { 2 - 6 } \multicolumn{1}{c|}{} & \multicolumn{2}{c|}{ Poly } & \multicolumn{2}{c|}{ Oxide } \\
\cline { 2 - 6 } \multicolumn{1}{c|}{} & Etch Rate & Nonuniformity & Etch Rate & Nonuniformity \\
\hline \multicolumn{2}{l|}{ Pre-exponential Constant (A) } & 1147. & 4.31 & 37.7 & 3.10 \\
\hline \multicolumn{2}{|l|}{ Plasma Pressure Exponent } & 1.072 & 2.154 & 1.843 & 2.121 \\
& & & & \\
\hline NFF $_{3}$ Flow Exponent (a) & & & -1.011 & 0.149 & -1.146 \\
\hline Total Flow Exponent (b) & 0.546 & -0.676 & -0.548 & -0.883 & -0.384 \\
\hline Power Exponent (c) & (d) & 0.125 & -0.238 & 0.047 & -0.252 \\
\hline Fitting Error & & 0 & 0 & 0 \\
\hline
\end{tabular}

Table III-3(b). Correlation Based on Plasma Source Parameters with the largest influence. This correlation has the form: (Plasma Pressure) ${ }^{a}\left(\mathrm{NF}_{3}\right.$ Flow) ${ }^{\mathrm{b}}$ (Total Flow) $^{\mathrm{c}}$.

\begin{tabular}{|c|c|c|c|c|}
\hline & \multicolumn{2}{|r|}{ Poly } & \multicolumn{2}{|r|}{ Oxide } \\
\hline & Etch Rate & Nonuniformity & Etch Rate & Nonuniformity \\
\hline Pre-exponential Constant (A) & 1200. & 3.88 & 38.3 & 2.77 \\
\hline $\begin{array}{l}\text { Plasma Pressure Exponent } \\
\text { (a) }\end{array}$ & 0.921 & 2.508 & 1.783 & 2.499 \\
\hline $\mathrm{NF}_{3}$ Flow Exponent & 0.909 & -1.857 & 0.292 & -2.050 \\
\hline Total Flow Exponent & -0.627 & -0.664 & -0.864 & -0.508 \\
\hline Fitting Error & 6.91 & 13.06 & 2.61 & 13.84 \\
\hline
\end{tabular}


The etch rate and nonuniformity are known to depend on the species concentrations, flow rate into the etch chamber and pressure in the etch chamber. It is often convenient to consider separately the issues of etchant production from those of transporting the etchant uniformly to the wafer. For this reason we consider a correlation with pressure, mass flow and etchant (atomic fluorine) mole fraction, all at the etch chamber inlet, which is presented in Table III-5. Because all effects upstream of the etch chamber are included in this correlation, through $\mathrm{X}_{\mathrm{F}}$ and the volumetric flow rate, the transport tube case also was included. The pressure, inlet mass flow and $X_{F}$ have a positive effect on the etch rate. This is consistent with the etch mechanism, which is enhanced by increasing the concentration of atomic fluorine at the wafer surface. The correlation predicts etch rate and nonuniformity to better than $1 \%$.

Table III-4(a). Correlations Based on Plasma Source Flow Rate and Power and Etch Chamber Pressure.

This correlation has the form: (Etch Pressure) $^{\mathrm{a}}\left(\mathrm{NF}_{3}\right.$ Flow) ${ }^{\mathrm{b}}$ (Total Flow) $^{\mathrm{c}}$ (Power) $^{\mathrm{d}}$.

\begin{tabular}{|lc|c|c|c|c|}
\cline { 3 - 6 } \multicolumn{1}{c|}{} & \multicolumn{2}{c|}{ Poly } & \multicolumn{2}{c|}{ Oxide } \\
\cline { 3 - 7 } \multicolumn{1}{c|}{} & Etch Rate & Nonuniformity & Etch Rate & Nonuniformity \\
\hline Pre-exponential Constant (A) & 1147. & 4.31 & 37.7 & 3.10 \\
\hline Etch Pressure Exponent & (a) & 0.497 & 0.997 & 0.854 & 0.982 \\
\hline $\mathrm{NF}_{3}$ Flow Exponent & (b) & 0.899 & -0.302 & 0.756 & -0.447 \\
\hline Total Flow Exponent & (c) & -0.521 & -0.237 & -0.617 & -0.077 \\
\hline Power Exponent & (d) & 0.216 & -0.055 & 0.204 & -0.071 \\
\hline Fitting Error (\% R.M.S.) & 0 & 0 & 0 & 0 \\
\hline
\end{tabular}

Table III-4(b). Correlations Based on Plasma Source Flow Rate and Etch Chamber Pressure.

This correlation has the form: (Etch Pressure) ${ }^{\mathbf{a}}$ (NF3 Flow) $^{\mathrm{b}}$ (Total Flow) $^{\mathrm{c}}$.

\begin{tabular}{|l|c|c|c|c|c|}
\cline { 2 - 6 } \multicolumn{1}{c|}{} & \multicolumn{2}{c|}{ Poly } & \multicolumn{2}{c|}{ Oxide } \\
\cline { 2 - 6 } \multicolumn{1}{c|}{} & Etch Rate & Nonuniformity & Etch Rate & Nonuniformity \\
\hline Pre-exponential Constant (A) & 1235. & 4.23 & 40.4 & 3.10 \\
\hline Etch Pressure Exponent (a) & 0.358 & 1.036 & 0.723 & 1.033 \\
\hline $\mathrm{NF}_{3}$ Flow Exponent & (b) & 1.392 & -0.441 & 1.224 & -0.632 \\
\hline Total Flow Exponent & (c) & -0.484 & -0.247 & -0.581 & -0.092 \\
\hline Fitting Error (\% R.M.S.) & 10.69 & 2.65 & 10.08 & 3.49 \\
\hline
\end{tabular}


Table III-5. Correlations Based on Etch Chamber Parameters. This correlation has the form: (Etch Pressure) ${ }^{a}$ (Inlet Mass Flow) $^{\mathbf{b}}$ (F Mole Fraction) $^{\mathrm{c}}$.

\begin{tabular}{|l|c|c|c|c|}
\cline { 2 - 5 } \multicolumn{1}{c|}{} & \multicolumn{2}{c|}{ Poly } & \multicolumn{2}{c|}{ Oxide } \\
\cline { 2 - 6 } \multicolumn{1}{c|}{} & Etch Rate & Nonuniformity & $\begin{array}{c}\text { Etch } \\
\text { Rate }\end{array}$ & Nonuniformity \\
\hline Pre-exponential Constant (A) & 1142. & 4.31 & 37.6 & 3.11 \\
\hline Etch Pressure Exponent (a) & 0.526 & 0.999 & 0.878 & 0.970 \\
\hline Mass Flow Exponent (b) & 0.313 & -0.570 & 0.106 & -0.474 \\
\hline F Mole Fraction Exponent & 0.973 & -0.023 & 0.979 & -0.196 \\
\hline Fitting Error (c) & & & & \\
\hline
\end{tabular}

A comparison of correlations from Table III-3(b) ("Plasma Conditions"), Table III-4(b) ("Etch Pressure+Plasma Conditions") and Table III-5("Etch Conditions"), each of which is based on 3 independent variables, is shown in Figures III-4(a) and III-4(b) for poly etch. The first two correlations are based on easily controllable variables (plasma or etch pressure and inlet flow rates). Using these variables, correlations to within $7 \%$ are obtained using the plasma pressure to correlate etch rate and the etch pressure to correlate nonuniformity. A better (within 1\%) physically consistent correlation is obtained with the etch condition variables - etch chamber inlet volumetric flow rate, etch chamber pressure and etch chamber inlet atomic fluorine fraction. The importance of this correlation lies in the ability to predict etch rate performance as a function of the output of the combined plasma source, transport tube and showerhead components, which are computationally fast simulations. 


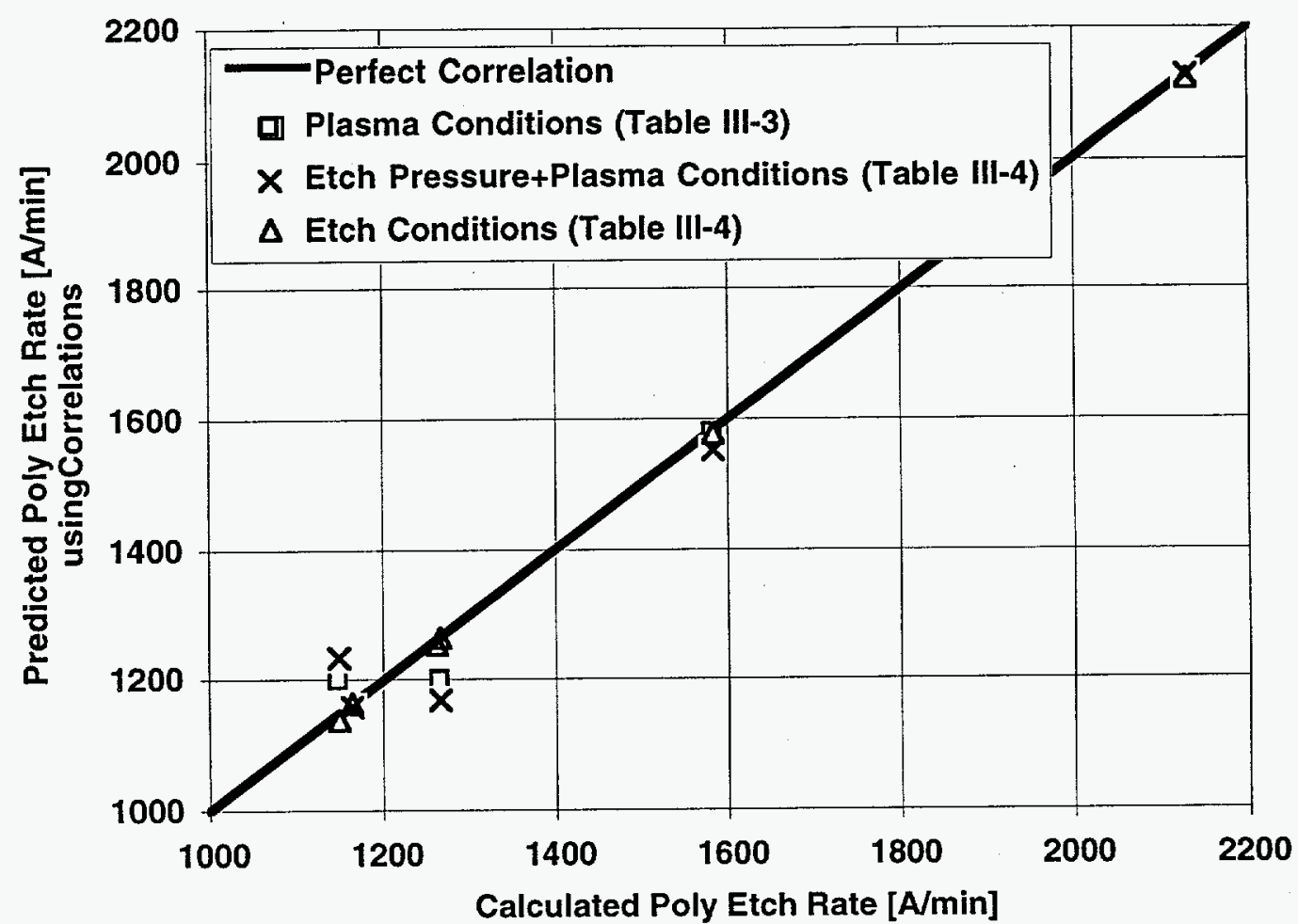

(a)

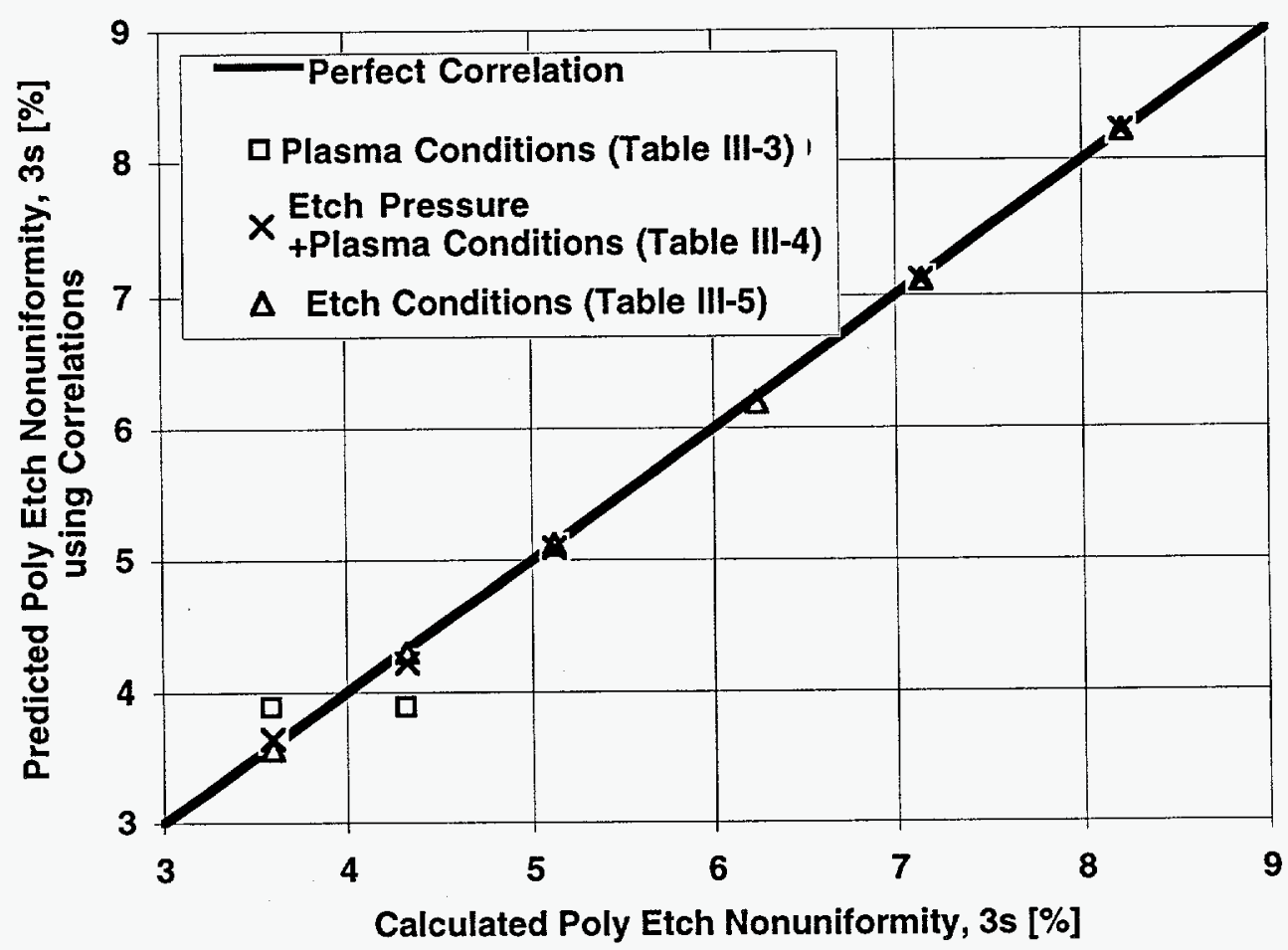

(b)

Figure III-4. Three-variable correlations of (a) poly etch rate and (b) poly etch-rate uniformity corresponding to Table III-3(b), Table III-4(b) and Table III-5. 
Nonuniformity results from the competition between etchant species convection and diffusion across the wafer surface. Greater nonuniformity results from increased pressure, decreased inlet mass flow and to a lesser extent decreased $X_{F}$. Rephrasing this last statement, uniformity is increased by decreasing the pressure and increasing the mass flow and $X_{F}$. Thus more uniform and faster etching will result from changes that increase $\mathrm{X}_{\mathrm{F}}$ and decrease the inlet velocity. Increased pressure can also be used to increase etch rate, but this increases the nonuniformity.

\section{SUMMARY AND CONCLUSIONS}

A model of Chemical Downstream Etching has predicted etch rate and nonuniformity for a range of operating conditions. A direct comparison between predictions and measured wafer etch rates reveals the accuracy of the models to be within $10 \%$ for a baseline set of operating conditions and $30 \%$ for an off-baseline condition. A systematic variation in flow rate, pressure, plasma source power and transport tube diameter was conducted, and the resulting etch rates correlated. The etch chamber and plasma source pressure, $\mathrm{O}_{2}$ and $\mathrm{NF}_{3}$ flow rates adequately predict calculated poly and oxide etch rates and uniformities to within $7 \%$. A much better correlation, relying on fewer independent variables and achieving a lower R.M.S. error (within $1 \%$ ), was achieved by correlating on the etch chamber pressure, etch chamber inlet flow rate and etch chamber inlet atomic fluorine mole fraction.

The conclusions from this study are:

- A first principles chemically reacting flow model can be used to predict etch rates and uniformities of polysilicon and silicon dioxide wafers in a $\mathrm{NF}_{3} / \mathrm{O}_{2}$ Chemical Downstream Etch system.

- Etch rates and nonuniformities can be correlated with operating parameters in a way that should prove useful in process design.

- Excellent correlations of etch rate and nonuniformity were obtained using etch chamber conditions. This should allow for prediction of CDE performance based on the output of combined plasma source, transport tube and showerhead components

- The positive ion concentration at the wafer is dominated by $\mathrm{NF}_{3}{ }^{+}, \mathrm{NF}_{2}+$, and $\mathrm{NO}^{+}$and is estimated to have a total concentration of much less than $10^{8} / \mathrm{cm}^{3}$. 


\section{REFERENCES}

1. Meeks, E., Larson, R. S., Shon, J. W. and Vosen, S. R.: Symposium on Process Control, Diagnostics, and Modeling in Semiconductor Manufacturing, The Electrochemical Society (1995).

2. Meeks, E., Larson, R. S., Vosen, S. R. and Shon, J. W.: J. Electrochem. Soc., submitted (1996).

3. Kee, R. J., Rupley, F. M. and Miller, J. A.: "CHEMKIN-II: A Fortran Chemical Kinetics Package for the Analysis of Gas-Phase Chemical Kinetics," Sandia National Laboratories Report SAND89-8009 (1990).

4. Kee, R. J., Rupley, F. M., Meeks, E. and Miller, J. A.: "CHEMKIN-III: A Fortran Chemical Kinetics Package for the Analysis of Gas-Phase Chemical and Plasma Kinetics," Sandia National Laboratories Report SAND96-8216 (1996).

5. Coltrin, M. E., Kee, R. J. and Rupley, F. M.: Int. J. Chem. Kinet., 231111 (1991).

6. Coltrin, M. E., Kee, R. J. and Rupley, F. M.: "SURFACE CHEMKIN (Version 4.0): A Fortran Package for Analyzing Heterogeneous Chemical Kinetics at a Solid-Surface - GasPhase Interface," Sandia National Laboratories Report SAND90-8003C (1991).

7. Coltrin, M. E., Kee, R. J., Rupley, F. M. and Meeks, E.: "SURFACE CHEMKIN III: A Fortran Package for Analyzing Heterogeneous Chemical Kinetics at a Solid-Surface - GasPhase Interface," Sandia National Laboratories Report SAND96-8217 (1996).

8. Coltrin, M. E., Kee, R. J. and Evans, G. H.: J. Electrochem. Soc., 136819 (1989).

9. Coltrin, M. E., Kee, R. J., Evans, G. H., Meeks, E., Rupley, F. M. and Grcar, J. F.: "SPIN (Version 3.83): A Fortran Program for Modeling One-Dimensional RotatingDisk/Stagnation-Flow Chemical Vapor Deposition Reactors," Sandia National Laboratories Report SAND91-8003 (1991).

10. Flamm, D. L., Mogab, C. J. and Sklaver, E. R.: J. Appl. Phys., 506211 (1979).

11. Ganguli, P. S. and Kaufman, M.: Chem. Phys. Lett., 25221 (1974).

12. Meeks, E. and Shon, J.: IEEE Trans. Plasma Sci, 23539 (1994).

13. Blain, M. Personal Communication: February, 1995.

14. Holber, W. Personal Communication: 
15. Bird, R. B., Stewart, W. E. and Lightfoot, E. N.: Transport Phenomena, Wiley, New York (1960).

16. Petzold, L. R.: "A Description of DASSL: A Differential-Algebraic System Solver," Sandia National Laboratories Report SAND82-8637 (1982).

17. Thompson, P. A.: Compressible-Fluid Dynamics, McGraw-Hill, San Francisco (1972).

18. Vosen, S. R.: Thirteenth International Conference on Chemical Vapor Deposition, The Electrochemical Society (1996).

19. Gosman, A. D. and Pun, W. M.: "Calculation of Recirculating Flow," Imperial College of Science and Technology Report (1973).

20. Patankar, S. V.: Numerical Heat Transfer and Fluid Flow, McGraw-Hill, New York (1980).

21. Kee, R. J., Dixon-Lewis, G., Warnatz, J., Coltrin, M. E. and Miller, J. A.: “A Fortran Computer Code Package for the Evaluation of Gas-Phase Multicomponent Transport Properties," Sandia National Laboratories Report SAND86-8246 (1986).

22. Kee, R. J., Rupley, F. M. and Miller, J. A.: "The Chemkin Thermodynamic Data Base," Sandia National Laboratories Report SAND87-8215B (1990).

23. Blain, M. Personal Communication: February, 1995. 


\title{
INITIAL DISTRIBUTION
}

UNLIMITED RELEASE

\author{
N. Alvi \\ SEMATECH \\ 2706 Montopolis Drive \\ Austin, TX 78741 \\ G. Powell (3) \\ Matrix Integrated Systems \\ 4131 Lakeside Drive \\ Richmond, CA 94806
}
0367 R. J. Buss, 1812
0601 J. Tsao, 1126
Attn: M. E. Bartram, 1126
W. G. Breiland, 1126
J. R. Creighton, 1126
H. K. Moffat, 1126
0601 M. E. Coltrin, 1126
0601 P. Ho, 1126
0601 G. H. Hays, 1128
Attn: G. A. Hebner, 1128
P. A. Miller, 1128
M. E. Riley, 1128
0826 W. Hermina, 9111
0827 R. T. McGrath, 9114
Attn: T. J. Bartel, 9114
R. B. Campbell, 9114
S. J. Choi, 9114
A. S. Geller, 9114
M. L. Hudson, 9114
D. J. Rader, 9114
A. J. Russo, 9114
R. Veerasingam, 9114
0827 J. Johannes, 9114
0841 P. J. Hommert, 9100
Attn: R. D. Skocypec, 9102
J. H. Biffle, 9103
E. D. Gorham, 9104
S. E. Gianoulakis, 9113
A. C. Ratzel, 9112
W. H. Rutledge, 9115
C. W. Peterson, 9116
1077 L. M. Cecchi, 1326
1077 M. G. Blain, 1326
1077 T. L. Meisenheimer, 1326
1077 J. E. Stevens, 1326
1077 R.S. Bennett, 1326
1078 C. W. Gwyn, 1302
1078 J. D. McBrayer, 1302


1079 A. D. Romig, 1300

Attn: R.S. Blewer, 1305

G. V. Herrera, 1308

P. Esherick, 1311

1111 J. N. Shadid, 9221

1427 P. L. Mattern, 1100

Attn: S. T. Picraux, 1112

J. Nelson, 1113

T. A. Michalske, 1114

G. A. Samara, 1152

E. B. Stechel, 1153

9001 T. Hunter, 8000

Attn: J. B. Wright, 2200

A. West, 8200

R. C. Wayne, 8400

P. N. Smith, 8500

L. A. Hiles, 8800

9042 C. M. Hartwig, 8345

9042 G. H. Evans, 8345

9042 J. F. Grcar, 8345

9042 S. K. Griffiths, 8345

9042 W. G. Houf, 8345

9042 R. J. Kee, 8303

9042 R.S. Larson, 8345 (10)

9042 A. E. Lutz, 8345

9042 E. Meeks, 8345 (30)

9042 R. H. Nilson, 8345

9042 F. M. Rupley, 8345

9042 J. W. Shon, 8345 (10)

9042 P. A. Spence, 8345

9042 A. Ting, 8345

9052 M. D. Allendorf, 8361

9053 R. W. Carling, 8362

9053 S. R. Vosen, 8362(30)

9054 W. J. McLean

Attn: C. W. Robinson, 8301

W. Bauer, 8302

J. L. Durant, 8353

R. J. Gallagher, 8366

D. R. Hardesty, 8361

L. A. Rahn, 8351

F. P. Tully, 8353

9162 K. L. Wilson, 8716

9162 D. A. Buchenauer, 8716 (10)

9214 C. F. Melius, 8117

9403 B. E. Mills, 8713

9403 D. K. Ottesen, 8713 
9405 T. M. Dyer, 8700

Attn: M. W. Perra, 8711

M. I. Baskes, 8712

J. C. F. Wang, 8713

G. J. Thomas, 8715

G. A. Benedetti, 8741

M. R. Birnbaum, 8742

P. E. Nielan, 8743

W. A. Kawahara, 8746

D. B. Nelson, 8783

9409 R. H. Stulen, 8250

9021 Technical Communications Department, 8815, for OSTI (10)

9021 Technical Communications Department, 8815/Technical Library, MS 0899, 4414

8099 Technical Library 4414 (4)

9018 Central Technical Files, 8950-2 (3) 